\title{
THE ACCOMMODATING SHOWMAN
}

\author{
by \\ Véronique Allard-Buffet \\ Bachelor of Architectural Science, Carleton University, Ottawa, Canada, 2008 \\ Masters of Interior Design, Florence Institute of Design, Florence, Italy, 2009
}

\author{
A design thesis | project \\ presented to Ryerson University \\ in partial fulfillment of the \\ requirements for the degree of \\ Master of Architecture \\ in the Program of \\ Architecture
}

Toronto, Ontario, Canada, 2012

(C) Véronique Allard-Buffet 2012 


\section{AUTHOR'S DECLARATION}

I hereby declare that I am the sole author of this thesis.

This is a true copy of the thesis, including any required final revisions, as accepted by my examiners.

I authorize Ryerson University to lend this thesis to other institutions or individuals for the purpose of scholarly research.

I further authorize Ryerson University to reproduce this thesis by photocopying or by other means, in total or in part, at the request of other institutions or individuals for the purpose of scholarly research.

I understand that my thesis may be made electronically available to the public.

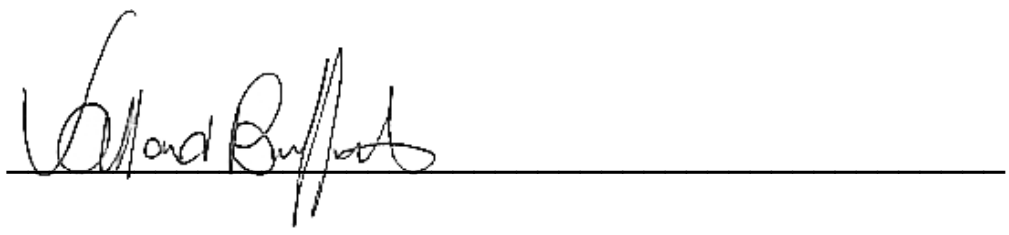

Véronique Allard-Buffet 


\section{ABSTRACT}

Portable performance spaces played an indispensable role in the architectural development of the theatre venue. The Victorian age and the evolution of the roadway, have acted as the underpinning catalysts of its proliferation. Today, we continue to make use of temporary performance spaces; however their conception is often intended for the one-time use, or for a show specific purpose. Unlike some of their historical counterparts, little thought is granted to their reuse or adaptability. For an approach which ought to boast flexible qualities, their accommodating nature typically ends at their transportability, and their plan often finds itself restricted to an inflexible layout.

This thesis will attempt to uncover how portable performance spaces can extend their adaptable nature beyond that of a simply changing site. By exploiting the pavilion's notion of temporality, the onus will be placed on its ability to achieve multiple configurations, rather than solely in the pursuit of one fixed absolute. 


\section{ACKNOWLEDGEMENTS}

Firstly, I would like to express my gratitude to my supervisor, Filiz Klassen for her guidance and support throughout the course of the year. In addition, would like to thank my advisor June Komisar, and program representative Colin Ripley for their invaluable insight and advice during the development of this thesis.

To my parents and brother, thank you for your unremitting motivation, support and patience throughout the course of my architectural education. I could not have done it without you. To Kate, I want to acknowledge how much I have valued your friendship throughout everything. From Carleton, to FIDI, to M.Arch; you have had such an immense role in some of my most memorable milestones. To Tony, your encouragement throughout this year has been immeasurable. Above all, I want to thank you for your transcontinental help and support during the whirlwind lead-up to my defense. I cannot wait for you to be back home.

Finally to my classmates at Ryerson, thank you for your help, feedback, and most of all company, during the late studio nights and long hours in the lab. 


\section{CONTENTS}

Author's Declaration

Abstract

Acknowledgements

Contents

List of Figures

$1.0 \quad$ Introduction............................................

1.1 Historical Context | Background 2

1.2 The Problem 5

1.3 Challenge and Intervention $\quad 7$

1.4 Research Outline 8

2.0 Characterising Flexibility and Transience .............11

2.1 Methods of Transportability 12

2.2 Human Scale | Size Matters 16

2.3 Creating Space 20

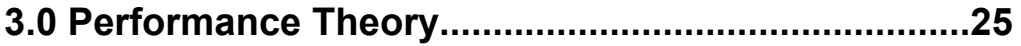

3.1 Dilemmas of the Empty Arts 25

3.2 Performance Relationships 28

3.3 Common Spatial Associations 30

4.0 Key Precedents........................................34

4.1 Teatro del mondo, Aldo Rossi 35

4.2 Prada Transformer, OMA 37

4.3 Rosy, Raumlabor $\quad 39$

4.4 BMW Gugghenheim, Atelier Bow Wow 41 
5.0 Design Parameters....................................................43

5.1 The Troupe 43

5.2 Site Conditions 45

5.3 Current Structure 46

6.0 The Design Proposal.................................................47

6.1 The Frame Modules 49

6.2 Frame Uses and Attachments 52

6.3 Configurations Based on Known Typologies 58

6.4 Site-Specific Configurations 67

6.5 Show-Specific Configurations 70

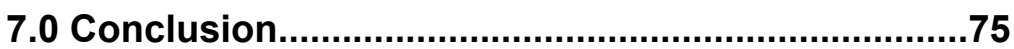

Image Sources $\quad 78$

$\begin{array}{ll}\text { Bibliography } & 78\end{array}$ 


\section{List of Figures}

Figure 1.1 Sketch by author of Roy Thomson Hall, Toronto....................................................

Figure 1.2 Sketch by author of a temporary stage at Yonge and Dundas Square, Toronto................1

Figure 1.1.1 Image from travelling circus show 1901-1910 .......................................................

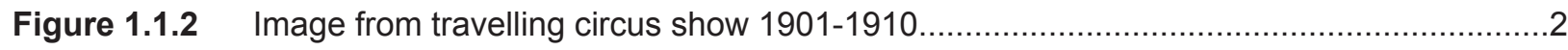

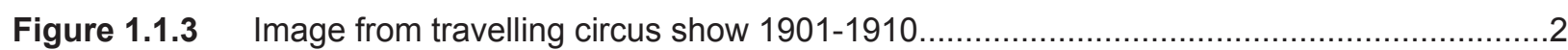

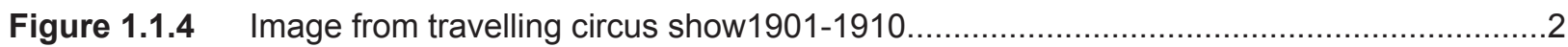

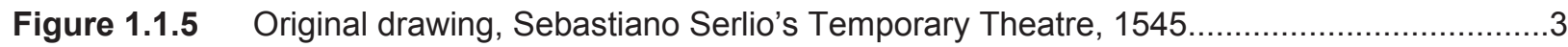

Figure 1.1.6 The Rolling Stones' 1994 Voodoo Lounge Set, designed by Mark Fisher........................4

Figure 1.1.7 The Rolling Stones' 1994 Voodoo Lounge Set, designed by Mark Fisher.........................4

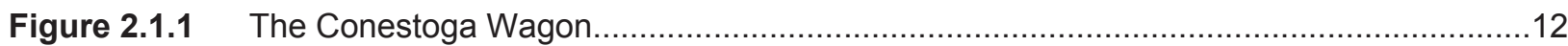

Figure 2.1.2 Buckminster Fuller's US Marine Dome being airlifted by helicopter, 1954...................13

Figure 2.1.3 Mogen Koch's Folding Chair, 1932 ...................................................................14

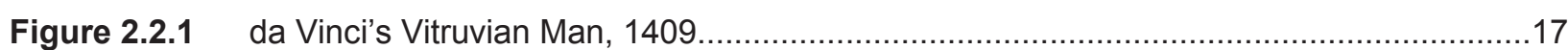

Figure 2.2.2 Henry Dreyfuss' Joe and Josephine, 1955.............................................................18

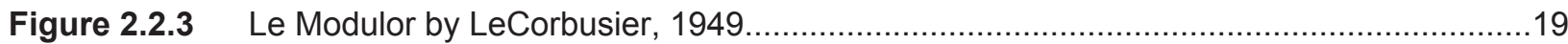

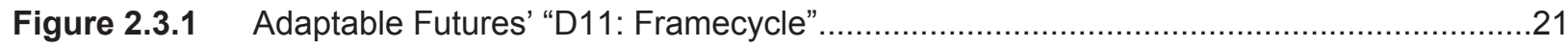

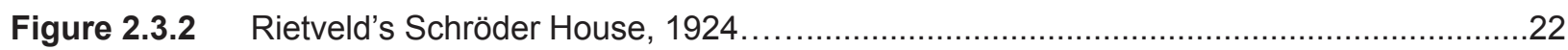

Figure 2.3.3 Kuysuitei Pavilion, Shugakuin Imperial Villa, 1659......................................................22

Figure 2.3.4 Photographs of Nakao's model for Black Maria, in various configurations....................23

Figure 2.3.5 Drawing by Nakao of Black Maria in plan view.........................................................23

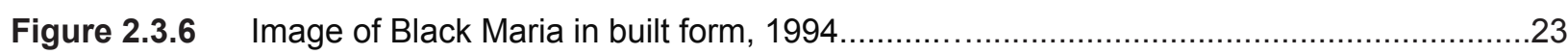

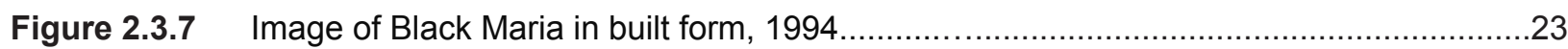

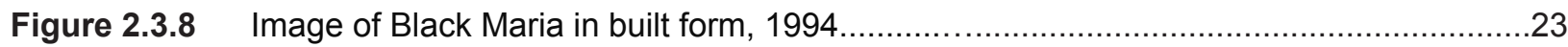

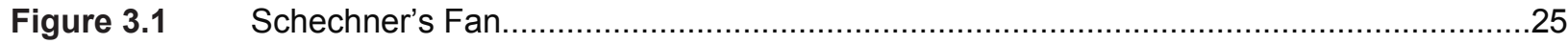

Figure 3.3.1 A section of Étienne-Louis Boullée's unbuilt Opera House ............................................30

Figure 3.3.2 Diagram by thesis author of Proscenium Theatre layout.................................................30

Figure 3.3.4 Epidaurus Theatre in Greece. Thesis author's own image …...................................31

Figure 3.3.5 Diagram by thesis author of Thrust Theatre layout....................................................

Figure 3.3.6 Diagram by thesis author of Arena Theatre layout ................................................

Figure 3.3.7 Diagram by thesis author of possible Black Box plan configurations...............................32

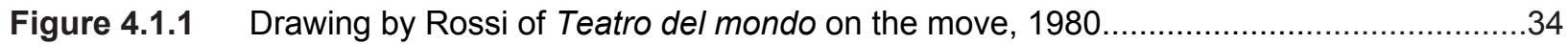

Figure 4.1.2 Teatro del mondo in built form, being docked in Venice..............................................34

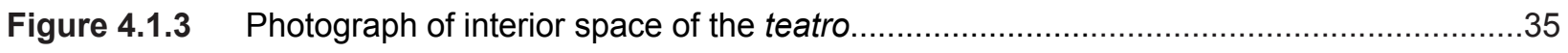

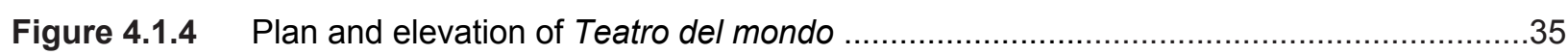

Figure 4.2.1 Diagram perspectives of the four program orientations...............................................36 
Figure 4.2.2 View of the Transformer placed next to Seoul's $16^{\text {th }}$ Century Gyeonghui Palace............36

Figure 4.2.3 View of the Transformer in "Cinema" mode..............................................................36

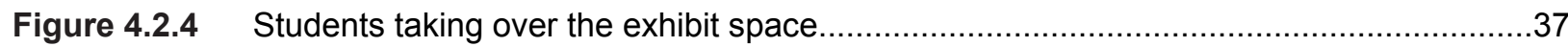

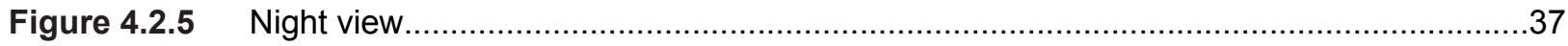

Figure 4.2.6 TheTransformer mid-air, undergoing a program change

Figure 4.2.7 Section-cut through the Transformer in its Cinema position...........................................37

Figure 4.2.8 A 3D rendering demonstrating the various orientations..............................................37

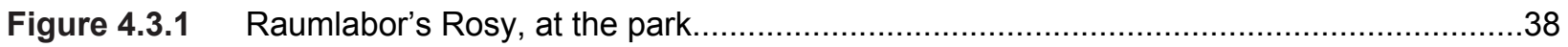

Figure 4.3.2 Rosy, at the park

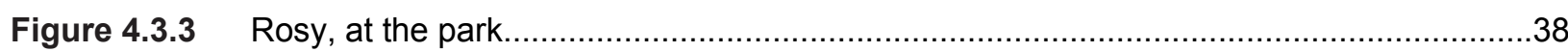

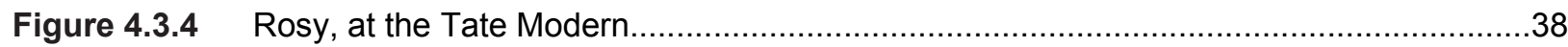

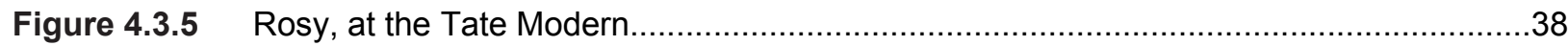

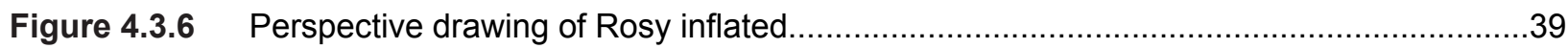

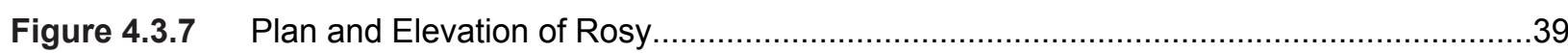

Figure 4.4.1 BMW Guggenheim, Cycle 1 in Berlin location........................................................40

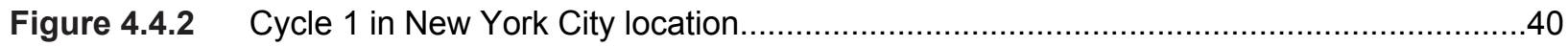

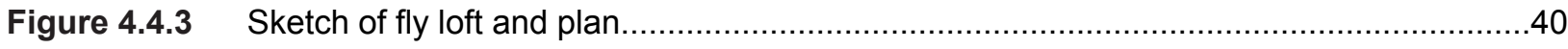

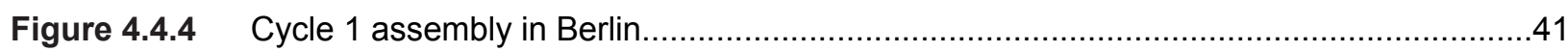

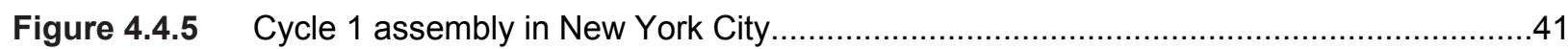

Figure 4.4.6 View of activated space in New York City.................................................................

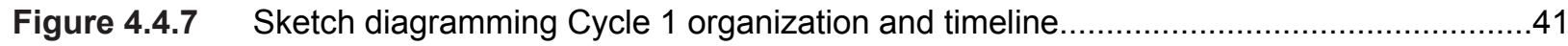

Figure 5.1.1 HerciniArts Collective performances........................................................................... 43

Figure 5.1.2 HerciniArts Collective performances.....................................................................43

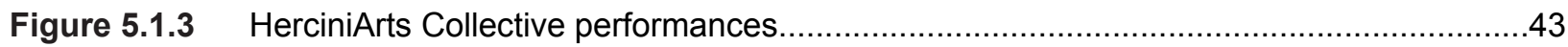

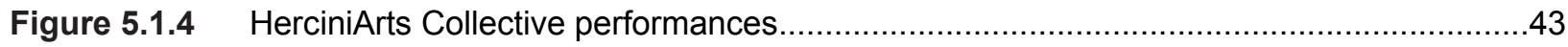

Figure 5.2.1 Map of central Toronto, demarcating various locations of HerciniArts productions..........44

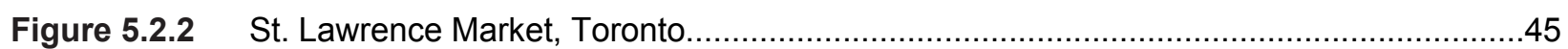

Figure 5.2.3 Rendering of unoccupied indoor Studio Space, Toronto...........................................45

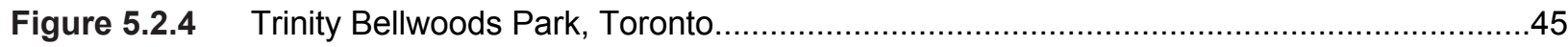

Figure 5.3.1 Diagram of existing performance structure.........................................................46

Figure 6.1 Diargram of existing performance structure versus early design iterations.....................47

Figure 6.2 Diargram of existing performance structure versus proposed model............................48

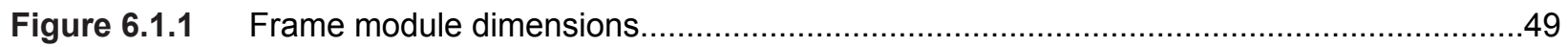

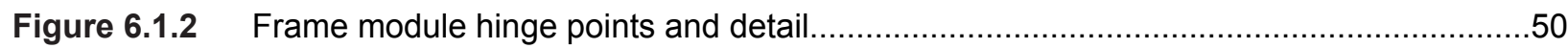

Figure 6.1.3 Renderings of frame collapsibility and extension abilities...........................................51

Figure 6.2.1 Diagrams depicting the four primary performance uses of the frame module.................52

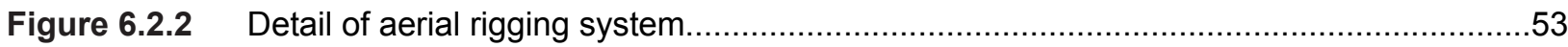


Figure 6.2.3 Diagram of flat bench | stage surface.................................................................54

Figure 6.2.4 Detail of double ledger clamp connection..........................................................55

Figure 6.2.5 Diagram of horizontal structural frame add-on.........................................................56

Figure 6.2.6 Diagram demonstrating relocatable abilities of frame modules..................................57

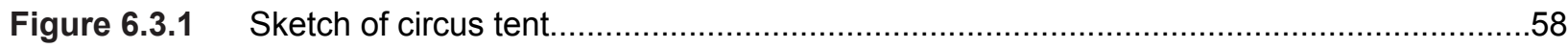

Figure 6.3.2 Rendering of Accommodating Showman as circus tent.............................................58

Figure 6.3.3 Diagram of four primary theatre typologies...........................................................59

Figure 6.3.4 Diagram of Showman in proscenium stage layout..................................................60

Figure 6.3.5 Diagram of Showman in proscenium stage layout alternative.....................................61

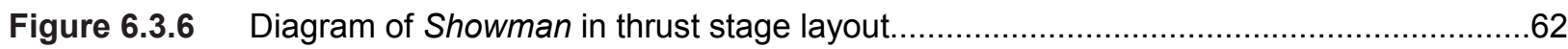

Figure 6.3.7 Diagram of Showman in thrust stage layout alternative ................................................63

Figure 6.3.8 Diagram of Showman in arena stage layout..........................................................64

Figure 6.3.9 Diagram of Showman in arena stage layout alternative ..............................................65

Figure 6.3.10 Diagram of Showman as black box theatre interpretation...........................................66

Figure 6.4.1 Rendering and plan of Showman in troupe's studio | training space, Toronto.................67

Figure 6.4.2 Rendering and plan of Showman stationed in St. Lawrence Market, Toronto.................68

Figure 6.4.3 Rendering and plan of Showman stationed in Trinity Belwoods Park, Toronto..............69

Figure 6.5.1 Rendering of Showman in all four show-specific scenes...............................................70

Figure 6.5.2 Rendering and section of Showman: Scene I.......................................................

Figure 6.5.3 Rendering and section of Showman: Scene 2 .......................................................

Figure 6.5.4 Rendering and section of Showman: Scene 3 …..................................................

Figure 6.5.5 Rendering and section of Showman: Scene 4.......................................................74 

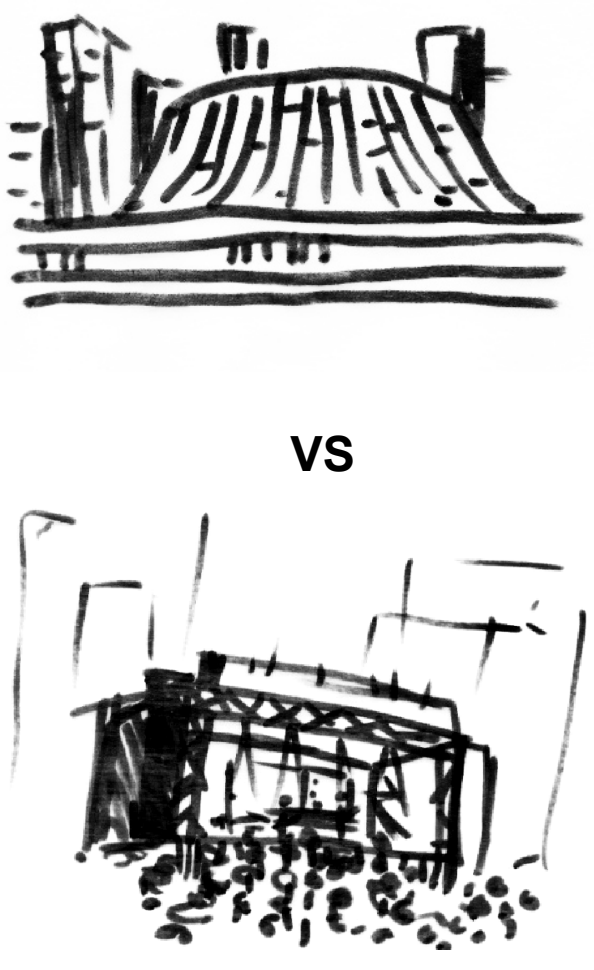

The Local Example:

Figure 1.1- Sketch by author of Roy Thomson Hall, Toronto.

Figure 1.2- Sketch by author of a temporary stage at Yonge and Dundas Square, Toronto.

\section{Introduction}

This thesis originated from a fascination with the impermanent nature of transportable spaces. Their ability to be relocated once they had exhausted their use in a architectural approaches reflected a sensitivity to our changing (and at times fleeting) needs, far beyond that of our surrounding traditional static structures. In the wake of current environmental and climate unpredictability, experimental approaches to traditional structures such as these should particularly be coveted. While contemporary associations and preconceptions of portable structures continue to be of substandard-make (Kronenburg, 2002); transportable, temporary structures service us under a plethora of functions. Albeit often unnoticed, many do so within our daily contiguous environments.

As a result, this particular architectural research endeavour has focused itself on the development and proliferation of non-traditional design approaches. There exists an evident duality in our surrounding built environment between permanent and temporary structures. While temporary methods of construction may respond to our ever-changing needs and wants, the appeal of the permanent and enduring remains our primary outlet of choice. This duality is equally if not even more pronounced in the design and existence of the performance space. Both occupy strong roles in our existing context, while the design of the temporary is often overshadowed by its more boisterous counterpart. An undeniable amount of recognition is attributed to the commission and design of static performance venues, as a result causing us to often forget the equal presence of the temporary venue. 

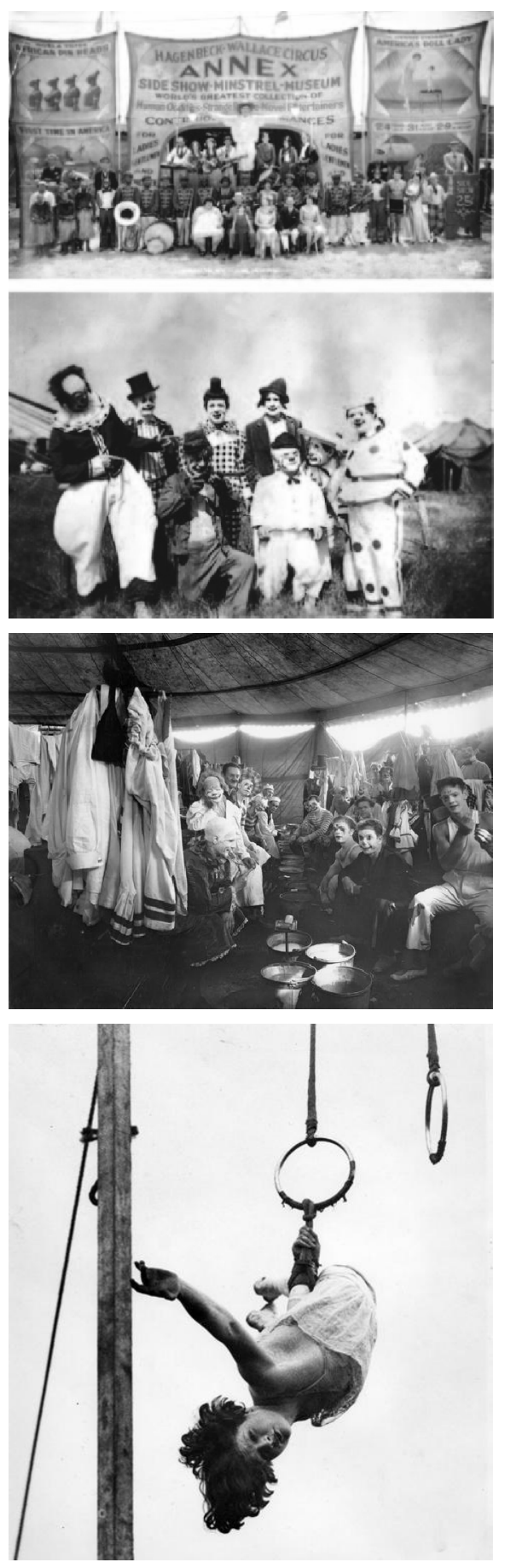

Figure 1.1.1 to 1.1.4 - A series of images from travelling circus and shows from 1901-1910.

\subsection{Historical Context | Background}

The history of the temporary and portable performance space is often linked to the likes of the travelling theatres and circuses of $19^{\text {th }}$ and early $20^{\text {th }}$ Centuries. However, a number of the earliest-cited developments in temporary stage design are linked to the Renaissance period, where theatre performances made up a large part of public entertainment.

Florentine Renaissance architect, Sebastiano Serlio (14751554), developed a series of architectural theatre plans which he then wrote about in his 1545 Vitruvius-inspired treatise Architettura (Banham, 1995). Serlio described in detail the design of a temporary wood-construction stage along with semi-circular bleacher seating. The design was suited for use within existing interior spaces, hence its title teatro della sala, theatre in the hall (Encyclopedia Britannica Inc. , 2011).

It was not until the late $18^{\text {th }}$ Century, as outer city roadways became more commonplace, that relocatable performance spaces truly came to be (Harrop, 1989). During the period concurrent to Queen Victoria's reign (1837-1901), two travelling theatre typologies in particular prospered. The first were the fit-up troupes. Like Serlio's earlier example, these troupes "fitted-up" a stage or performance spaces within existing unoccupied spaces with little intervention. Comparatively, the second typology was much more portable in design and required more elaborate methods of transportation, since its scale and components were far greater in detailed (Harrop, 1989). These examples were acknowledged as the Victorian Portable Theatres, because they essentially rebuilt the theatre experience from ground 

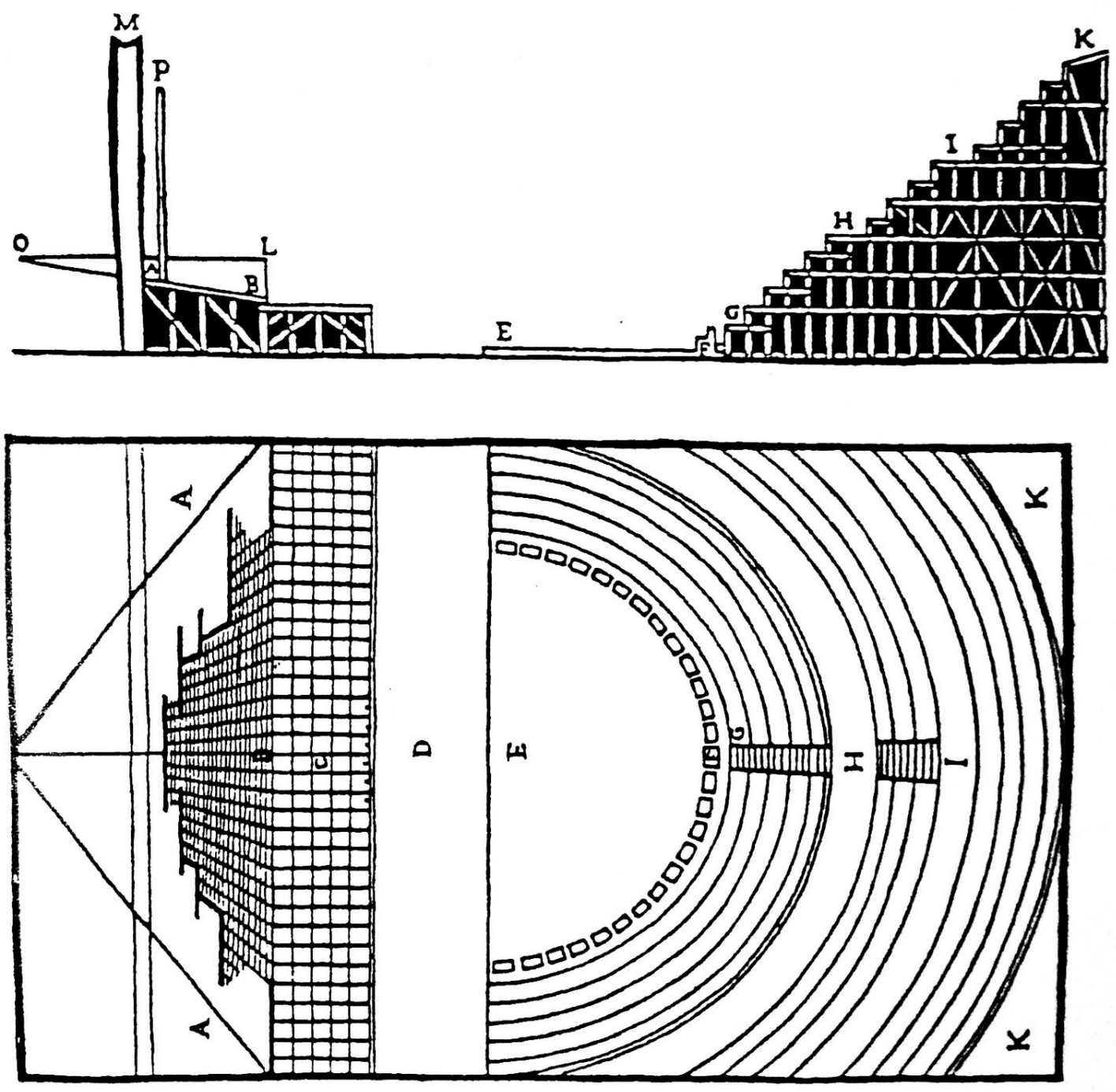

Figure 1.1.5 - Original drawing by Sebastiano Serlio of his temporary theatre, 1545. 


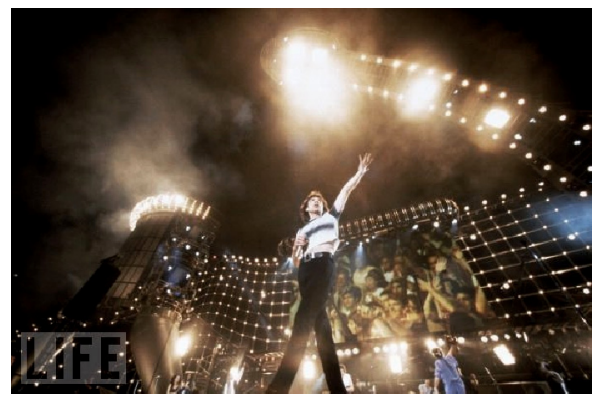

up, with every stop they made. Their use was often for popular fairgrounds, and some of the larger examples, such as the British proprietor, Sam Wild's 1835 structure could hold up to 1200 people at once (Harrop, 1989).

Today we have re-appropriated that notion of the Victorian LIF travelling troupe, with the global tours put on by major musical celebrities. Firms such as Stufish Entertainment Architects, focus their design practice solely on the design and development of innovative stage sets. Lead by British architect Mark Fisher, the firm has an impressive body of work, as the primary designers for Cirque du Soleil and the Opening Olympic Ceremonies in Beijing 2010. The 1960s marked the beginning of his career, concurrently with the rise of fan-crazed music talents such as Elvis Presley and the Beatles (Kronenburg, 1996). His stage set development for travelling tours demonstrates the impressive extents relocatable structures can achieve. Perhaps his most wellknown piece of work is the $\$ 4$ million stage set he designed for the Rolling Stones 1994 "Voodoo Lounge" tour. The enormous stage was raised 180 times over the bands one year tour-period. The components of the $100 \mathrm{~m}$ wide by $25 \mathrm{~m}$ high backdrop were said to fit neatly within 16 trucks for site to site transportation (Kronenburg, 1996).

Fischer's work is the most prolific example today, of the temporary performance space. While his work demonstrates a great deal of architectural and technical ingenuity, his design along with many others within the practice, bring forward some rather pressing issues with

Figure 1.1.6 \& 1.1.7 - The Rolling Stones 1994 Voodoo Lounge Set, designed by Mark Fisher. regards to the accepted approach to temporary performance spaces. 


\subsection{The Problem}

Current temporary performance spaces often demonstrate little flexibility beyond (if present) their ability to relocate. Their blatantly disposable fate ought to be exposed, for it perpetuates a condition which consequently makes them far less environmentally responsible than their permanent counterparts. This unfortunate final outcome, leads their ephemeral nature to emerge as a liability rather than an benefit.

Their use falls into one of three categories:

- the stage for the travelling tour

- the one time performance use

- or the re-erectable rental stage

Of the three the latter presents itself perhaps as the least prejudicially "architectural", but it nonetheless demonstrates a timeless and incredibly functional module which recalls (with little need for alteration over Centuries) Serlio's aforementioned teatro della salla.

The primary issue with temporary structures is that if they are designed with the expectation of a short lifespan, very little thought is allocated to what happens to the structure following its initial intended use. From a socioenvironmental perspective, architects should have a heightened awareness of what they produce and how it is "consumed".

From this perspective there are two chief identifiable ways to deal with the predicated limited lifespan of the temporary performance space: 
1. Design with the reuse and disassembly of all parts in mind, in an effort to consider the full material lifecycle (i.e. Design for Disassembly).

2. Design a performance structure which possesses the inherent ability to be readapted, or altered based on the performers changing needs in an effort to extend the structure's usage period.

In the earlier stages of this research, it was suggested that the first option ran the potential of leaning more heavily within the parameters of an engineering investigation. Therefore, to respond to the expectations of an architectural exploration, the second option presents itself of particular interest. It commands an inventive solution for accommodating multiple spatial relationships, and a grasp of anticipated future uses. 


\subsection{Challenge and Intervention}

Based on the information provided in 1.2, this thesis seeks to exploit the portable performance venue's notion of temporality, in order for no one setting to be finite or absolute. It strives to uncover an approach which can offer a flexibility beyond solely that of its siting, by responding formally (in relation to change of shape, orientation, order) to changing client and audience uses.

The outcome is the design of a transient performance space which acts as an adaptable instrument and possesses the ability to transform or shape-change based on the performers' needs. 


\subsection{Research Outline}

The project research has been divided into two equal parts, the first being the investigation of the architectural responsibilities and the second into the world of the performer. The following chapters 2 and 3, act as the bulk of the thesis literature review.

Chapter 2, under the title of "Characterising Flexibility and Transience", seeks to examine relevant contemporary associations of space and define various approaches which lend themselves to an architecture of changing site and form. At first glance, some of the selected topics and examples may not present themselves to have obvious correlations to the thesis research. However it is imperative to acknowledge that many of their conceptual and design intentions demonstrate overlying ideals relevant to the design project outcome.

Chapter 3 is in its entirety, program-based. "Performance Theory" strives to define common theatre and performance relationships, from the experiential to the architectural. By identifying recognizable typologies, the latter end of the chapter helps instruct some of the formal qualities required of the design exploration.

Architectural project references are provided throughout the text to reinforce and provide visual aid of the various design intentions. However, Chapter 4 presents the most thorough evaluation of the key qualitative architectural project precedents. These projects all share similar program references, despite providing a varied architectural outcome. Finally, Chapter 5 introduces "The Design Exploration" by presenting the selected client and project 
parameters. Unlike many thesis investigations, this project does not have one set site and as a result, must respond to a variety of changing site conditions. If the reader wishes to explore in further detail the development of the design exploration, an appendices has been provided at the end of the text. Selected exercises have been included within it to reflect the morphology of the design process. 


\section{THE TRANSIENT PERFORMANCE SPACE}

Literature Review 


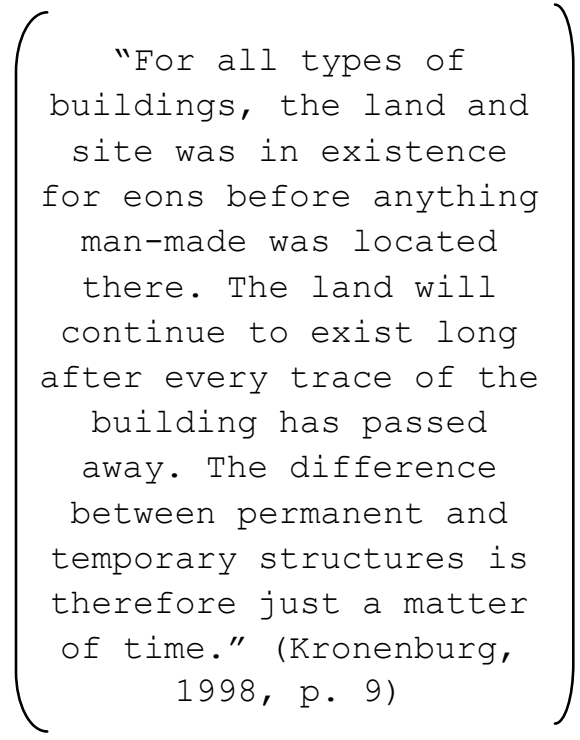

The primary adaptable characteristic of the temporary performance venue is its ability to be relocated to a new site. Transportable environments were established as a key research point at an early stage in this thesis investigation, and a great deal of information on transportable environments was collected for the mid-semester draft report. The following section (2.1) attempts to summarize some of that information in order to provide some background research into the origins of transportability in architecture. 


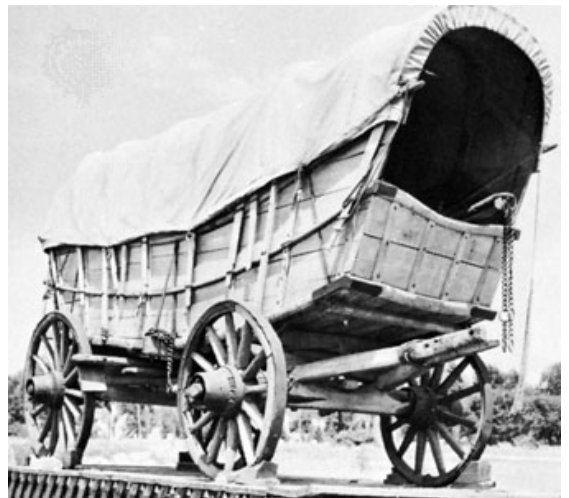

Himh

\subsection{Methods of Transportability}

Transportable environments in their nature display characteristics which are uncommon to our standard static building typologies. Various approaches can be used to facilitate the relocation of a temporary structure. Since the 1990s, mobile, portable, relocatable, and prefabricated structures have been featured as key topics in Dr. Robert Kronenburg's research endeavours. It is paramount to acknowledge that the definitions listed below, expand on terms as defined by Kronenburg, and therefore may reflect variances when measured against those of other scholars.

Mobile (architecture) refers to a building type designed with mechanisms which provide autonomous mobility. Such a building possesses the inherent ability to move on its own without assistance of ulterior modes of transport. To understand mobile architecture one must first grasp that many of its concepts and mechanisms are concurrent with those from our most common modes of transportation. As the automobile, the boat, and the airplane developed technologically, so too did the mobile building.

The caravan is perhaps the most prolific example of the mobile building. The Pennsylvanian Conestoga Wagon is one of the earliest citable examples of the caravan. Established in 1725, prior to railroad systems, the wagon was used by farmers to hull loads of up to 8,000 tones (The Columbia Encyclopedia, 2008). The term caravan stems from the Persian word kārwān which was used to reference to groups of travellers, be it by ship, cart, or carriage (Etymology, 1996). As caravans evolved in the $19^{\text {th }}$

Figure 2.1.1 - An image of the Conestoga Wagon, used by Dutch settlers in Pennsylvania.
Century, their use began to extend beyond that of transport vehicles for heavy cargo and they became a favourite of 


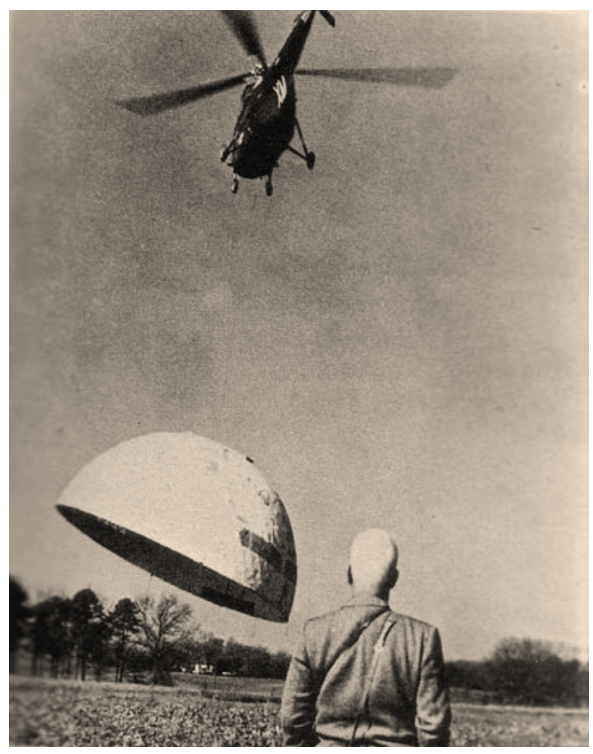

travelling showmen, and the gentlemen of the Grand Tour. Due to the autonomist character of the mobile building, its undoubtedly greatest trait remains that does not require the assistance of any other methods of transportation in order for it to be displaced.

Portable (architecture) refers to a building type which can be transported as a whole unit without disassembly. Portability is often considered advantageous in emergency cases, when need for the building is immediate. The traditional trailer home offers itself as the unbecoming poster-child of portable architecture. Its small scale allows for facility of transport on a flatbed trailer, and its often lowcost make it a viable housing option (based on 2001 Statistics Canada Study) for 380,000 Canadians (Frances Kremarik, 2001). Typically, the trailer is hauled with the assistance of a chasis and sited on a pad or block base and concealed with a skirt. Despite the lack of any imbedded mobile traits, the popular term of choice in reference to the portable trailer home continues to be the mobile home; forever linking it to its origins of the recreational vehicle. A detriment to both mobile and portable structure (at times one and the same), is that their offsite pre-assembly places constraints on their overall maximum size.

Relocatable and pre-fab structures, in comparison, do not suffer from the same scale constraints because their disassembled travels allow larger building types to be transported with the help of innumerable vehicles and methods. Their downfall is that pieces can be lost or

Figure 2.1.2 - Buckminster Fuller's US Marine Dome being airlifted by helicopter, 1954. damaged following repeated use, and their assembly can be complex and time consuming. 


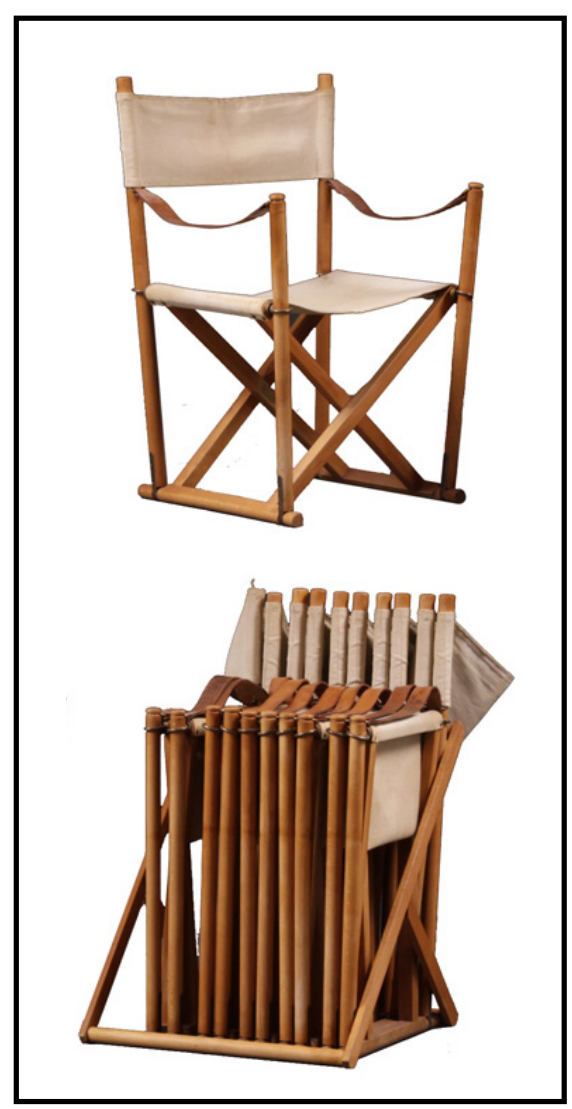

Figure 2.1.3 - Mogen Koch's Folding Chair, 1932.
Prefab (architecture) essentially refers to buildings whose components have been prefabricated offsite. Pinpointing the origins of prefab methods proves a difficult task. Britain's influences on its developments were profound. Its colonization of foreign territories during the $16^{\text {th }}$ and $17^{\text {th }}$ Centuries within North America and Australia depended on the shipment of goods across seas. Since these colonies did not yet possess the infrastructure or the knowledge of local materials available; buildings materials were brought over from Britain, prepared for assembly (Smith R. E., 2011). It was however the Industrial Revolution of the $18^{\text {th }}$ to $19^{\text {th }}$ Century which marked a period of drastic change in the fabrication of goods and had the greatest impact in the proliferation of prefabricated prototypes. Barry Bergdoll suggests, that since that point there has been a "near systematic avoidance of the topic of prefabrication, or, more accurately, industrially produced, off-site building" on behalf of the architectural community (Bergdoll, 2008, p. 9).

Collapsible (architecture) refers to a building type which can be compressed or flattened in order to facilitate transport. The term itself, prompts an imagery of accordionlike shapes whose bellows possess the ability to contract and expand at the request of its user. They remain typically at a smaller scale due to their limitations as an all-inclusive cover. Some may consider their design conception to require greater ingenuity in the methods used to allow their collapsibility than their other (as listed) transportable counterparts. Collapsibles are of particular interest because they represent a building type which continues to have a rather small research and precedent base in terms of built form. Their characteristics however materialize rather frequently in the objects and furniture which surround us. Foldable chairs, camp beds/cots, parachutes, utility and 
Swiss Army knives, card tables, Luxo lamps, truck lifts, and umbrellas; all reflect elements of collapsibility. Just as in the paper form, collapsibles can come to form from one autonomous material or a series of linked layers and intersecting connections. They present an interesting precedent in the study of architecture which is expected to demonstrate transportable qualities, as their space-saving character offers an uncommon solution to structures which must be moved easily. Their flaw, is essentially that which makes them most intriguing. As with any movable mechanism, the constant opening and closing can cause issues and defects. Their greatest asset is their ability to be flattened or minimised when space and storage are an issue.

A grasp of the basic meaning of each of these subcategories is integral in the understanding and analysis of the upcoming literary and precedent sources, as well as in the manifestation of the imminent design exploration. When considering the extension of the usage period of temporary spaces, transportability presents itself a welcomed solution. 


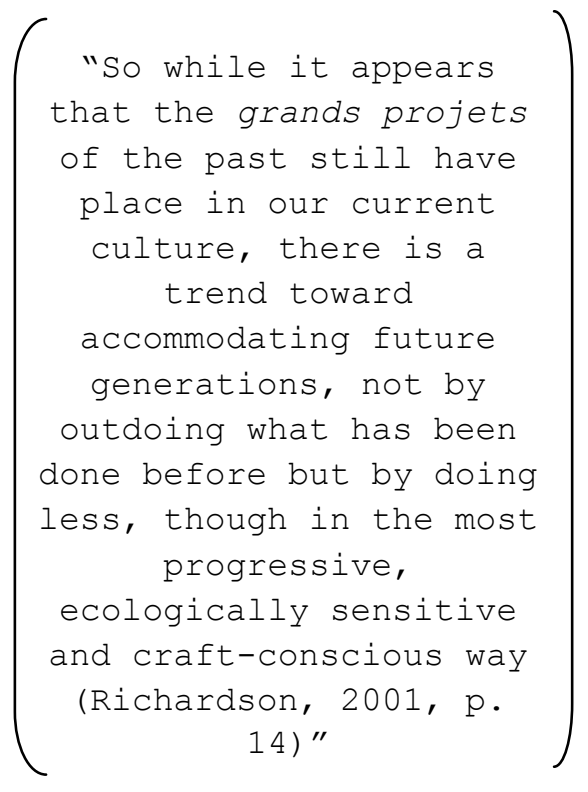

\subsection{The Human Scale | Size Matters}

In the design and development of relocatable structures, scale plays a particularly important role. Evidently, as the scale of the structure increases, so too does the complexity of its transport methods. When repeated assembly and disassembly is required, buildings at a smaller scale offer themselves as more manageable alternatives.

The natural world has increasingly demonstrated its obvious irritation with human activity, as natural disasters and unpredictable weather patterns become more commonplace. While as a society we may depend on many of larger scale permanent structures, equal emphasis should be placed on the design of smaller temporary structures. This approach is no doubt not new to the architectural discipline; however it does seem to have reemerged as a strong point of interest recently. One of many examples is an exhibition put on in October 2010 by New York's Museum of Modern Art titled "Small Scale, Big Change". The exhibition presented eleven projects, which proposed small community interventions and buildings which sought to serve various underprivileged areas (Lepik, 2010). While none of the projects shared this thesis' performance program scope, they demonstrated a clear shift towards the welcomed results of architectural interventions at the small scale.

The interest in the small scale with regards to the design of a transient performance space remains primarily for practical reasons. As elaborated by Phylis Richardson in $X S$ : Small Buildings, Big Ideas the reigning qualities of the small building are:

- they allows for a more human/manageable scale 


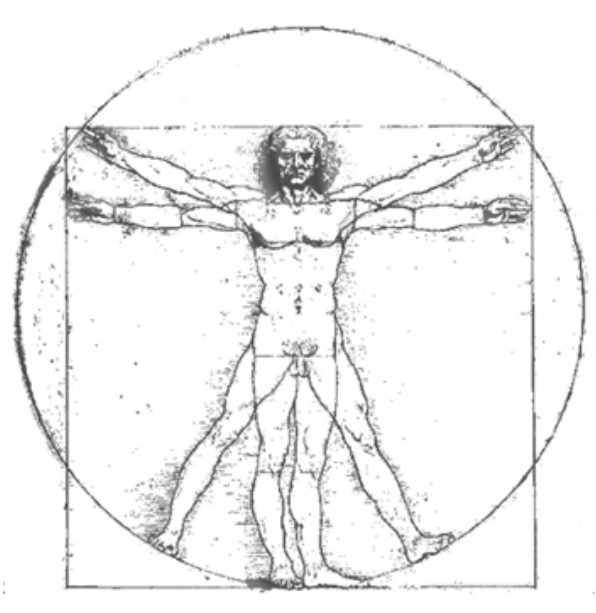

- they do not overpower their surroundings topographic conditions

- they allows for an intricacy of detailing hard to come by at the larger scale

- their environmental impacts are less pronounced

In line with Richardson's suggestions, keeping the scale of the proposed performance space more subdued would not only facilitate the project's ability to be moved from site to site, but could potentially allow for its parts to be lifted or altered manually by individuals, rather than depend on the use of larger machinery when a transformation was required. The small gesture of managing the scale of the components would allow increase the overall flexible nature of the structure. Allowing for the reconfigurations to occur with minimal aid, would encourage the users to take advantage of the structure's shape-shifting qualities.

This notion of human interaction plays into the exploration of anthropometrics. Anthropometry is essentially the study of human proportions (Merriam-Webster Inc., 2012). Its role has been pronounced throughout the history of architecture because it allows us to establish comparative relationships between human measurements and built environments. da Vinci's infamous "Vitruvian Man", is perhaps one of its most recognized visual representations. The drawing was based on an excerpt from Book III of Marco Vitruvius' canonical De Architettura. Like many of his peers, da Vinci believed that his studies of the Vitruvian Man reflected a cosmografia del minor mondo (cosmography of the microcosm) (Encyclopædia Britannica, Inc., 2012)

Figure 2.2.1- da Vinci's Vitruvian Man, 1409.

The connections made by Renaissance architects and scholars, between the human proportion and divine built 

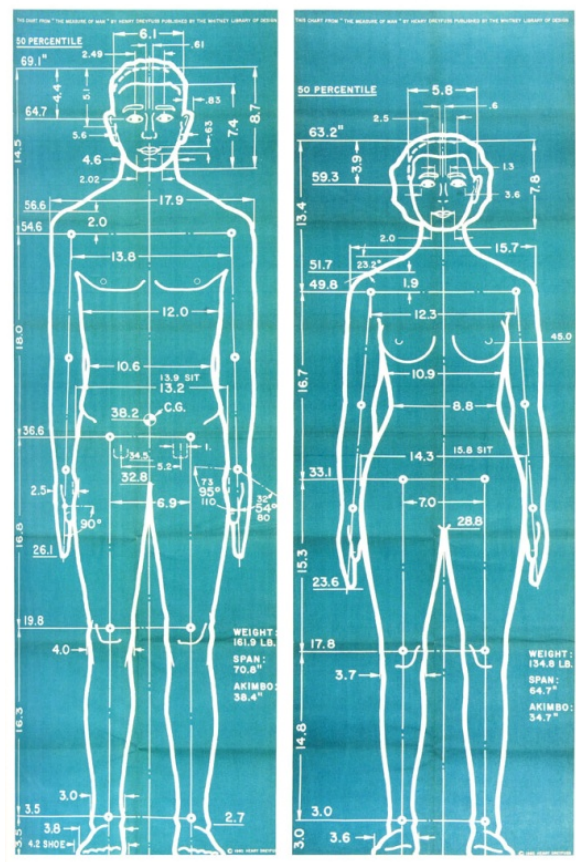

outcomes are a thesis study in themselves. However they present a critical understanding of the user versus the built space, which some may argue is largely forgotten in many contemporary architectural endeavours. More recent architectural associations to anthropometrics, such as those by Le Corbusier, approached the study of human proportion from a seemingly more ergonomic standpoint. Le Modulor was established to provide a new unified code of dimensions to be used internationally as the global design proportions. The proportions were intended to facilitate the calculation of spatial relationships to human interaction.

Around the same period that Le Modulor emerged, so too did Joe and Josephine. They were the 1955 creation of Henry Dreyfuss, an American product designer. Like Le Modulor they were presented as simple line images of a man and woman, surrounded by dimensions. Throughout the book and in the descriptions of Dreyfuss' product designs, Joe and Josephine act as the invisible critics. Not only are their adjustable anatomical measurements considered in the development, but so too are their psychological stigmas, phobias, preferences and disabilities (Dreyfuss, 1955). In the design development of a product in Dreyfuss' office, their opinions and suggestions were of paramount importance. They might respond poorly to a certain colour, dislike a seat which is too hard, or have a hearing disability which prevents them from audibly reconignizing a certain sound. The characters presented a whole new layer untouched in the study of anthropometry. Unlike classical associations of human proportion to harmonious metrics, Dreyfuss's approach was completed disassociated from religious undertones. 
The importance of height, and spatial ratios are of vital importance within this thesis design exploration. The revelation of the selected client in Chapter 5 will provide more insight into the users' interactions with the structure. Since the primary goal of the investigation is to exploit performance space's adaptability a great deal of interest will be placed on how the user can manually alter the space in which he/she is performing.

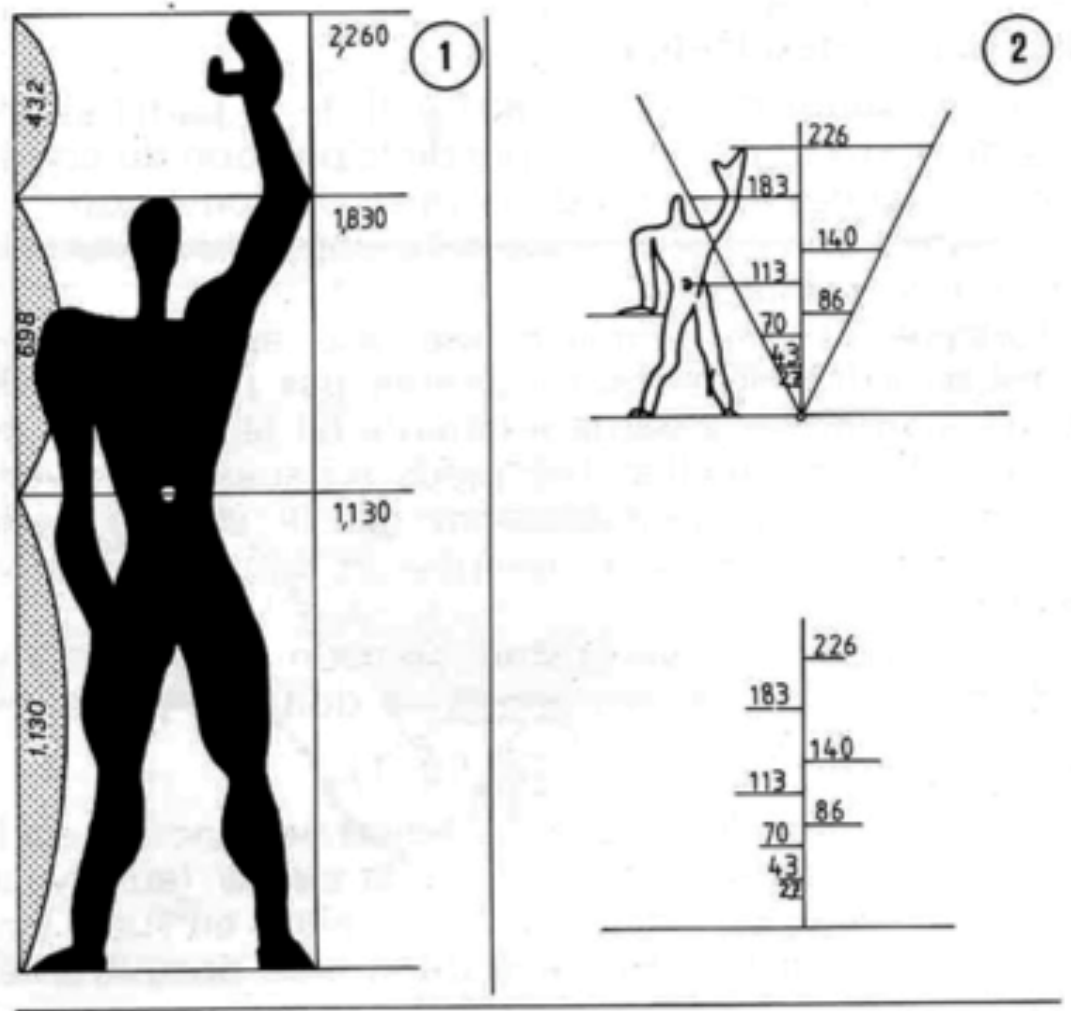

LE CORBUSIER . LE MODULOR

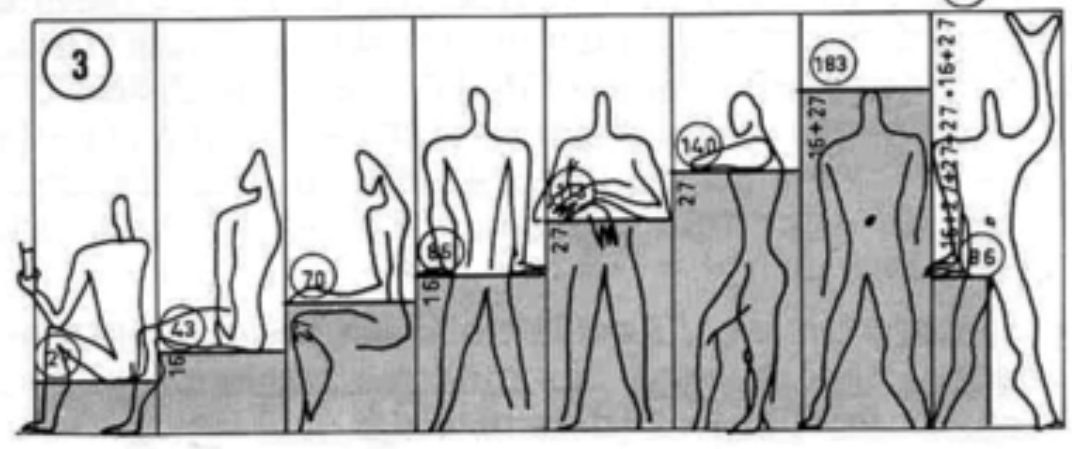

Figure 2.2.3- Le Modulor by LeCorbusier, 1949. 


\subsection{Creating Space}

Just as acknowledged in section 1.3, the challenge of this design exploration is in the creation transient performance space which possesses the ability not only to be moved from one location to another, but most importantly, to be altered and reconfigured to meet the changing needs of its performers.

Shape-shifting has been long-running punitive theme throughout our literary history from Greek mythology, to fairy-tales, appearing even within our contemporary Disney productions. While the intention of the design project is not to adopt an approach as extreme as that demonstrated in the Transformers film franchise, an integral component of the design is that it have the ability to adapt to changing demands. As an objective, this could be reflected in a plethora of ways.

Adaptable Futures is a team of students and professor from Loughborough University (UK), which has endeavoured to assemble a four year research project on the nature of adaptability in the built environment. Their studies attempt to unpack the many ways a building can seek to outlast its counterparts. The primary differentiation is that this thesis seeks to exploit the notion of temporality at its very core, while they work actively to avoid it. Their findings are geared towards permanent structures and the tools which can be used to make them extend their lifecycle (an undeniably commendable approach). Despite the differences in their intentions, many of their findings fall within the scope of this investigation. 


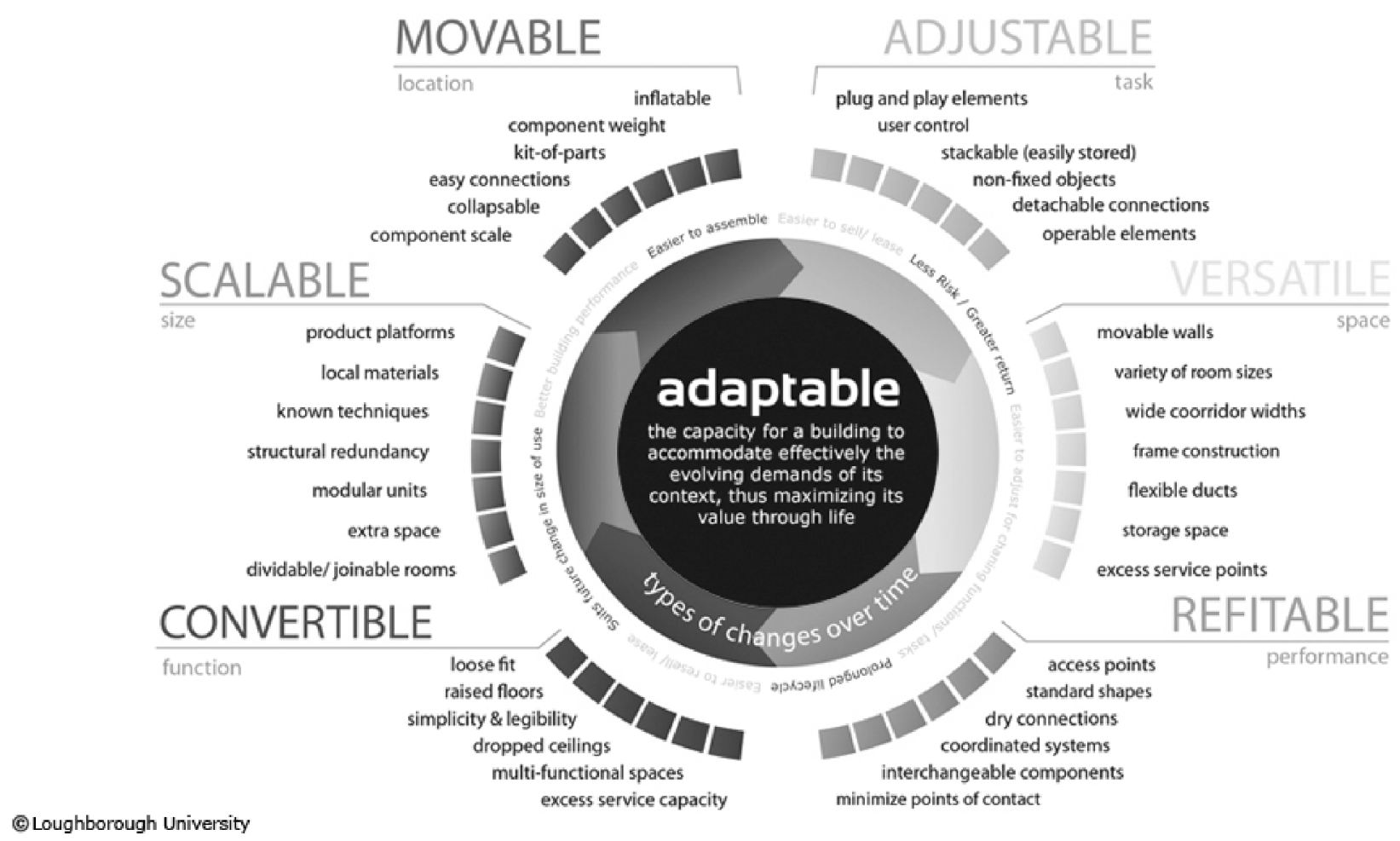

Figure 2.3.1 - Adaptable Futures "D11:Framecylce".

Figure 2.3.1 demonstrates a range of design strategies which can be used to provide greater adaptability. While the scale of the proposed performance venue, may not lend itself to some of the more substantial adaptable strategies provided in "D11", the diagram does however provide a complete list of potential methods of transformation worthy of consideration. 

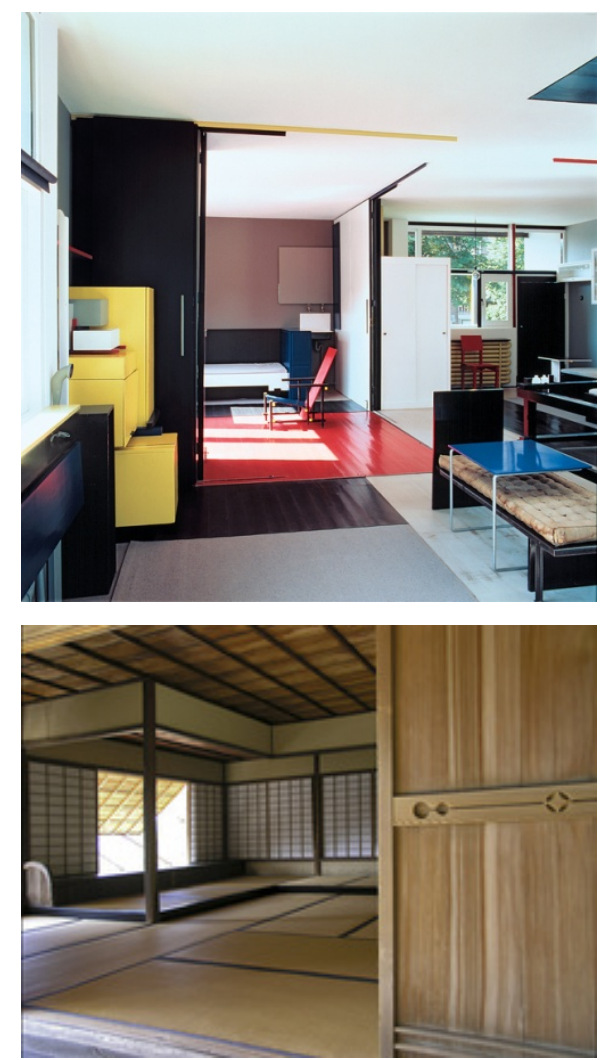

Figure 2.3.2 - Rietveld's Schröder House, 1924.

Figure 2.3.3 - Kuysuitei Pavilion, Shugakuin Imperial Villa, 1659.
Examples such as the upper floor Guerritt Rietveld's 1924 Schröder House, and early Japanese pavilions such as the ones part of the 1659 Shugakuin Rikyu Imperial Villa, provide movable wall partitions which allow the users to reconfigure the space. In performance architecture, this idea is also reflected in the simplicity of the Black Box Theatre. These approaches are of particular interest with respect to this thesis because while the overall program remains the same overtime, the way the space is framed can be changed to create alternate formal outcomes. For example, in the case of the Schröder house, the upper floor remains used as a bedroom and general living space, however the way the rooms are enclosed is based on the whim of the user.

Like many of the examples provided by Adaptable Futures, Rietveld's and the Imperial Villa's Pavilions are set within the scope of a permanent built environment. The challenge therefore remains that there are few examples of temporary structures which lend themselves to the same level flexibility. Hiroshi Nakoa's Black Maria project, is one these select few. The project is composed of two $C$ shaped frames which each have two primary hinge points along their span. The frames sit upon large industrial castors, which allow them to be moved to create new forms. Figure 2.3.4 is composed of a series three of photographs of the Nakoa's original model, demonstrating three potential frame configurations. 

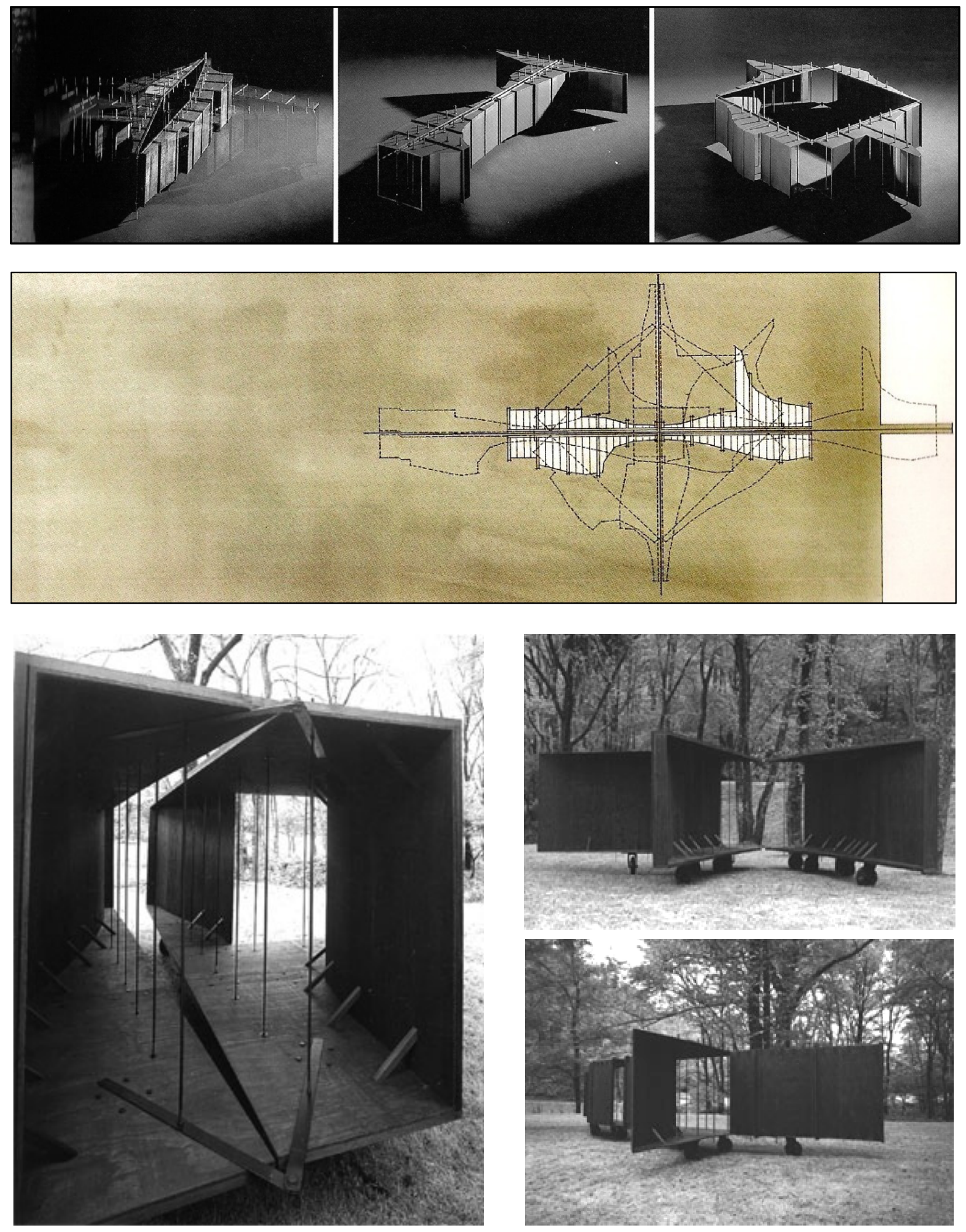

Figure 2.3.4 - Photographs of Nakao's model for Black Maria in various configurations.

Figure 2.3.5 - Drawing by Nakao of Black Maria in plan view.

Figure 2.3.6, 2.3.7, 2.3.8 - Images of Black Maria in built form, 1994. 
Bernard Tschumi identified the established role of the architect following modernism as "the form-giver, the creator of hierarchal and symbolic structures characterized, on one hand, by their unity of parts and, on the other, by the transparency of form to meaning (Tschumi, 1994)".

The environment created for the purpose of a performance demands a particular understanding of the required spatial conditions. Unlike a space in which the user passes through quickly, the audience and performer are completely consumed within or by, the environment which surrounds the performance for its however brief, duration. The overall outcome of the performance feeds greatly on the spatial qualities manifested by the design or lack thereof. The subsequent chapter will begin to delve a bit further into our grasp of the act of performing and the various relationships which play role in the overall experiential quality. 


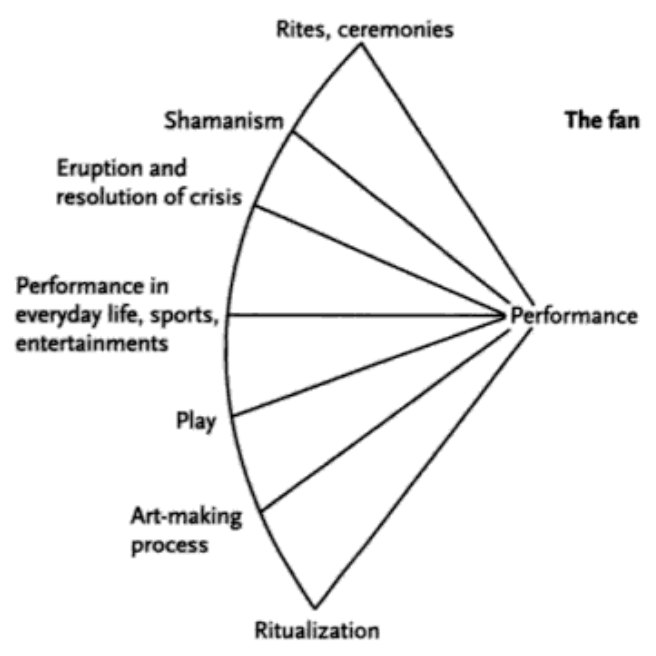

\section{Performance Theory}

Enter the world of the performance. The term performance takes on many meanings. For Richard Schechner, a noteworthy theorist on all matters of theatre and production art, the term performance envelopes everything from secular child's-play, sports, legal courses of action, entertainment and theatre, to the sacred ritual. Thus demonstrating that it is important to note that this thesis' interest is in the creation of a performance space, where the word performance denotes an intentional demonstration and show before a group of observing spectators. Under this similar umbrella of theatre practices, Schechner devises that performance reflects the full sequence of events which take place between the audience and the assigned performer (Schechner, 2003).

\subsection{Dilemmas of the Empty Arts}

Peter Brook's critical intentions may diverge from Schechner's, his unapologetic exposé of the theatre experience and its interpretation from the uninvolved spectator, reflects a dichotomy existent in most if not all performing arts. This dichotomy of intention versus consumption is one that even reverberates across the arts (performed, visual, and built). Empty Space attributes four separate meanings to the word theatre. The first is the notion of the "Deadly Theatre" which he essentially refers to as unauthentic reproduction of a piece, in a manner which is believe to stand true to the classic interpretation, with little passion and driven by biased preconceived notion of how it should be. A Deadly Theatre, takes no new risks, Figure 3.1 - Schechner's Fan. and makes little effort at revisions. 
The discussion on his second definition, the Holy Theatre, brings about a certain air of despair. It unearths the ultimate goal of the artist, or in Brook's case the director, who seeks more than anything else for the spectator to consciously find some likeness between the interpreted and his own personal reality. To create a sort of personal connection with the piece, bringing them to a new level of understand. He speaks of Theatre's of Cruelty, (as Artaud strove for) which sought desperately to shock the audience into some form of outer body reaction. The "Happening" he claimed, was true aim of the Holy Theatre (Brook, 1969). It represented that "ah-ha" moment, even short-lived, which broke all barriers between the performance and reality.

The third definition delves further into that understanding of barriers and begins to discuss some of the material and tactile gestures used to form the performance environment. The Rough Theatre, lives well to its name. It demands a raw and uncensored approach, striped down from the excessive cover of intricate costumes, embellished scenery, and classical theatre spaces. It constantly breaks boundaries, as a Brook's states must always be in a state of revolution to exist (Brook, 1969, p. 88). The performer's role in the Rough Theatre is expected to break away from norms, rebelling from traditional tactics.

The fourth and final definition is title the Immediate Theatre. It delineates itself from other entertainment methods such as the cinema, in that it is live and in the present. As the final chapter of the book, it also doubles as Brook's portrayal of how a performance ought be conceived. This conception he breaks down from the event itself, to the various supporting components of the set, the scene artwork, and the costumes. What appears incredibly 
relevant to this thesis discussion, is his critique of working with designers. The primary conflict he sites is that the development of a performance is a work in motion, and the built-environment's design is one that should be malleable and prepared to respond to the changes and evolution of the play as rehearsals move closer to the day and the performance itself begins to find its identity. The relationships he cherished the most with designers, were based on their ability to quickly withdraw from on design idea and restart when needed, with those who were unattached to initial iterations and prepared to see their design scenery dismissed, altered, or reconceived repeatedly throughout the course of the rehearsals.

"The one thing that distinguishes the theatre from all the other arts is that it has no permanence. Yet it is very easy to apply - almost from force of critical habit- permanent standards and general rules to this ephemeral phenomenon.” (Brook, 1969, p. 117)

When considering Brook's four definitions, points of correlation arise reflecting the intentions of the designer architect. Once the design exploration has been presented this negotiation will become ever more clear. The goal of this project is to propose a transient performance space which can not only play the role of the dull "deadly theatre", reproducing existing known spatial relationships; but ultimately proposing something which goes above and beyond the traditional and offer a new, raw approach such as the "rough theatre" so unapologetically aspires to do. 


\subsection{Performance Relationships}

Several relationships are established throughout the duration of a performance. The primary one, being that between the artist/performer and his audience.

The fourth-wall was a term originally coined to reference that invisible barrier which divides the audience's reality from the fictional narrative occurring on stage. The term was first ever describe by the French encyclopaedist, Denis Diderot in his writings on the comedic and dramatic theatre arts in France.

"When you write or act, think no more of the audience than if it had never existed. Imagine a huge wall across the front of the stage, separating your from the audience, and behave exactly as if the curtain had never risen."

"Soit donc que vous composiez, soit que vous jouiez, ne pensez non plus au spectateur que s'il n'existait pas. Imaginez sur le bord du théâtre un grand mur qui sépare du Parterre. Jouez comme si la toile ne se levait pas. " (Diderot, 1771, p. 301)

The reference to the fourth wall was based on the common theatre layout of the most French theatre houses of the period, where three of the rooms four walls were flanked with layered seating and the last was composed of a curtain-lined frame which separated the audience from the performance (Wilson, 2005).

This practice was one continued for centuries to come. Rarely in traditional theatre did the actor ever intentionally interact with his spectator during an a performance. Some contemporary performances however seek to break that 
wall. Stand-up comics often address their audience, feeding off their reactions as part of their routines. Popular musicians have been known to call fans onto their stages, only to serenade or encourage them into conversation. This notion is not a new one, and is a particularly intriguing factor in the design of a performance environment. The formal manifestation of a design can play a large role in the outcome of the audience/performer relationship. Gestures such as the distancing of the stage, can produce a forced fourth-wall perception, discernibly hard to break by the performer. Conversely the overlap of seating and stage, or entire lack of stage can create an equally unalterable break in the fourth wall. 

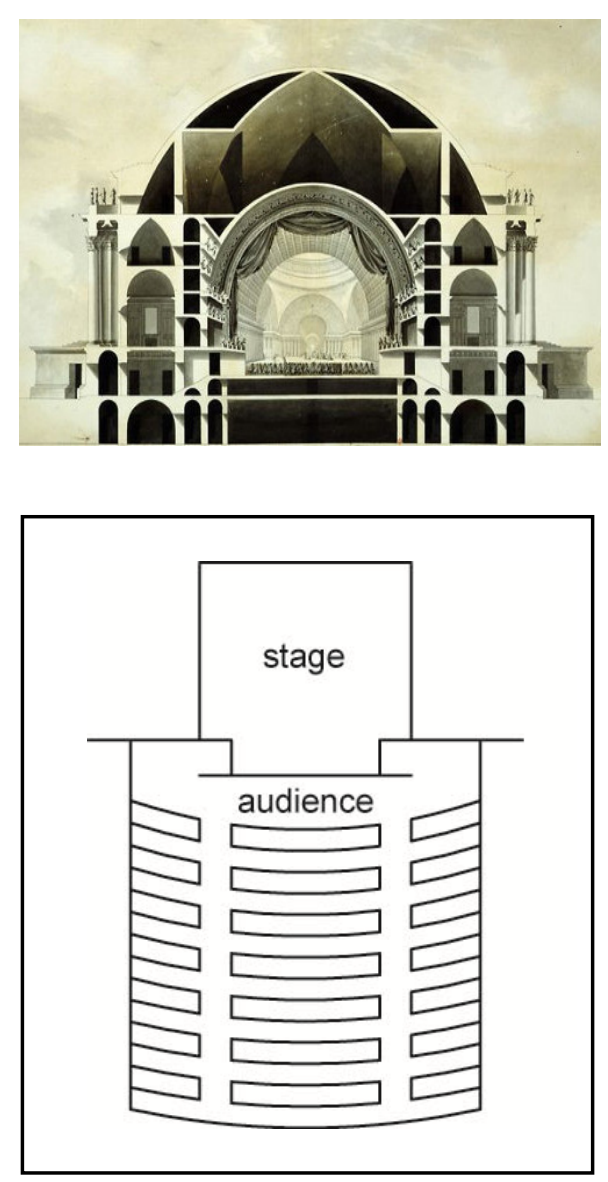

Figure 3.3.1 - A section looking towards the proscenium. Étienne-Louis Boullée's unbuilt Opera House design.

Figure 3.3.2 - Diagram by thesis author of the Proscenium Theatre Layout.

\subsection{Common Spatial Associations}

Theatre and the performing arts have bread a wide range of stage environments throughout the course of history. Listing each of these would make for an endless feat, therefore for the purpose of this research the four primary models described in this chapter are those selected and elaborated in the research of the recognized critic and professor Edwin Wilson. In his book Theatre Experience, Wilson examines the history behind the proscenium stage, the thrust stage, the theatre-in-the-round, as well as the contemporary black box theatre.

The proscenium stage continues to be the most identifiable stage environment. It's traditional picture-frame stage front origins are linked back to the Italian Renaissance, however by the late $17^{\text {th }}$ Century, the proscenium layout was the widespread in the architecture of European theatres (Wilson, 2005). As demonstrated in many of our contemporary local theatres and operas, the seating was placed on a slant to maximize audience sightlines. The main floor is identified as the orchestra, and above are commonly placed boxes on the three opposing walls of the auditorium. Wings and a fly-loft allow for the scenery used on stage to be slyly concealed from the audience's view when not in use. The proscenium layout reflects a traditional approach to theatre and performance presentations, adopted even in many of the designs of travelling Victorian theatres of the $18^{\text {th }}$ Century and reflected in the design of Aldo Rossi's 1979, Teatro del mondo.

The thrust stage was based on the Ancient Greek amphitheatre. Prior to $5^{\text {th }}$ Century B.C.E. the stage house 


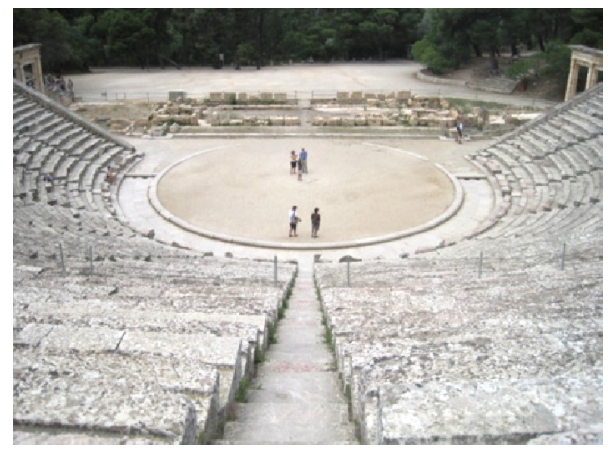

would have been built temporarily from wood and disassembled following the end of the festival for which it would have been erected. However in the centuries which followed that structure eventually became permanent and constructed of stone (Wilson, 2005). Siting sought after for the placement of these stages were often along hill sides, which facilitated the creation of tiered seating. This approach to stage layout went on to be appropriated by the Romans (Wilson, 2005). Come the $13^{\text {th }}$ Century and the platform stage. The performance space was no more than a raised stage with a small concealed area for performers to stand unseen. Many of these could be converted into wagon stages simply by adding wheels below them. The stages simple enough in nature, were pulled throughout town garnering new crowds in every area in which they sojourned. Seating was provided, but audiences would congregate in a semi-circle recalling the layout of early Greek thrust stages.

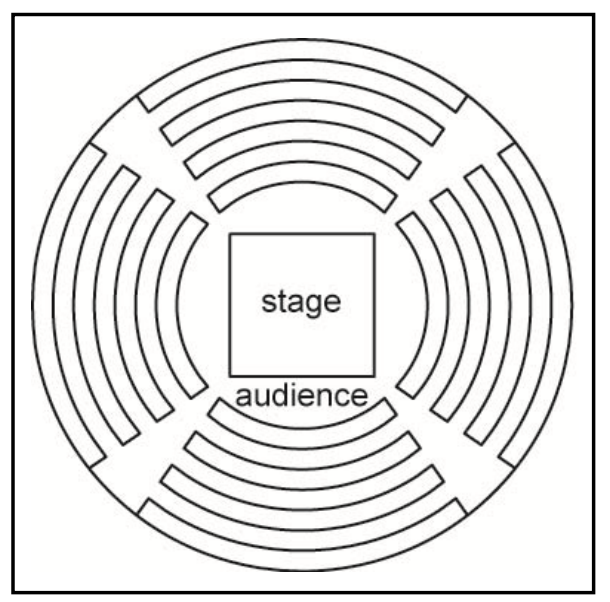

Figure 3.3.3 - Epidaurus Theatre, in Greece is an early built example of the Thrust Stage Layout. Thesis author's own image.

Figure 3.3.4 - Diagram by thesis author of the Thrust Stage Layout.

Figure 3.3.5 - Diagram by thesis author of the Arena Stage Layout.

An extension of this idea of the thrust stage, is what is indentified as the arena stage or theatre-in-the-round. Its geometry resembles greatly that of the Ancient Rome Colliseum. A stage sits at the centre of an enclosed circular space, upon which seating radiates outwards. This setting does not what is known as a back-of-house. The stage is fully exposed from all sides, completely exploiting the notion of stage-front. To some, the design provides a more intimate setting, and breaks the traditional theatre convention of a fourth wall. This particular planar layout was said to have regained popularity particularly in the United States following the Second World War (Wilson, 2005). One hypothesis for its widespread use is that it reflected a more economical model, because the stage could be used at once for theatre as well as various sports 


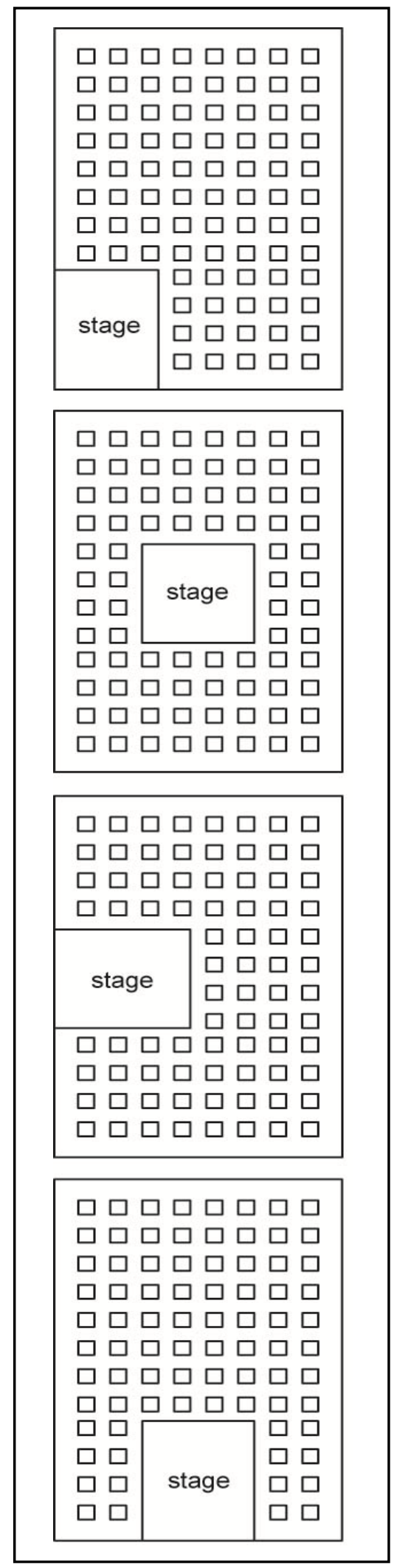

events such as boxing, and it required no more than a large empty space to occupy, unlike the two earlier mentions whose erections demanded significant structural and aesthetic modifications.

The black box theatre is perhaps the one example out of the four, which Wilson offers the least details for. Ironically, the design aspirations of the black box theatre, are those which fall the most in-line with the intentions and ambitions of this thesis. There lies an impressive simplicity in the design of a black box. Iterations are endless; lighting, seating, and the stage can all be adapted to meet the changing needs of a new director or the demands of an incoming show. Its flexible plan allows for its manipulator to recreate the thrust, arena, or proscenium-like layouts, as well as also provides many more opportunities unobtainable from its more static counterparts. In essence it is nothing more than an inactivated rectangular space, void of static obstacles. This flexibility makes it a favourite for many young theatre companies as well as college and university theatre and performance programs, which are constantly seeking to break traditional barriers.

Figure 3.3.6 - Diagrams by thesis author of potential Black Box plan configurations. 


\section{THE TRANSIENT PERFORMANCE SPACE}

Thesis Design Project 


\section{Key Precedents}

As mentioned earlier in the text, the design component of this thesis is in the proposal of a transient performance space. The intent is that the design act as an adaptable instrument and possess the ability to transform or shapechange based on the performer's need. When considering precedents that offer at once an adaptable plan as well as a potential for relocatibility; very few make themselves known.

The following case studies were selected based on the strength of their temporal architectural approaches, and their relevance with regards to the overall project research. Each of these projects helped define the scope and parameters of interest of the design proposal. Their victories along with shortcomings, have helped instruct several of the design conditions established within the parameters of this thesis investigation. 

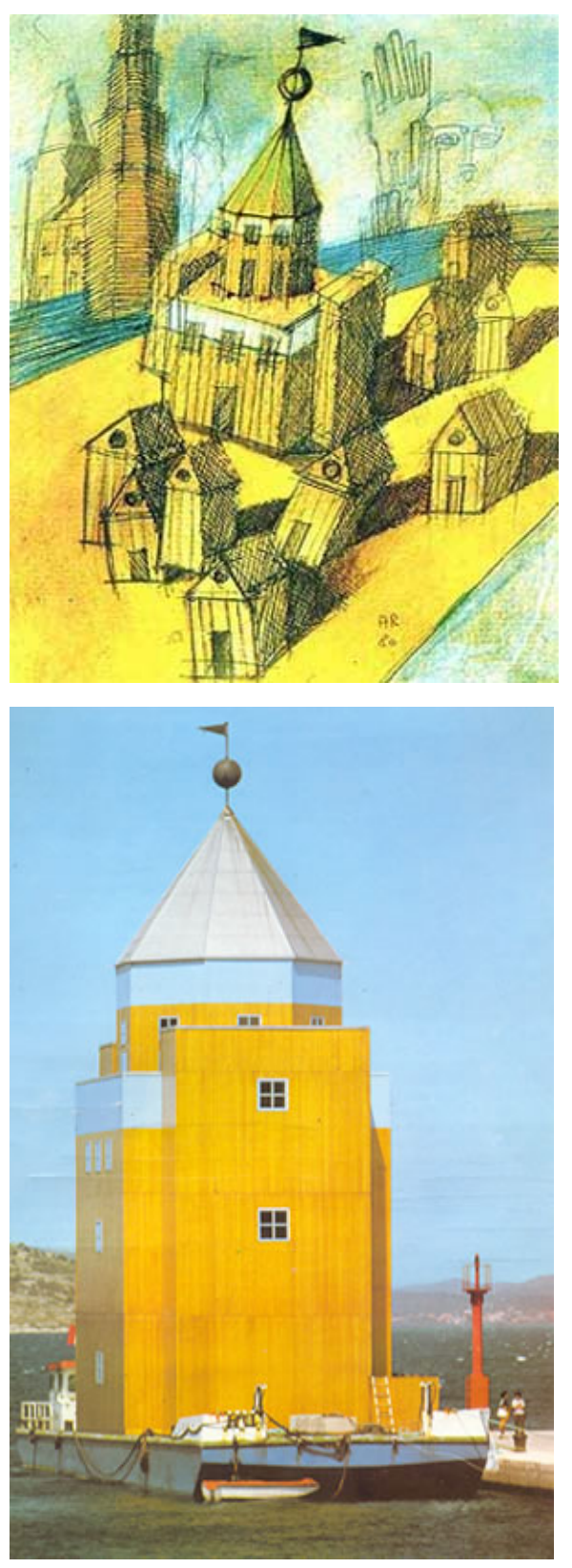

Figure 4.1.1 - Drawing by Rossi of Teatro del mondo on the move, 1980

Figure 4.1.2 - Teatro del mondo in built form, being docked in Venice.

\subsection{TEATRO DEL MONDO} Aldo Rossi

Year: $1979-1980$

Program: Temporary theatre composed of a classically inspired stage and tiered bench seating.

Specs | Materials: Tubular steel structure and wood panelling.

Context | Site: Assembled in Italy's Fushina Shipyards and towed by sea to rest by Venices Punta della Dogana. (source)

The design of a theatre edifice presented itself a major point of contention throughout Rossi's career. This fixation conceivably emerged during his university thesis explorations, which resulted in the proposed design for a theatre in Milan (Alberto Ferlenga, 1990). His desire to recall historic elements, and re-envision their use in the contemporary urban context was demonstrated in the materialization of teatro del mondo.

The small temporary structure is no doubt the culmination of a series of historical references. The interior layout classical in its geometric simplicity, the hard opaque wood facade recalls the surrounding bluntness of the marble venetian urban fabric, and the notion of a theatre on a boat references the historical carnival showboats of the $18^{\text {th }}$ Century. As in many Rossi projects, teatro del mondo neither lacks in metaphorical nuances. When asked about the project a year after its conception John Hedjuk suggested "It expresses the drift of architecture; it goes from place to place. It can only be moored for a period of time at each place. Nothing is fixed. It is all temporal (Oechslin \& Buschow, 1995, p. 10)." Hedjuk's perception of 

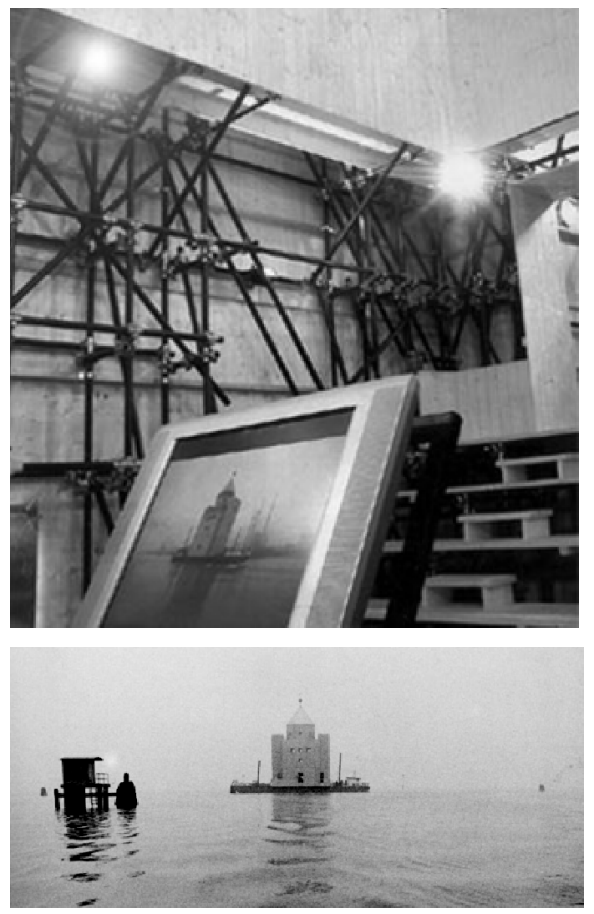

the project demonstrates why this project is considered such a key precedent. In its temporary assembly method, its relocatable base, its largely unprogrammed performance space, and immeasurable references to existing architectural symbols; it presents a comparable likeness to many of the thesis project intentions in its approach to exploiting temporality.

The accompanying drawing visuals and recognizable Rossi design playfulness offer but another layer of admiration from an outsider's perspective. Of the four precedents presented, teatro del mondo is the project which reflects best the spirit (graphically and conceptually) that this thesis would like to strive to impart.
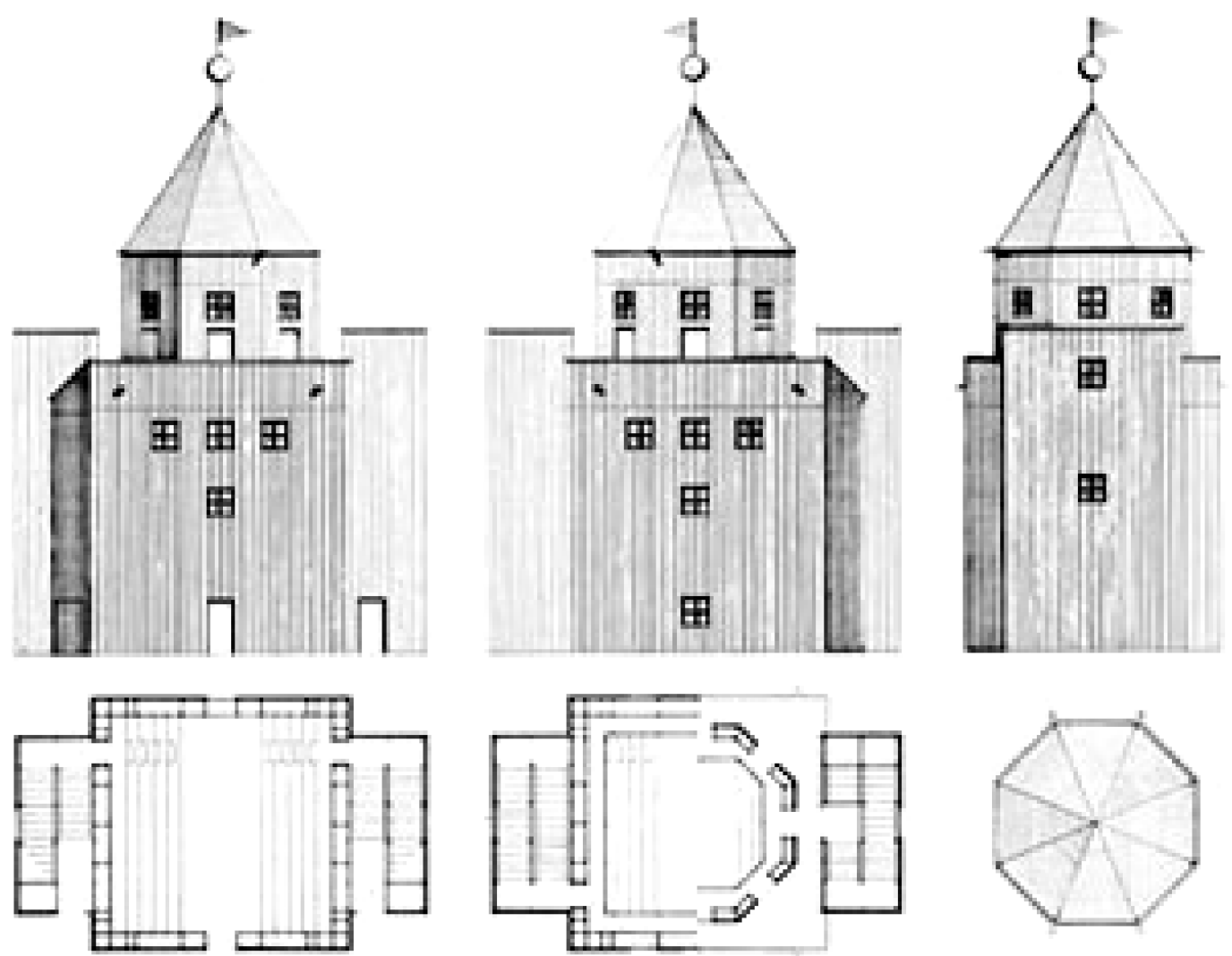

Figure 4.1.3 - Photograph taken of the interior space of teatro del mondo.

Figure 4.1.4 - Plan and elevation of teatro del mondo. 


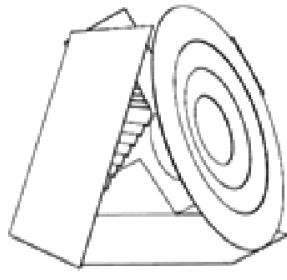

FASHION EXIEITION

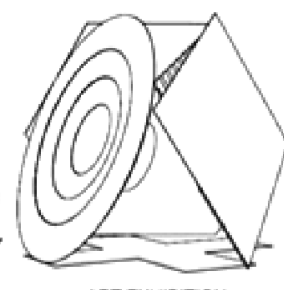

ART EXMIBITION

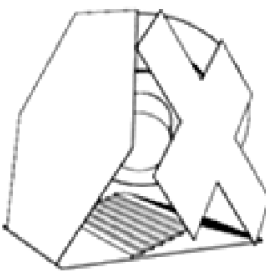

cINEM
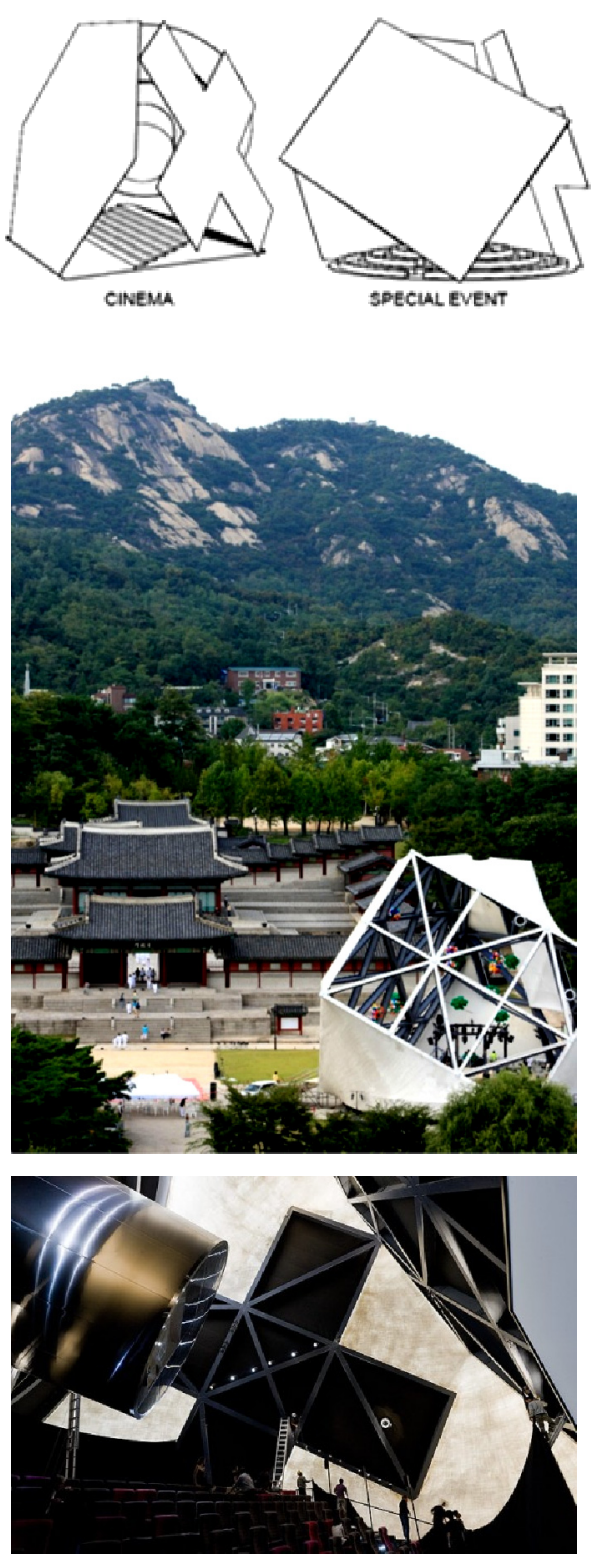

Figure 4.2.1 - Diagram perspectives of the four program orientations.

Figure 4.2.2 - View of the Transformer placed next to Seoul's $16^{\text {th }}$ Century Gyeonghui Palace.

Figure 4.2.3 - View of the Transformer in "Cinema" mode.

\subsection{THE PRADA TRANSFORMER OMA | Rem Koolhaus}

Year: 2010

Program: Prada Fashion Runway, Movie Theatre, Art Exhibition Space, Fashion Exhibit Space.

Specs | Materials: Primarily cloth \& steel piping.

Context | Site: Seoul, South Korea.

Conceived as a pavilion gathering space, the uniqueness of this building is its ability to change functions. Essentially, the Transformer is a tetrahedron which has four different floor plans and four front facades. Based on the activity for which it is needed, th e Transformer can be flipped and rotated on the required side using four cranes. Depending on which side it is placed, the wall can become the floor, the ceiling the wall, the floor the ceiling. This adaptability represents a rather large structural endeavour, if one considers that each surface must be structurally sound enough to uphold the entire building load.

The Prada Transformer reflects impressive ambition and a new approach to building. A rather grave draw-back however is that despite its ingen uity and rather visionary nature the project was only used for a six month period, further propelling the notion that buildings which are built without a set site in mind typically have an incredibly short lifespan. While the project is fascinating due to its flexibility of program and adaptable structure, it ultimately propagated a notion of transportable architecture, which this thesis categorically attempts to contest the short-sided nature of movable buildings. What has become of the materials used to construct the pavilion, do they remain in storage until their ne xt use, have they been recycled and 

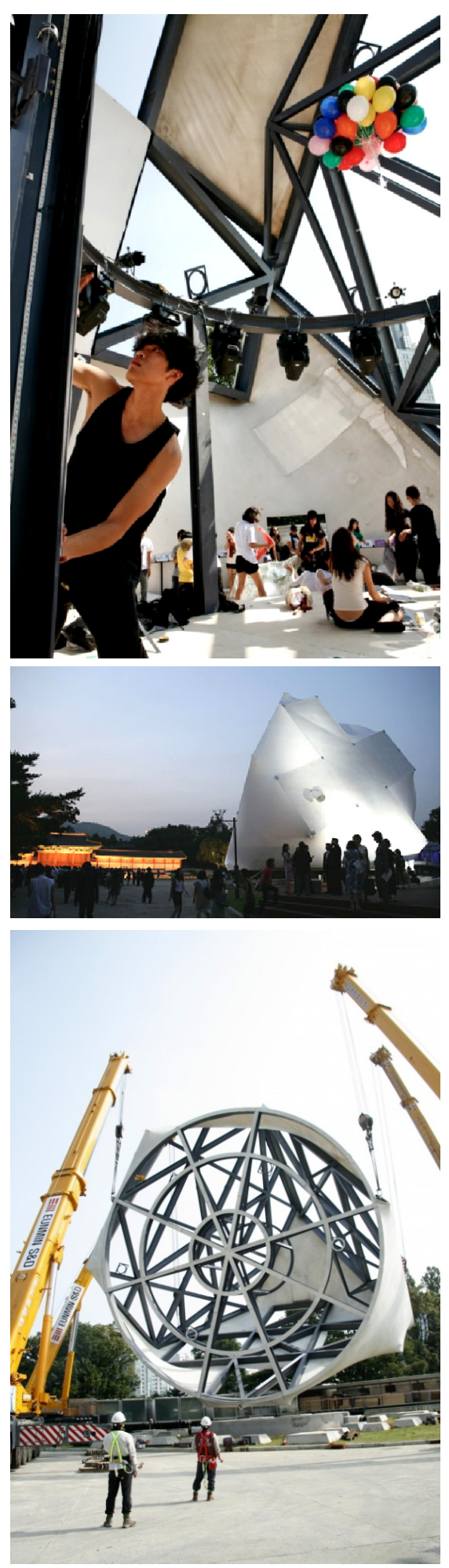

Figure 4.2.4 - Students taking over the exhibit space.

Figure 4.2.5 - Night view.

Figure 4.2.6 - The Transformer mid-air, undergoing a program change. repurposed, or simply have they been disposed of? An ongoing issue remains that these structures are often conceived as major momentary statement pieces without any consideration for their future use, or lifecycle period.
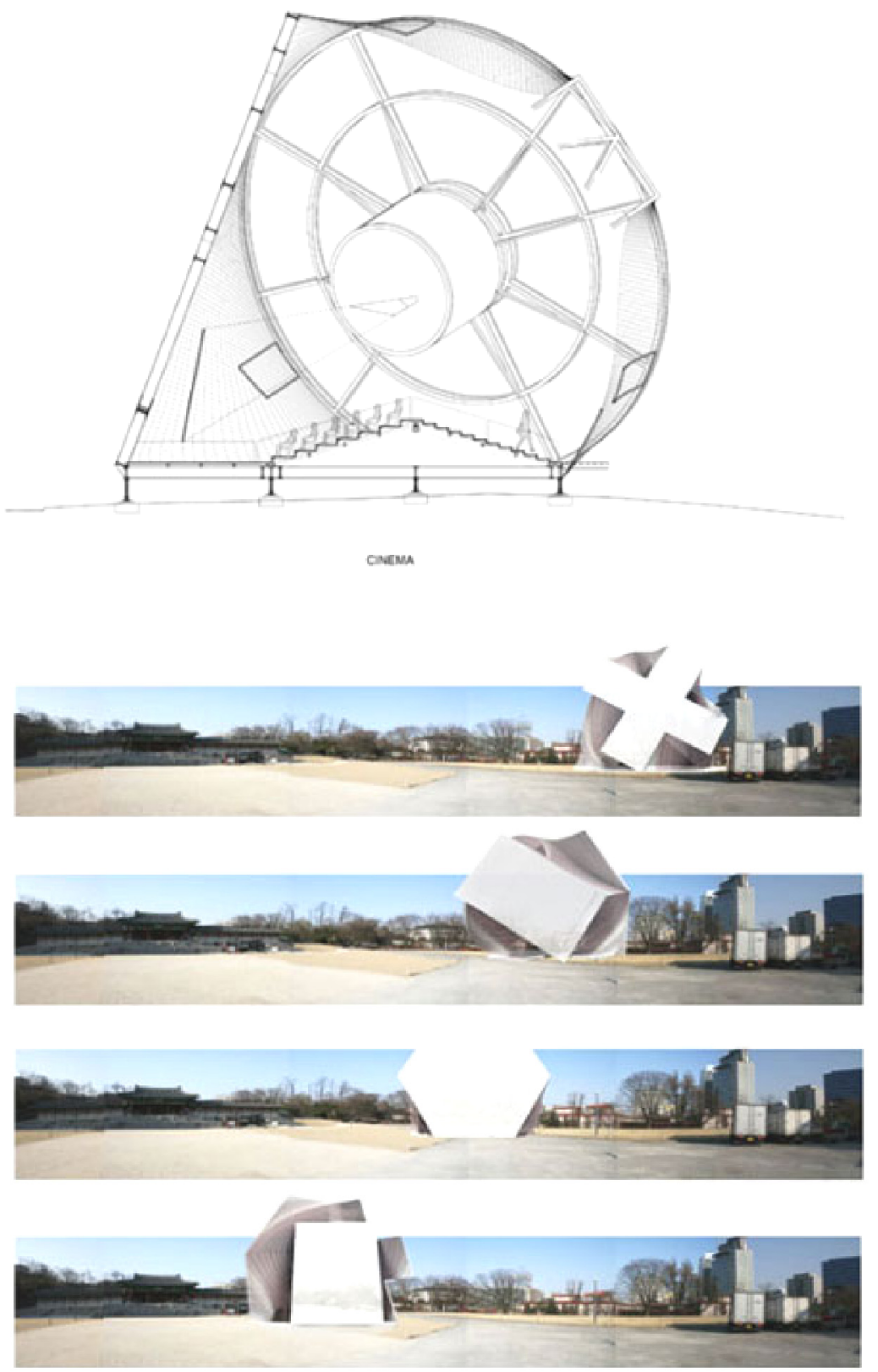

Figure 4.2.7 - Section-cut through the Transformer in its Cinema position. Figure 4.2.8 - A 3D rendering demonstrating the various orientations and transformations that the Transformer can undergo. 

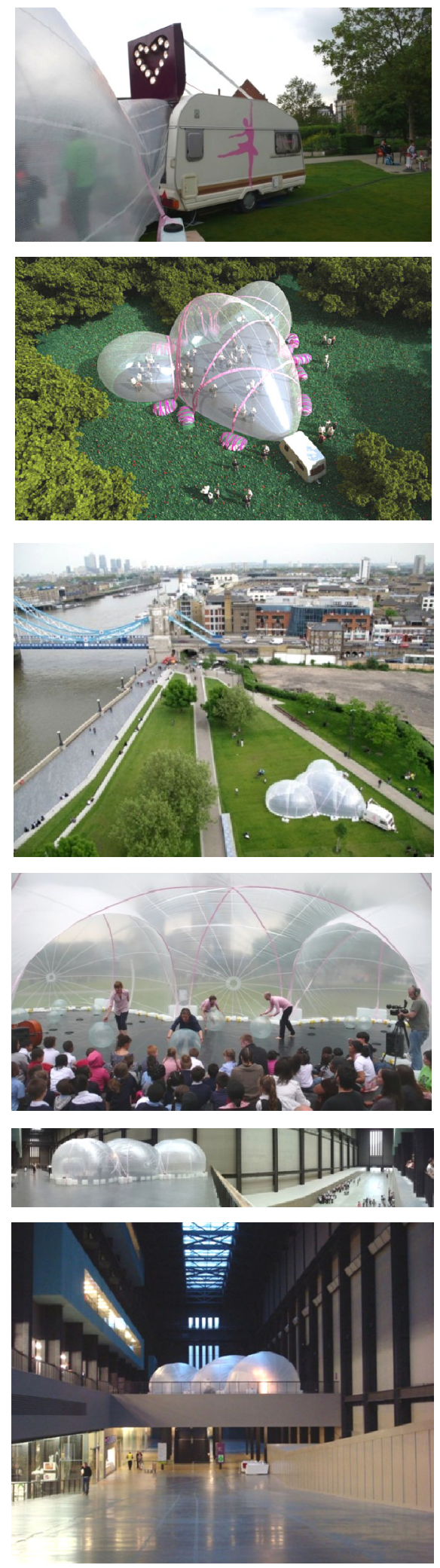

Figures 4.3.1 - 4.3.3 - Rosy at the park. Figures 4.3.4- 4.35 - Rosy at the Tate Modern.

\subsection{ROSY THE BALLERINA \\ RAUMLABOR Berlin}

Year: 2010

Program: One large unactivated gathering space, two smaller supporting spaces.

Specs | Materials: a 1980s RV + inflatable pellicle

Context | Site: Anywhere, anytime. Publicly occupied a variety of London Parks, as well the Tate Modern.

Rosy was commissioned by Portapavillion in 2010. Her design inspired by a letter found in Paul H. Millard's dressing room, the principle dancer of Ladbrooke Grove Dance Company. Letter was written about a young talented star ballerina named Rosy, who's bubble was burst following an audition with a major dance producer and slowly deflated over time. The built project was essentially the materialization of the interpreted feelings experienced by Rosy as well as Paul (the narrator) as described in the letter. "There's the bell - I have to go on stage now. I've starred in more than 50 shows by now George and still when I'm on the stage I feel like I don't belong there... (Raumlabor, 2011)"

Raumlabor is a relatively new Berlin-based architectural team whose work often intentionally blurs the line between art and building. Their most well-known projects seem to act more as temporary catalyst interventions. Rosy the Ballarina (german) represents a rather simple construction approach to the transportable structure, by using the found condition of 1980s RV as the basis for its new space. From it, a massive engulfed bubble extends to create a performance and activity space for the users of whichever surrounding neighbourhood it chooses to locate itself. Rosy 


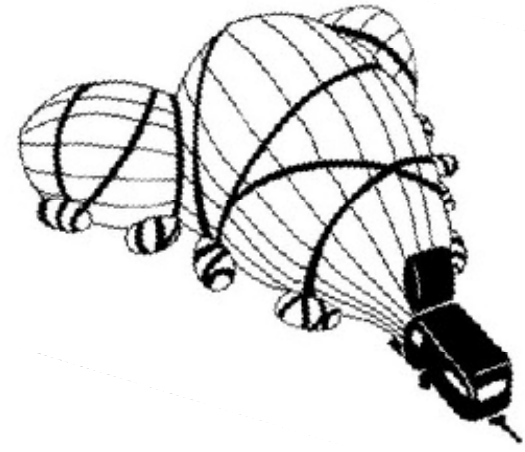

Figure 4.36 - Perspective drawing of Rosy inflated acts as an ideal case study because it seeks out its audience just as this thesis' project hopes to do. It creates a simple uncomplicated space, which can be reactivated to suit a plethora of functions, and be easily flattened and moved to another location. It leaves no mess behind, does not require the intrusive use of massive cranes as does the previous case study by Rem Koolhaus.
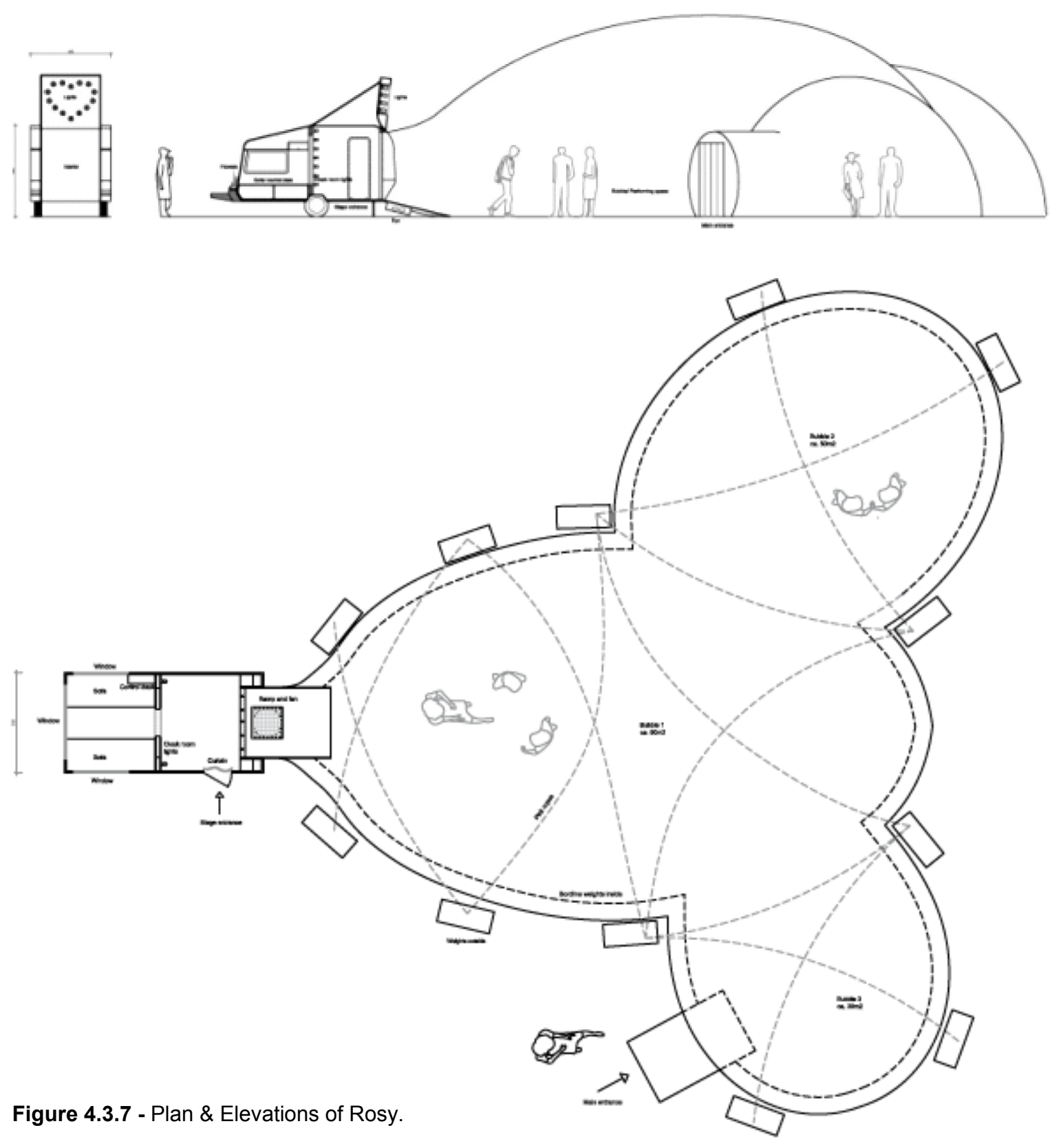


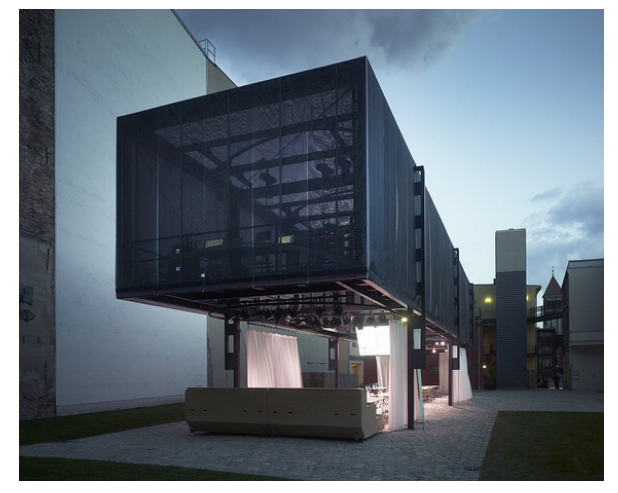

\subsection{BMW GUGGHENHEIM LAB (CYCLE 1) Atelier Bow Wow}

Year: August 32011 to October 162011

Program: Mobile Laboratory, part community centre, part gathering space.

Specs | Materials: Carbon fibre frame, transparent polyester mesh fabric. $30 \mathrm{~m}$ length $\times 8 \mathrm{~m}$ height $\times 6 \mathrm{~m}$ width

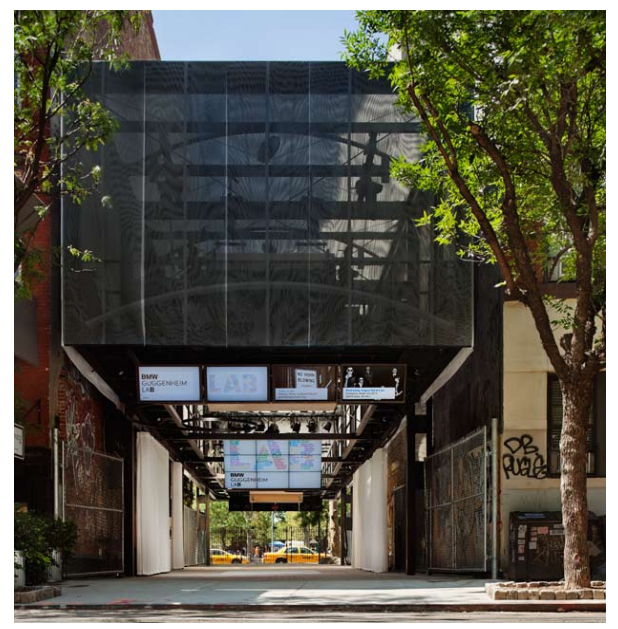

Context | Site: Initially sited on an unoccupied site in Manhattan, and relocate d to Berlin, and Mumbai.

This project was the first of three project cycles for the Gugghenheim. The intent was for the three built transportable iterations to travel to nine international locations over six years. Each cycle has the thematic goal to provide a novel experimental approach to contemporary urban spaces. The theme specified for the first cycle was "Confronting Comfort: exploring notions of individual and

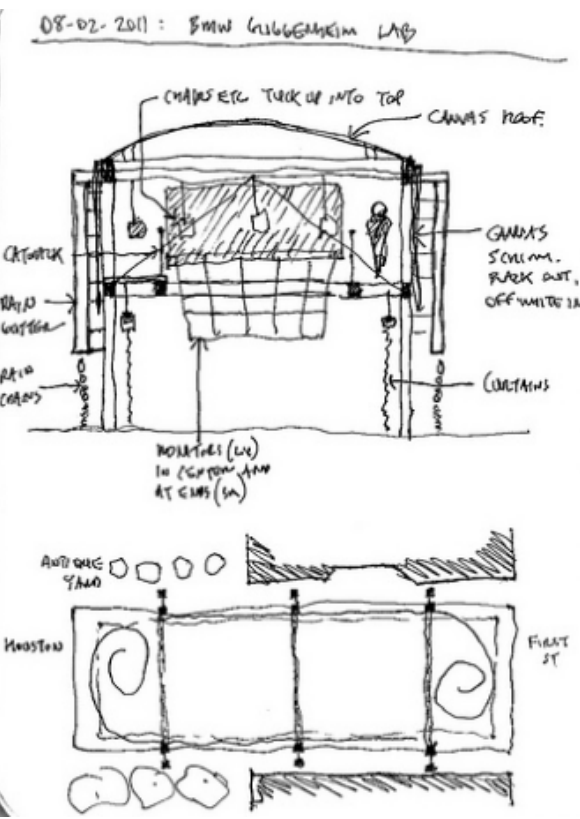

Figures 4.4.1 - Cycle 1 in Berlin location. Figures 4.4.2 - Cycle 1 in New York City location.

collective comfort and the urgent need for environmental and social responsibility (The Solomon R. Guggenheim Foundation, 2012)"

The design is composed of a framed central space with an adjustable canopy height in addition to a series of smaller plywood structures acting as support spaces (i.e. washrooms, cafe, bench seating). The conceptual title for the project was "travelling toolbox". A mesh-enclosed frame is raised well above ground level and acts as a fly loft (as those found in stage backs) where screens, lighting and electrical features are all rigged on a pulley systems and pulled down when needed. The outcome is the provision of a fully open and unactivated ground floor which is intended Figures 4.4.3 - Sketch of fly loft and plan. to recall the Italian loggia. 

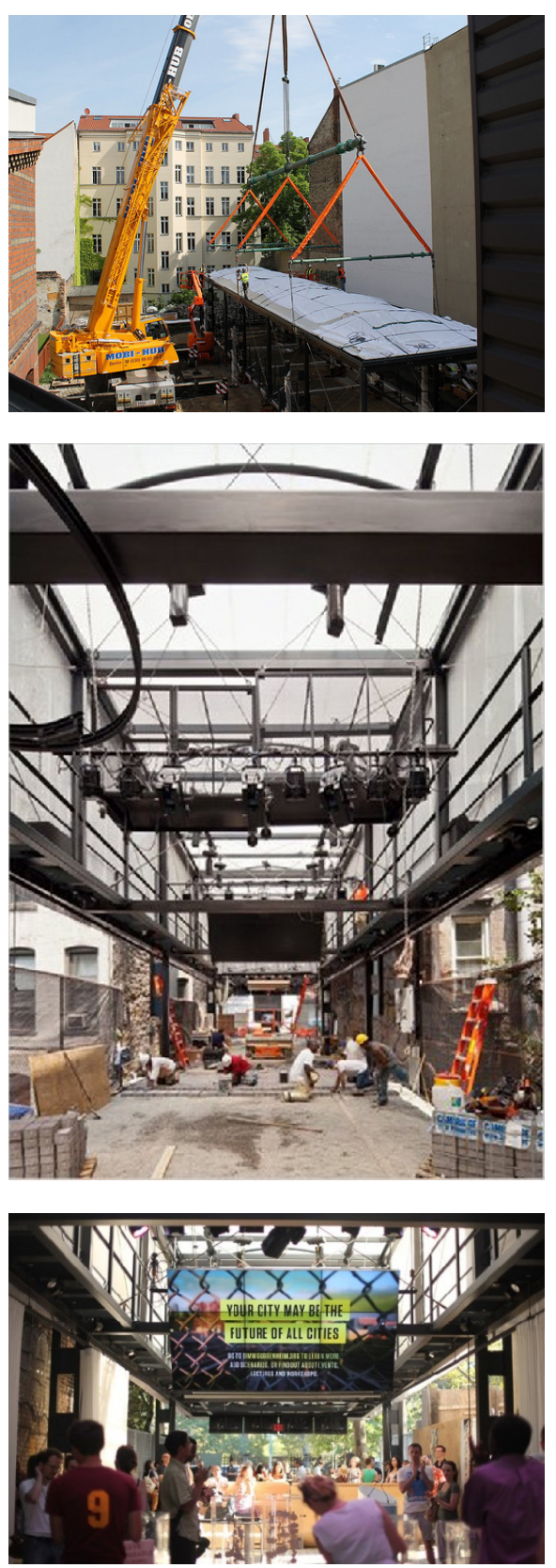

Figures 4.4.4 - Cycle 1 assembly in Berlin Figures 4.4.5 - Cycle 1 assembly in New York City

Figures 4.4.6 - View of activated space in New York City.

Figures 4.4.7 - Sketch diagramming Cycle 1 's organization and timeline.
The project's program shares a performance likeness to that of the thesis and an ability to be interrupted by the various "tools" concealed in the upper fly loft. The primary criticism of the project is directed at its self-titled mobility, which from the perspective of the author is nullified when structural requirements for the design require concrete footings to remain balanced and new interlock ground cover at every stop. The simplicity of the project concept is perhaps one of its strongest points, but this is muddled with the introduction of scattered and fragmented plywood support spaces and furniture fittings which are introduced to occupy and induce program. The final point of contention, is primarily personal, but reflects some of the criticism brought forth for the previous precedent, the Prada Transformer. The requirement of heavy machinery such a cranes and lifts in the installation process at every location seems to negate many of the nomadic claims made by the client and architect. The result seems to resemble more a lightweight prebricated permanent structure whose only temporary value is the period of time in which it remains in one locale. Despite criticism of the architectural manifestation, the reigning trait of the project is the establishment of the BMW Gugghenheim Lab, which acts as a think tank form minds across a range of fields and has for a purpose to encourage experimentation and nontraditional ideas to the world of design.

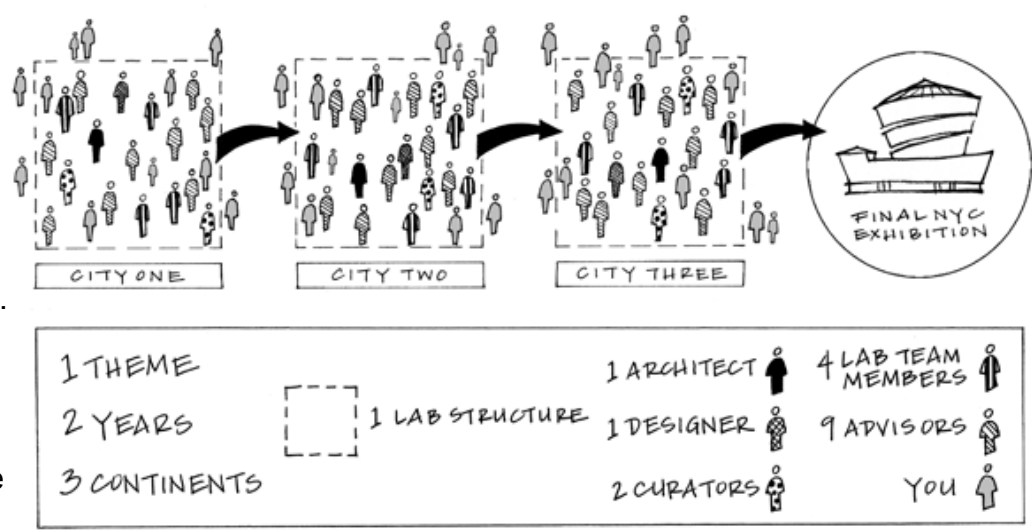



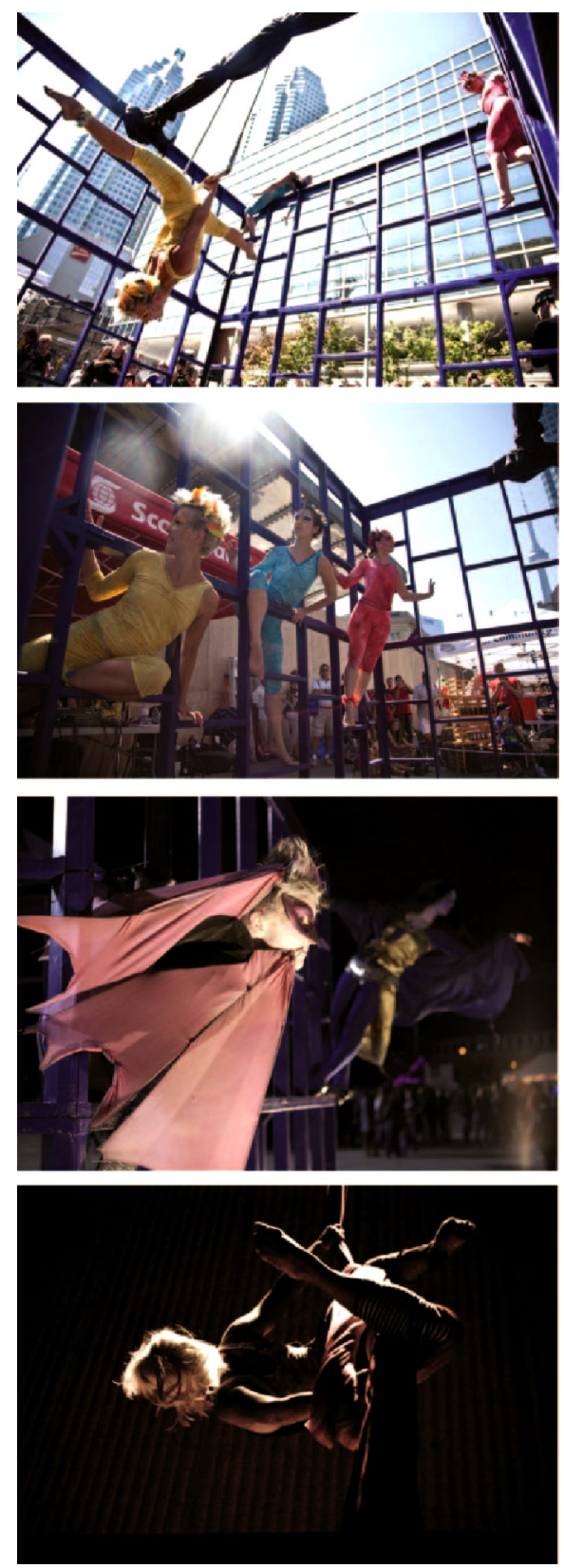

Figure 5.1.1 to 5.1.4 Images of various HerciniArts Collective performances

\section{Design Parameters}

\subsection{The Troupe}

Since this thesis design exercise is in the conception of a transient/temporary performance space. It therefore seemed suiting to select a travelling performance group. In order to help frame the design project, the local Toronto acrobatic and performance art group HerciniArts Collective was loosely selected as the client. As the research evolved it became evident that there would be no one set site location to speak of. The selection of the acrobatic group helped structure some of the impending design decisions.

This group in particular puts on range of performances. They present themselves in some respects as a modernday adaptation of the $18^{\text {th }}$ Century Hanlon Brothers. Their work comprises of climbing, dancing, acting, trapezes, and rope choreographies, amongst others. They capture a great deal of the spirit of evoked in the Cirque du Soleil shows with their bright costuming and face paints, their abnormal flexibility and strength, and their fantastically inspired shows; but at a smaller scale. Ultimately, just like the group itself, the designed built environment would have to be anything but conventional. 


\subsection{Site Conditions}

Performances for a group of this nature take form in a variety of locales. As a relocatable structure, it is important to acknowledge that the design project will therefore not be associated to one site in particular, however to identify it as "siteless" would also be flawed.

The new performance space would have to be suitable for use in outdoor street and park performances (where they perform most commonly), as well as private indoor performances, such as in schools or entertainment at major events. The map below demonstrates some of the potential performance locales.

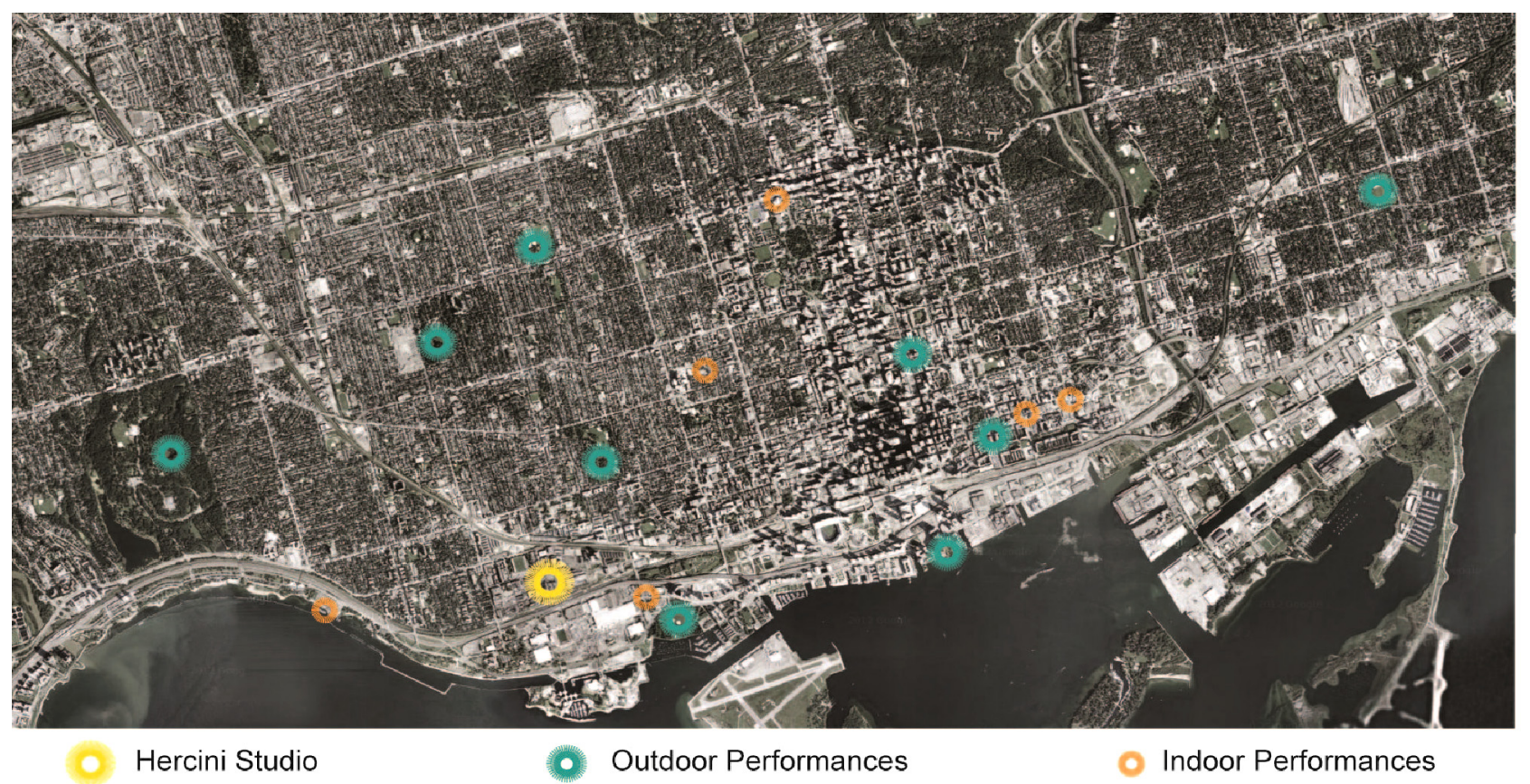

Figure 5.2.1 - Map of central Toronto, demarcating various locations of past and potential HerciniArts productions. 


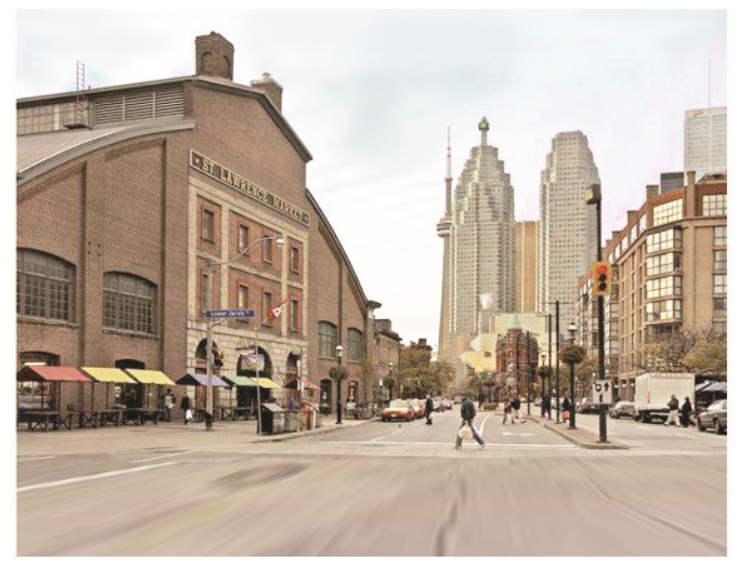

\section{Street | Busker Shows}

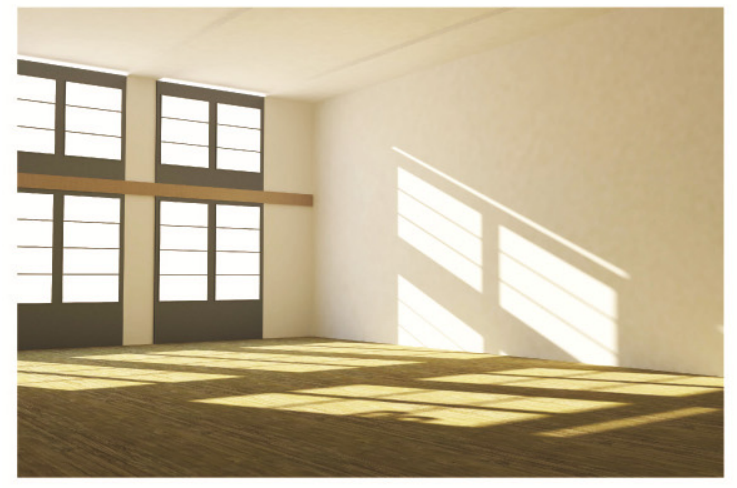

\section{In-Studio Training}

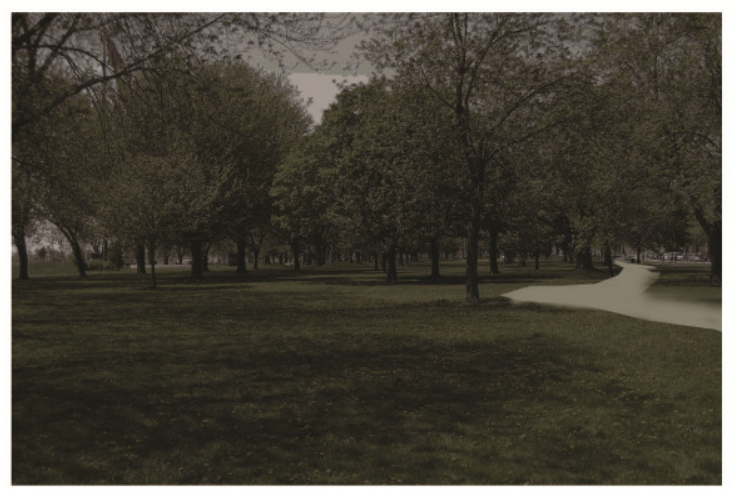

Theatre-in-the-Park

Figure 5.2.2 - St. Lawrence Market, Toronto.

Figure 5.2.3 - Rendering of unoccupied indoor Studio Space, Toronto.

Figure 5.2.4 - Trinity Bellwoods Park, Toronto. 


\subsection{Current Structure}

The troupe currently uses a collapsible wood frame structure, which is essentially square in dimension and completely open-air. Their performances occur within the square, while passersby's and spectators watch from outside.

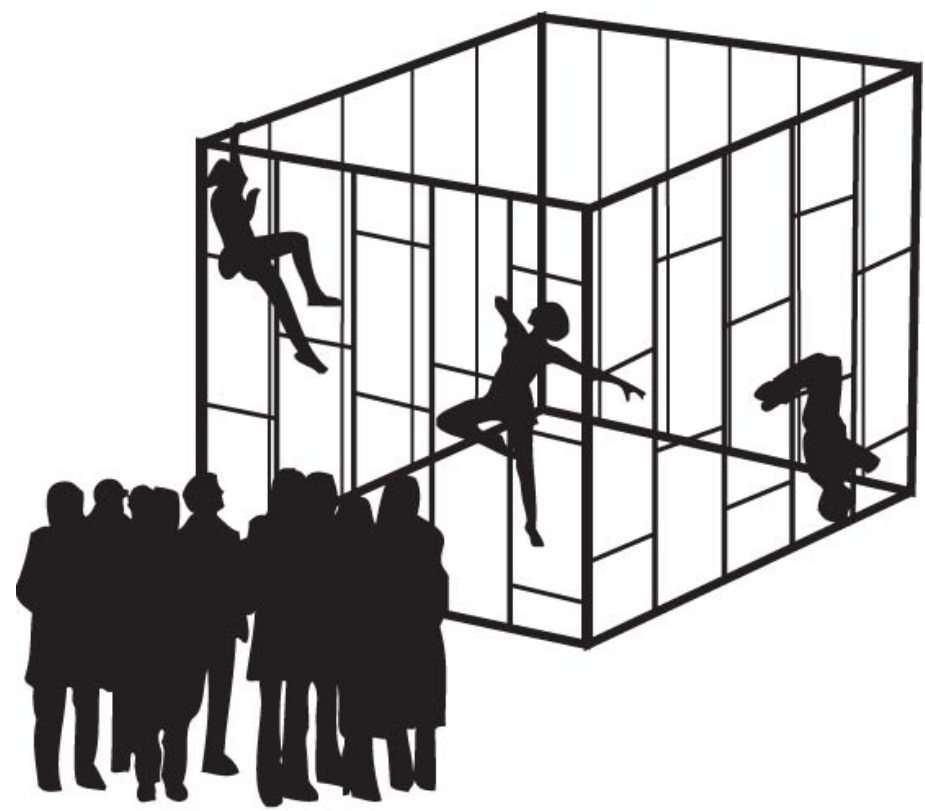

Existing

The Design Parameters for a new structure would reflect many of the original values upheld in the existing structure. Some of these characteristics include:

- its relocatable abilities

- that it be sturdy enough for performers to hang from and climb

- would allow for swings, ropes or trapezes to be held from it

- that it remain open-air

Figure 5.3.1 - Diagram by author of the existing performance structure used by the acrobatic troupe.

- continue to provide horizontal climbing ladders

- be designed for indoor and outdoor uses 


\section{The Design Proposal}

In an effort to negotiate a final outcome, various formal schematic approaches were taken (see figures below). Ultimately, the new proposal does not have an established fixed stage proponent, since it diverged from the conceptual basis of the project. It does nonetheless possess the ability to transform into a stage surface when required. Formally the object also still functions in many of the same ways as did the troupes existing space. The primary modification of the design being its multiple frame composition, which can be joined or separated, collapsed or extended allowing the user to create infinite performance settings.

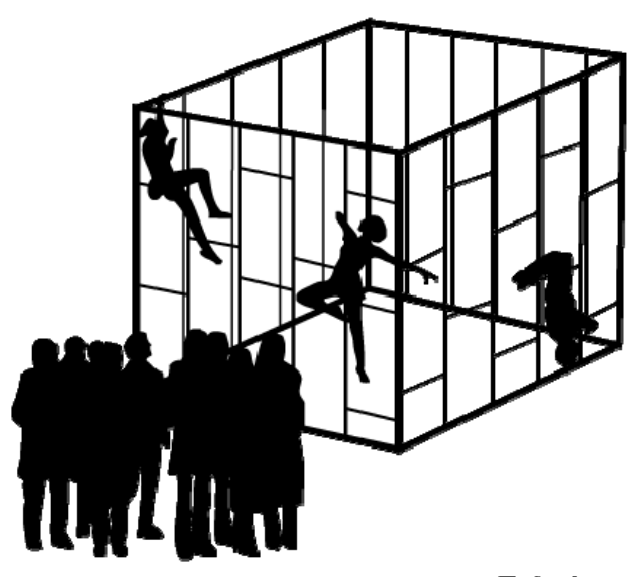

Existing
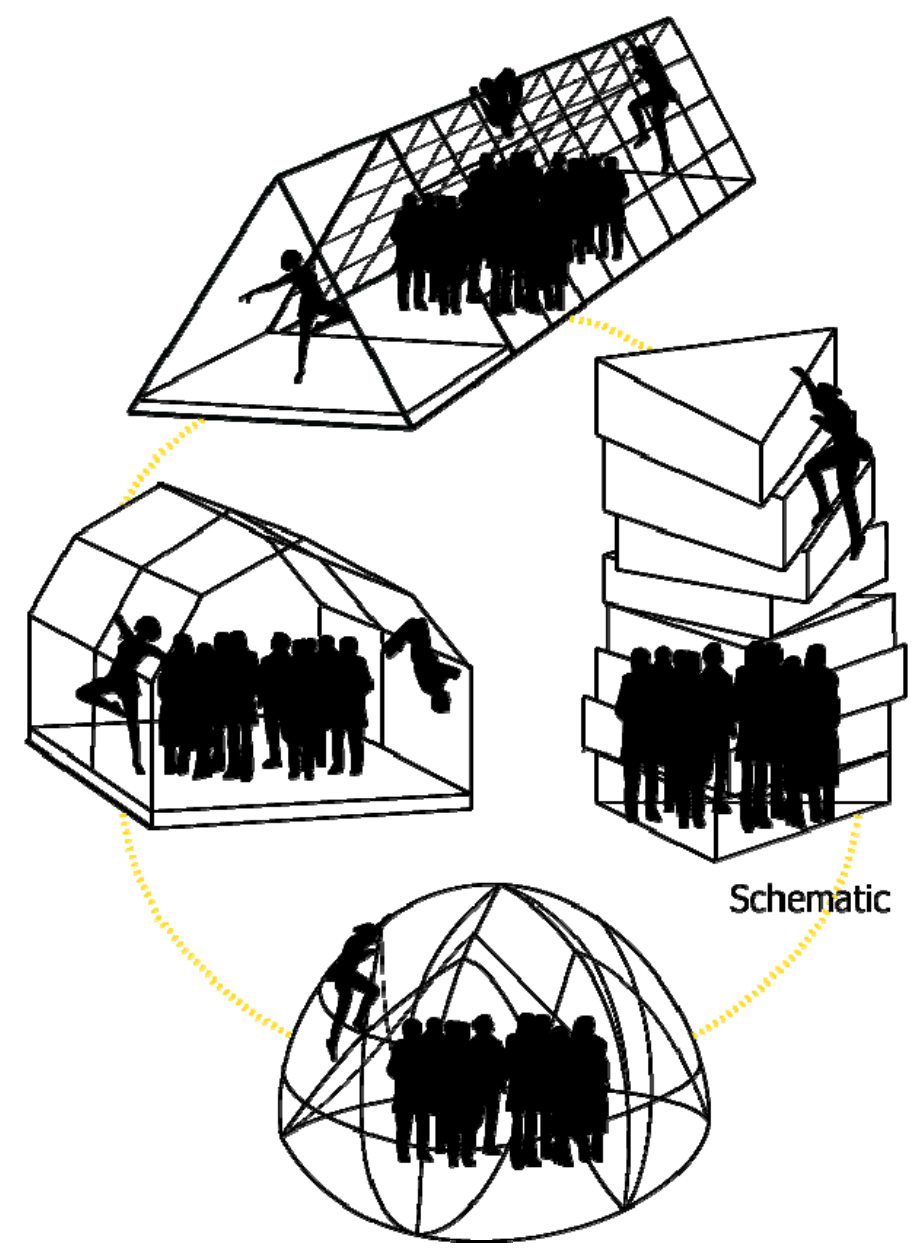

Schematic

Figure 6.1 - Diagram by authorof the existing performance structure versus some of the early iterations. 

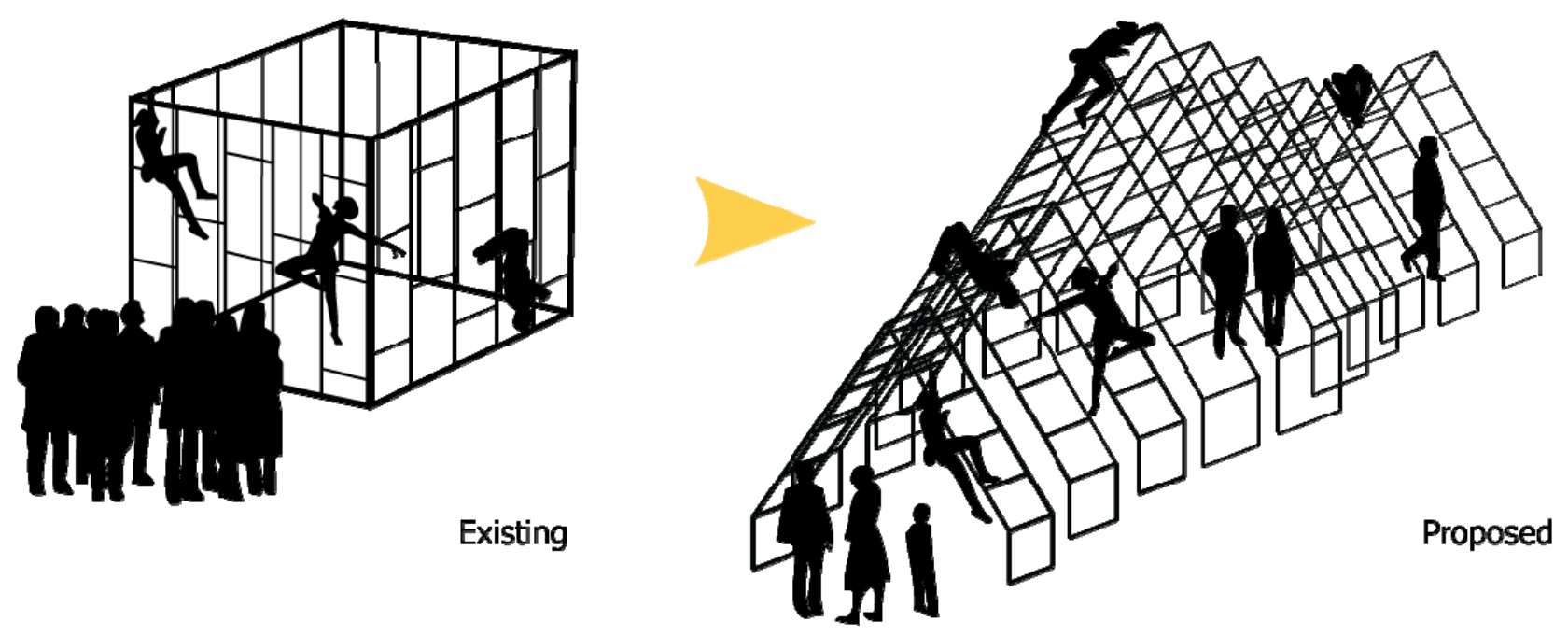

Figure 6.2 - Diagram by author, of the existing performance structure versus the current proposed model.

At an early stage, it was established that best way to maximize flexibility was to break the design into a series of individual modules. The triangle as a shape provides the greatest structural stability. Each module would need to support the weight of the acrobats climbing and hanging from it from all sides. Since the frames act as free standing modules, each piece would not always be able to depend on another for added stability (based on the layout they were placed in). Therefore the shape presented itself as the reigning formal approach. 


\subsection{The Frame Modules}

Breaking the design into a series of modules allowed for the plan to constantly be re-configured to create a variety of possible stage sets. The modules ranged in dimension, resulting in a tiered layering approach which allowed for the audience to view the performance with greater ease. It also allowed for the larger modules to overlap their small counterparts in order to provide added staged outcomes.

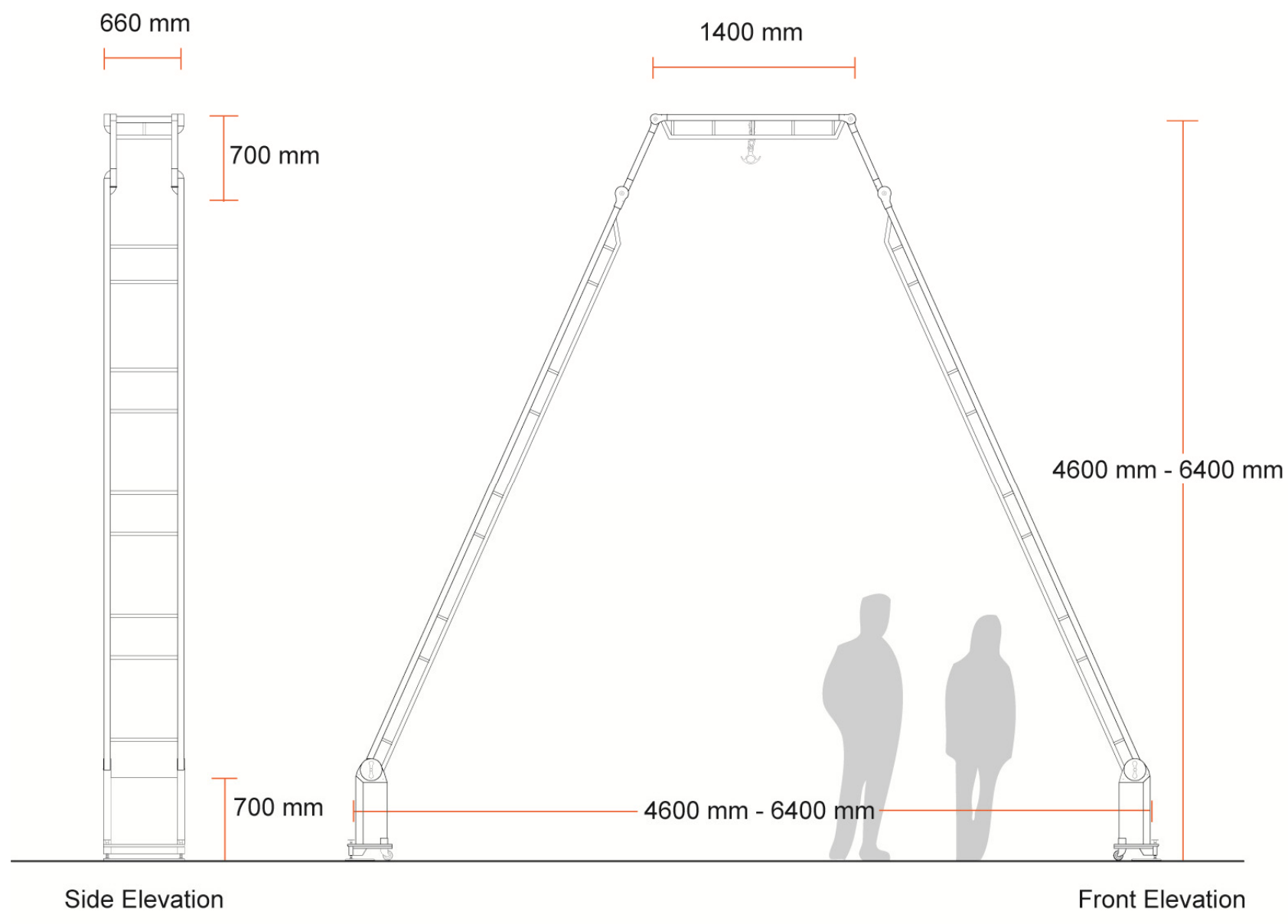

Figure 6.1.1 - Image by author of frame module dimensions. 
The hinges are an essential component of the design and essential consist of a push pin system which locks into the various pre-determined positions. As highlighted, the frames are composed of 6 six hinge points which allow it to adjust itself to meet the varying programmatic needs.

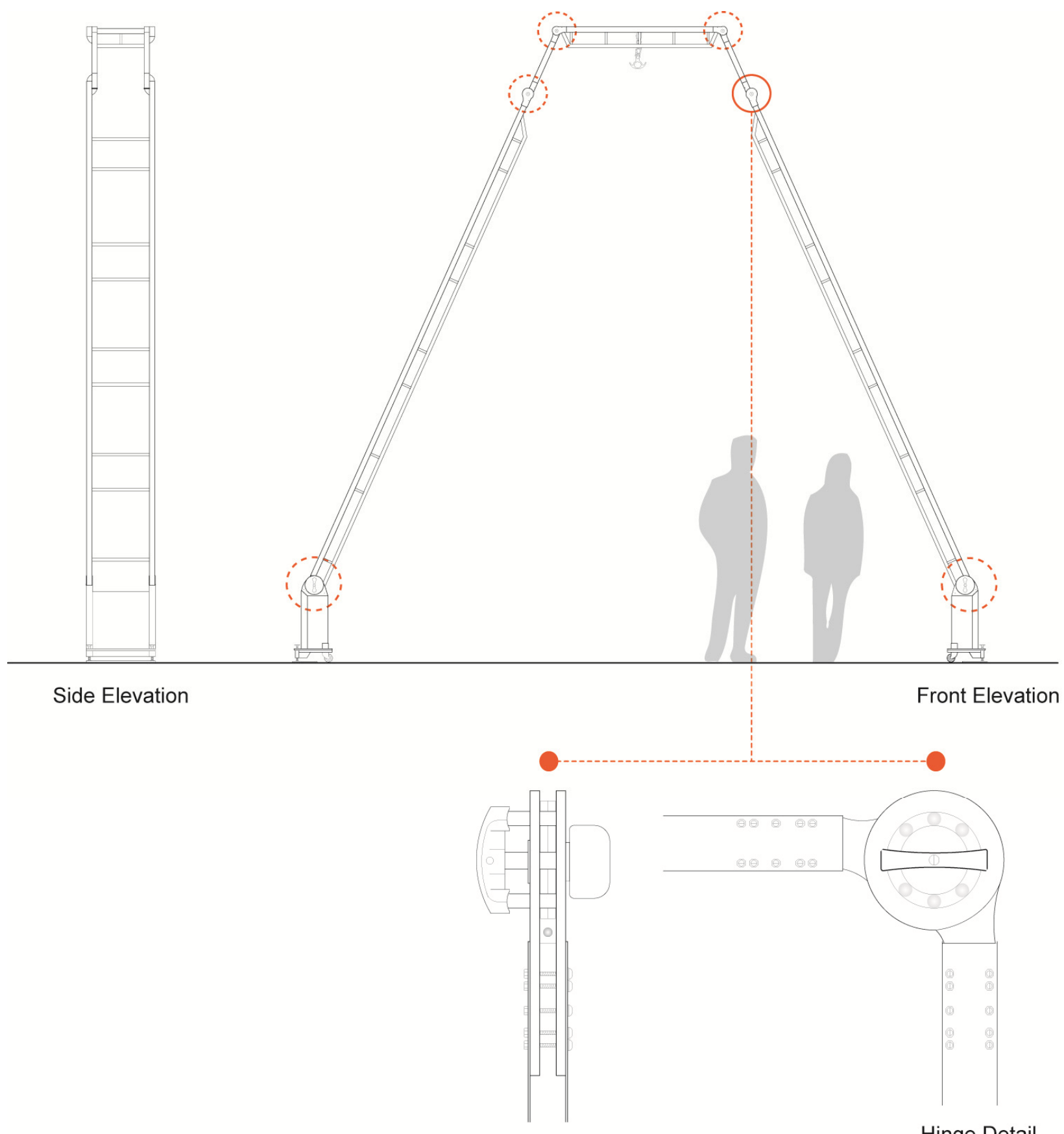

Hinge Detail

Figure 6.1.2 - Image by author of six hinge points and hinge detail. 
The sequence below present freeze-frame views of an animation which depicted the modules transformable abilities. The intention was that the modules possess the ability to collapse and extend for the purpose of transport and adaptability.
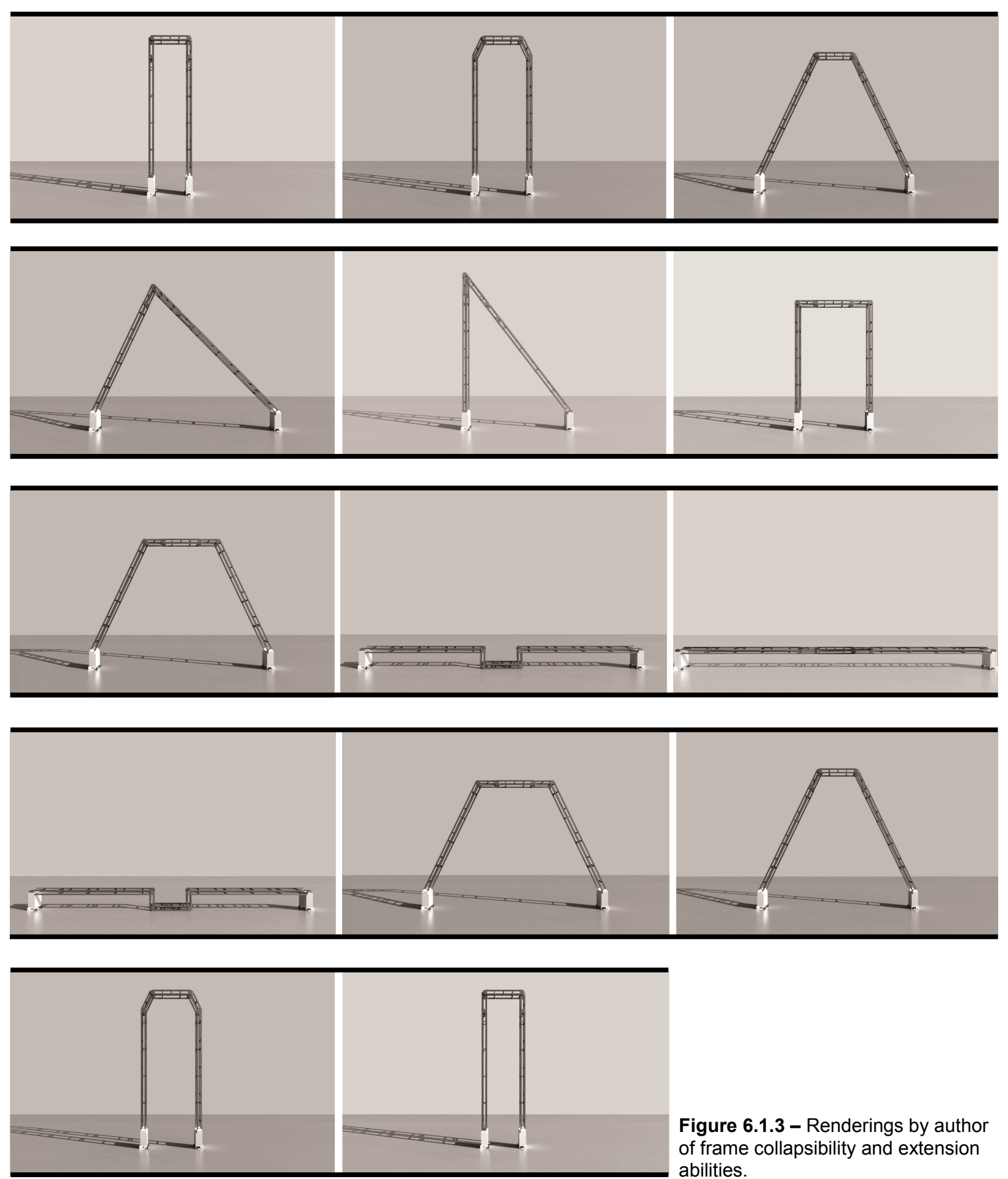

Figure 6.1.3 - Renderings by author of frame collapsibility and extension abilities. 


\subsection{Frame Uses and Attachments}

The frames' fold points and structure were profoundly guided by the performance uses required of the structure. Ultimately, it was establish that the structure be able to meet the guidelines of aerial silk rigging systems and dimensions, provide horizontal climbing bars much like the existing structure, and finally possess the ability to be flattened in order to double as a seating or horizontal stage surface.

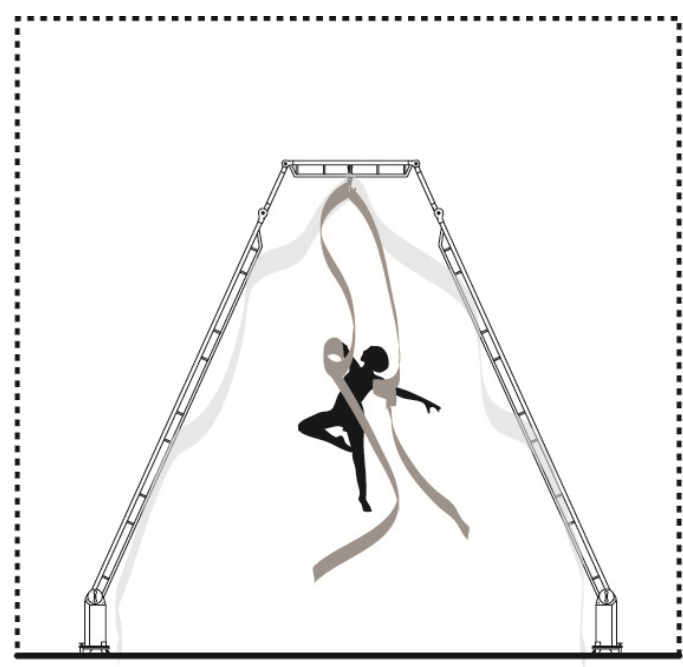

aerial silk rig

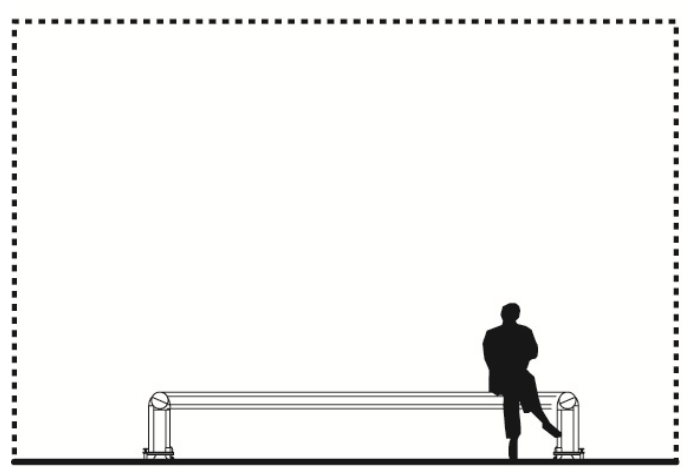

bench surface

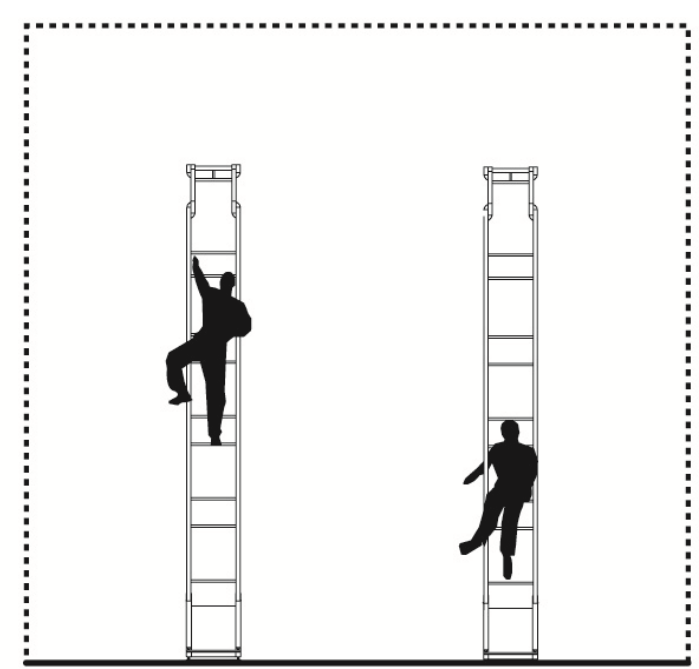

horizontal climbing frame

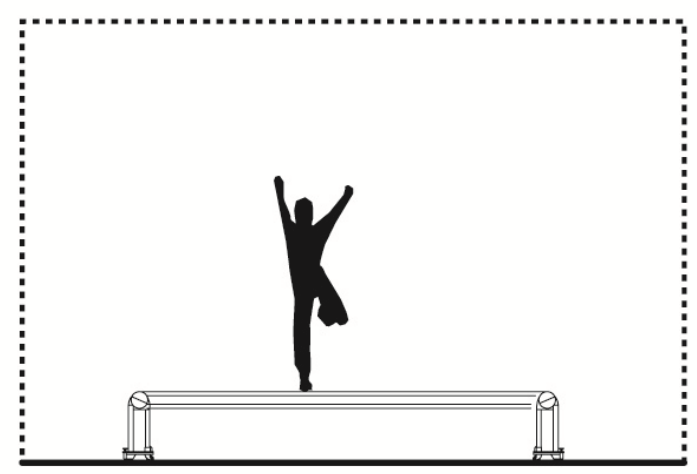

traditional stage surface

Figure 6.2.1 - Diagrams by author depicting the four primary performance uses of the frame modules. 


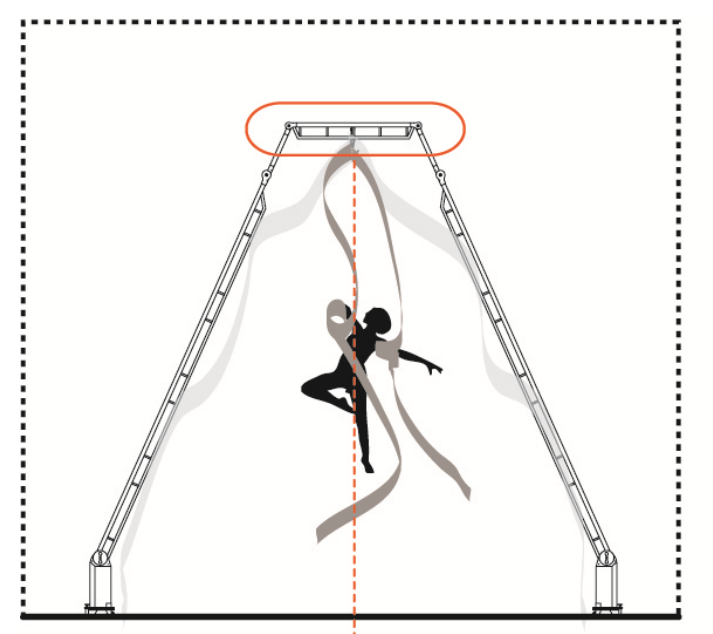

standard aerial silk width for adult use is 72 "- 84 " (1830-2134 mm)

the hanging silks add an additional layer to the space when left unused by the performer and can double as a curtain enclosure/ spatial boundary (see renderings).

the carabiner, figure-eight descender, rescue eight and swivel can all be removed from the hook when the silk is not required

aerial silk rig

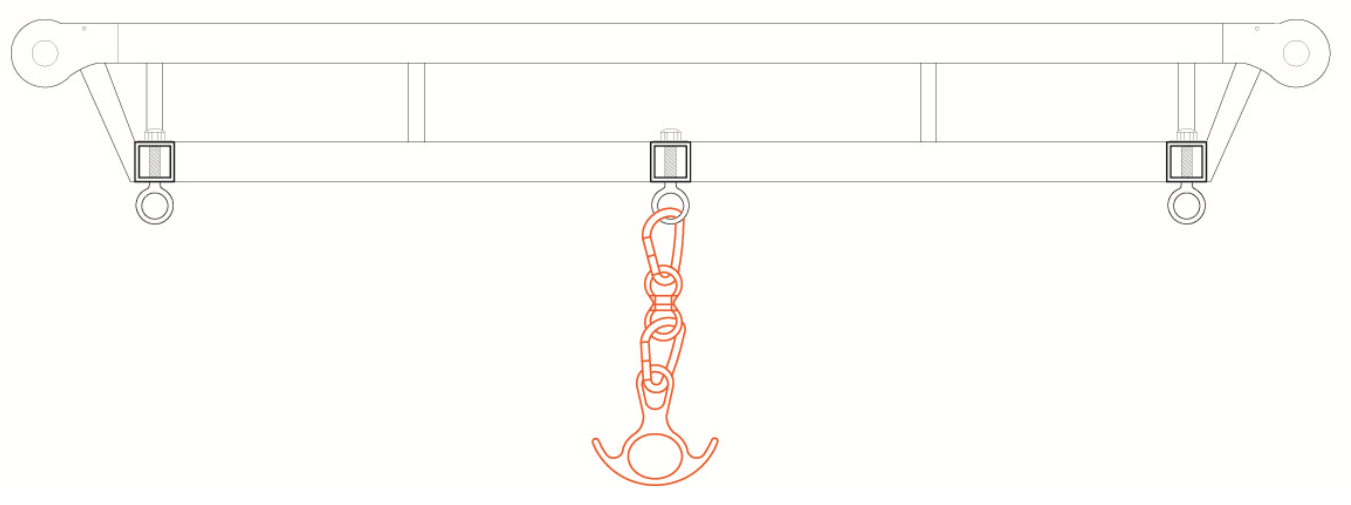

Figure 6.2.2 - Detail by author of the frames' aerial silk rigging system. 

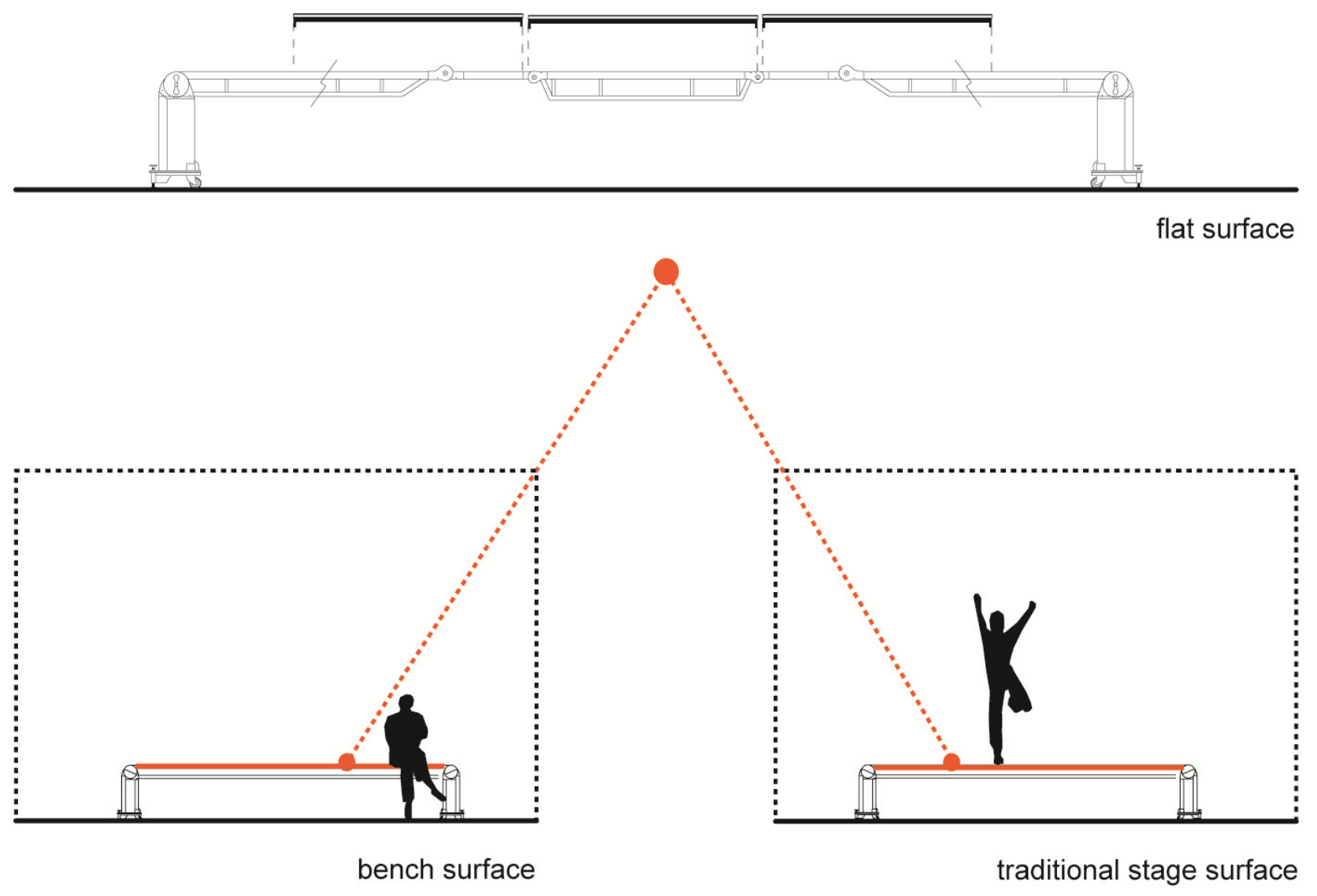

Figure 6.2.3 - Diagram by author of the frames' scaffold-like wood surface which can be attached to frame to provide a stage or flat bench surface. 
Other non-performance related frame features and add-ons include structural attachments, and considerations for transportability.

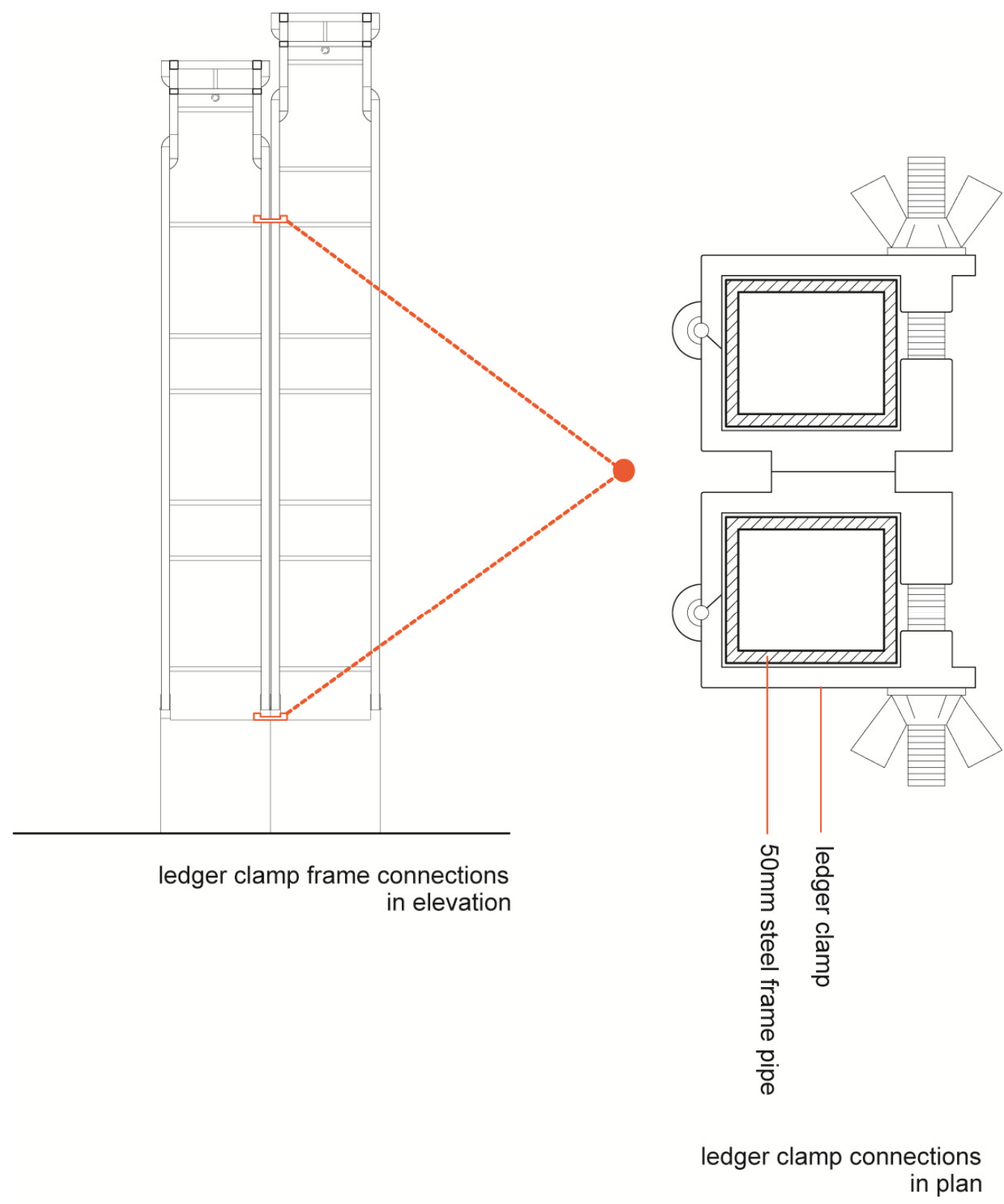

Figure 6.2.4 - Diagram by author of double ledger clamp connections used to link frames together. For added structural stability, use clamps at both base and top of frame 


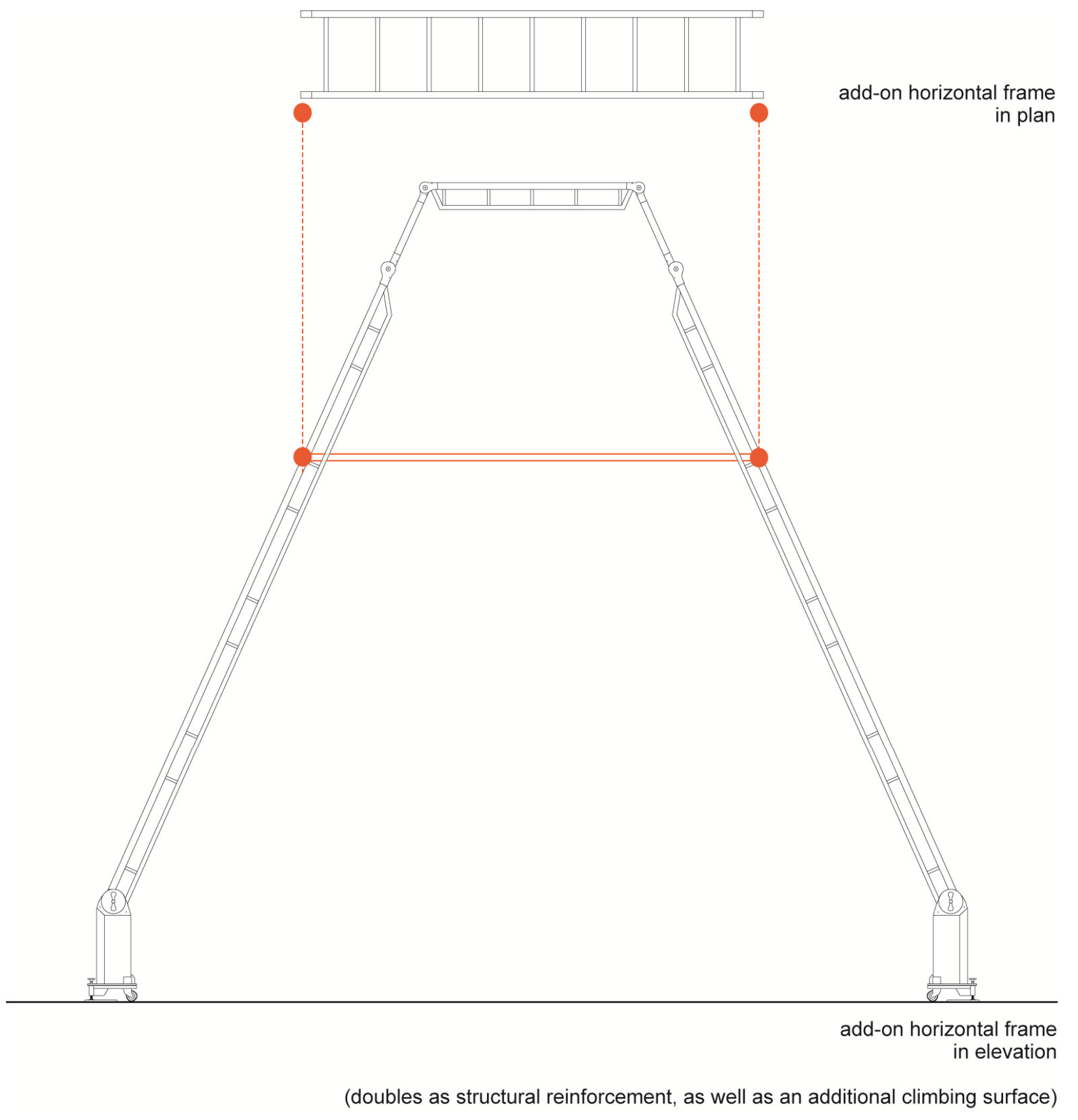

Figure 6.2.5 - Diagram by author of add-on horizontal frame. 


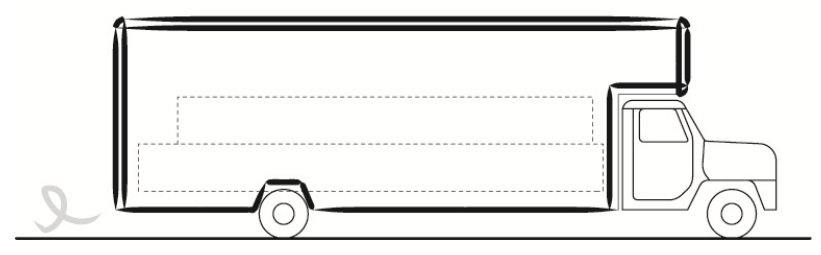

transport of units within one 24' truck

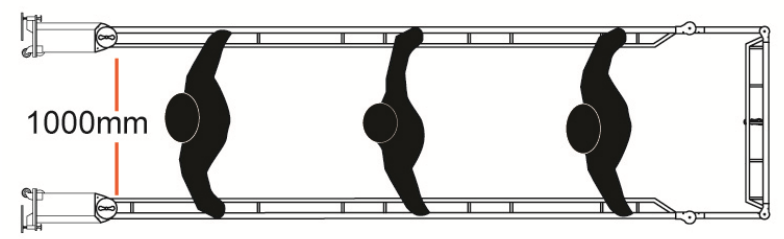

accommodate manual on-site relocation
The collapsible nature of the frames as well as their scale, have been tailored to allow for all 14 units to fit within the constraints of on 24 foot truck.

In addition, the provision of a secondary frame within the main exterior frame allows for the span of $1400 \mathrm{~mm}$ to be reduced to $1000 \mathrm{~mm}$, creating a more comfortablecarrying wing span. As demonstrated in the diagram below, the intention is that the units be conceived to facilate manual on site relocation in an effort to eliminate the need for heavy machinery support.

Figure 6.2.6 - Diagram by author demonstrating relocatable abilities of frame modules. 


\subsection{Configurations Based on Known Typologies}

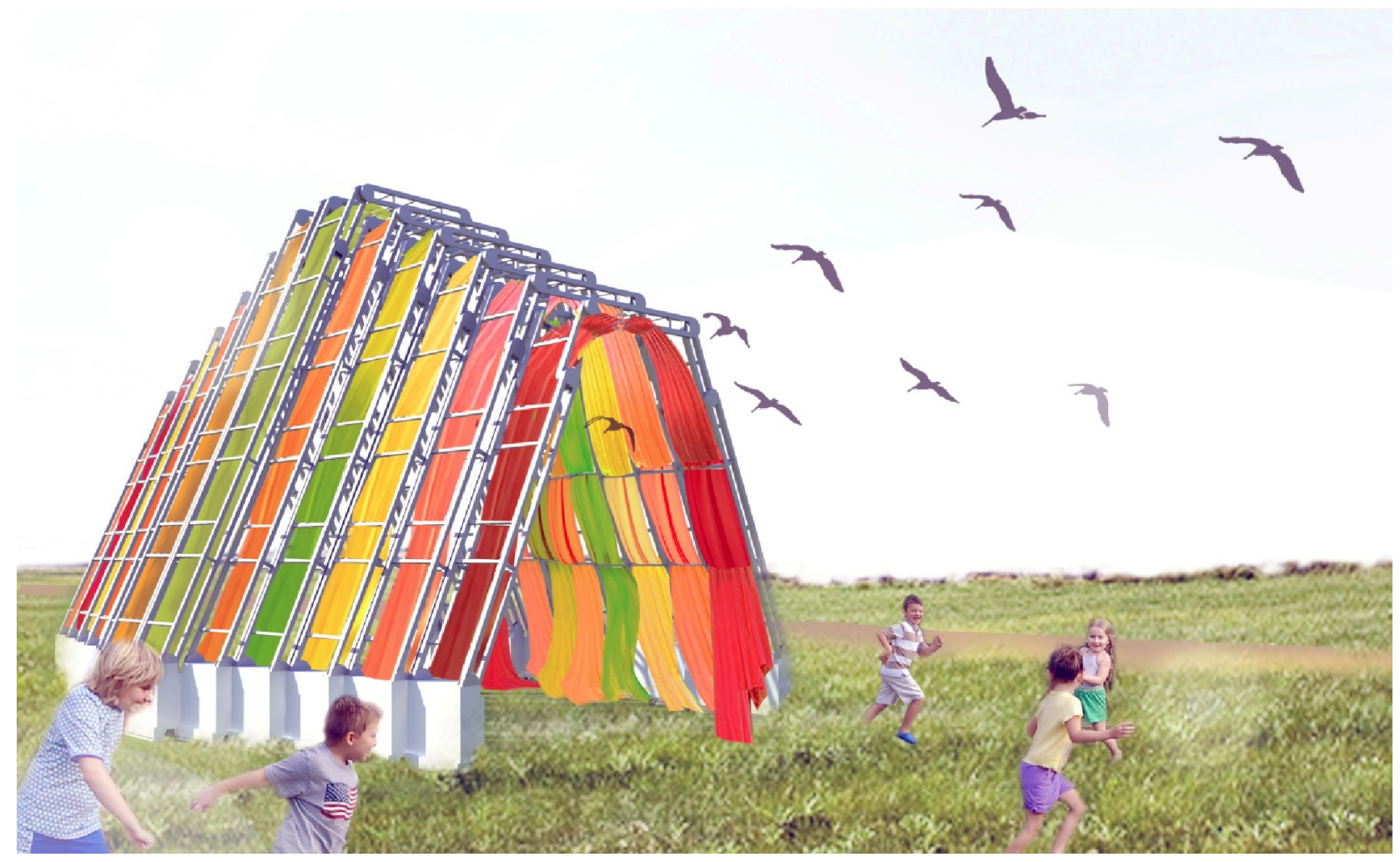

The Traditional Circus Tent

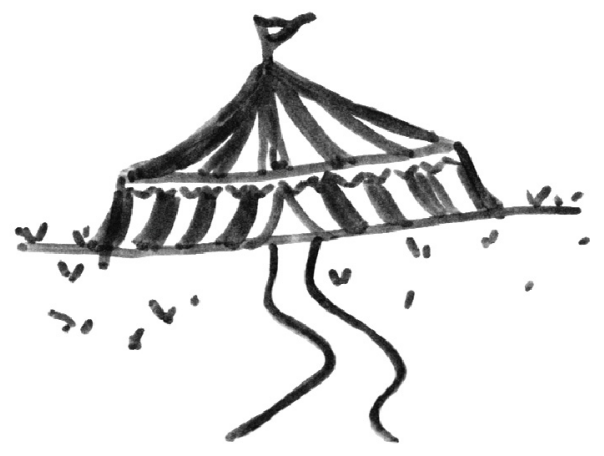

Figure 6.3.1 - Sketch by author of accepted idea of circus tent.

Figure 6.3.2 - Rendering by author of the Accommodating Showman's interpretation. 
In section 3.3, four primary theatre typologies are presented, based on critic and academic Edwin Wilson's text (Wilson, 2005). The following section first describes each of these typologies, outlines their notable characteristics, and finally displays two design iterations for each typology. The first iteration represents as Peter Brooks would have it, a deadly theatre representation by creating a configuration with the greatest likeness to the suggested (essentially a replica). The second iteration for each of these however takes a more whimsical approach by using the Showman to break the quoted $3^{\text {rd }}$ wall and present an inverted interpretation of the typology (where the relationship between the audience to the performer is inverted) rather than a formal copy like the previous.

The intention is to display, that like the black box theatre, the Accommodating Showman can meet many of the existing usable theatre and performance models amongst many others. While the following only demonstrates a few selected iterations, the variations can be countless.

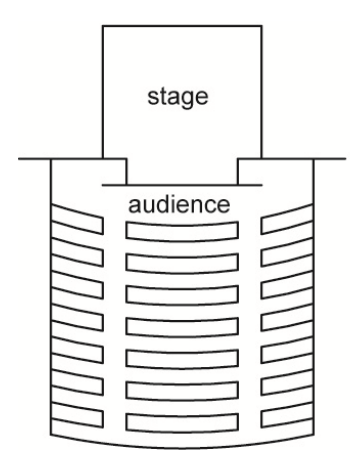

proscenium stage

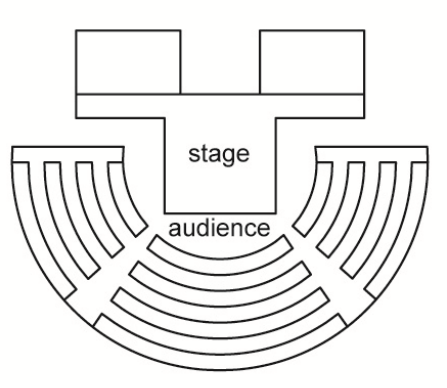

thrust stage

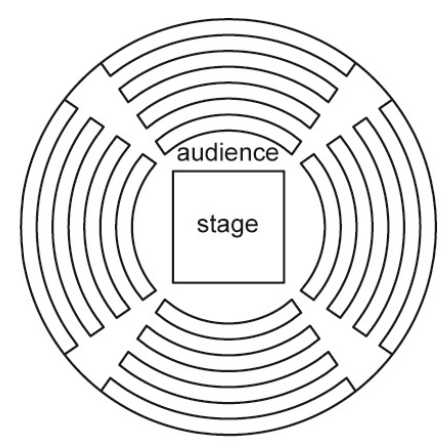

arena stage

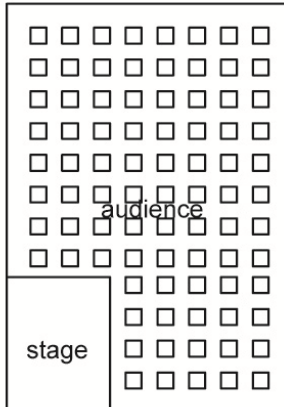

black box theatre

Figure 6.3.3 - Diagrams by author of primary four theatre typologies as identified by Edwin Wilson. 


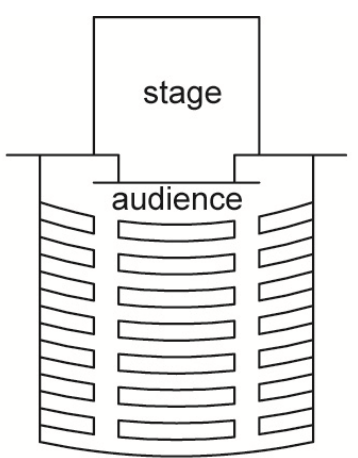

\section{Proscenium Stage - Replica}

perhaps the most identifiable stage environment

also known as the "picture-frame stage"

origins linked to the Italian Renaissance

seating at times placed on a slant to maximize audience sightlines

wings and a fly-loft in traditional iterations allow $\mathrm{fc}$ the scenery used on stage to be slyly concealed from the audience's view when not in use

the typology reflected in Aldo Rossi's 1979, Teatrc del mondo.
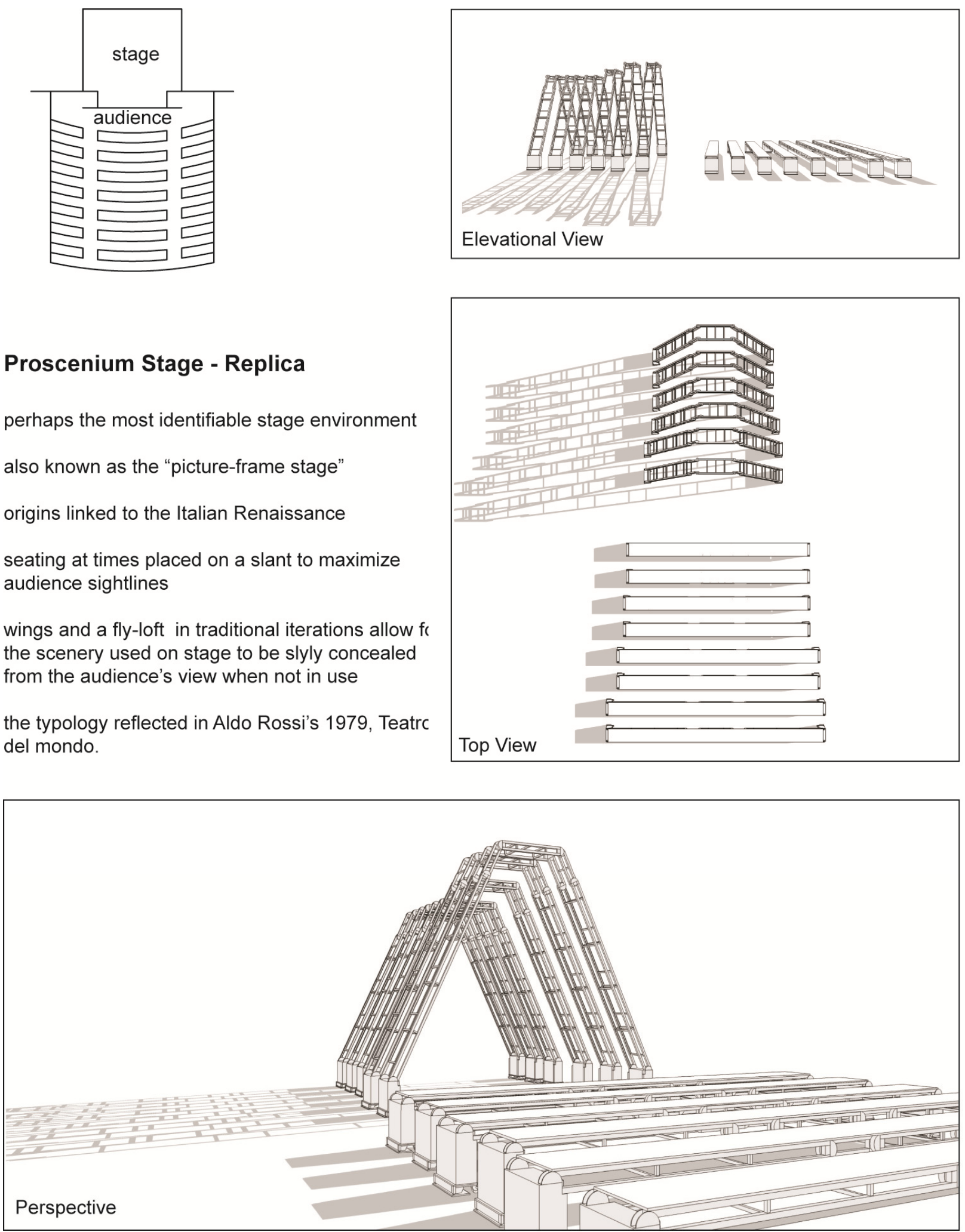

Figure 6.3.4 - Diagrams by author of the Showman in proscenium stage layout. 


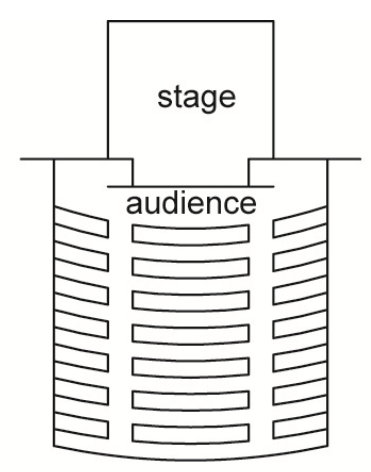

Proscenium Stage - Alternative
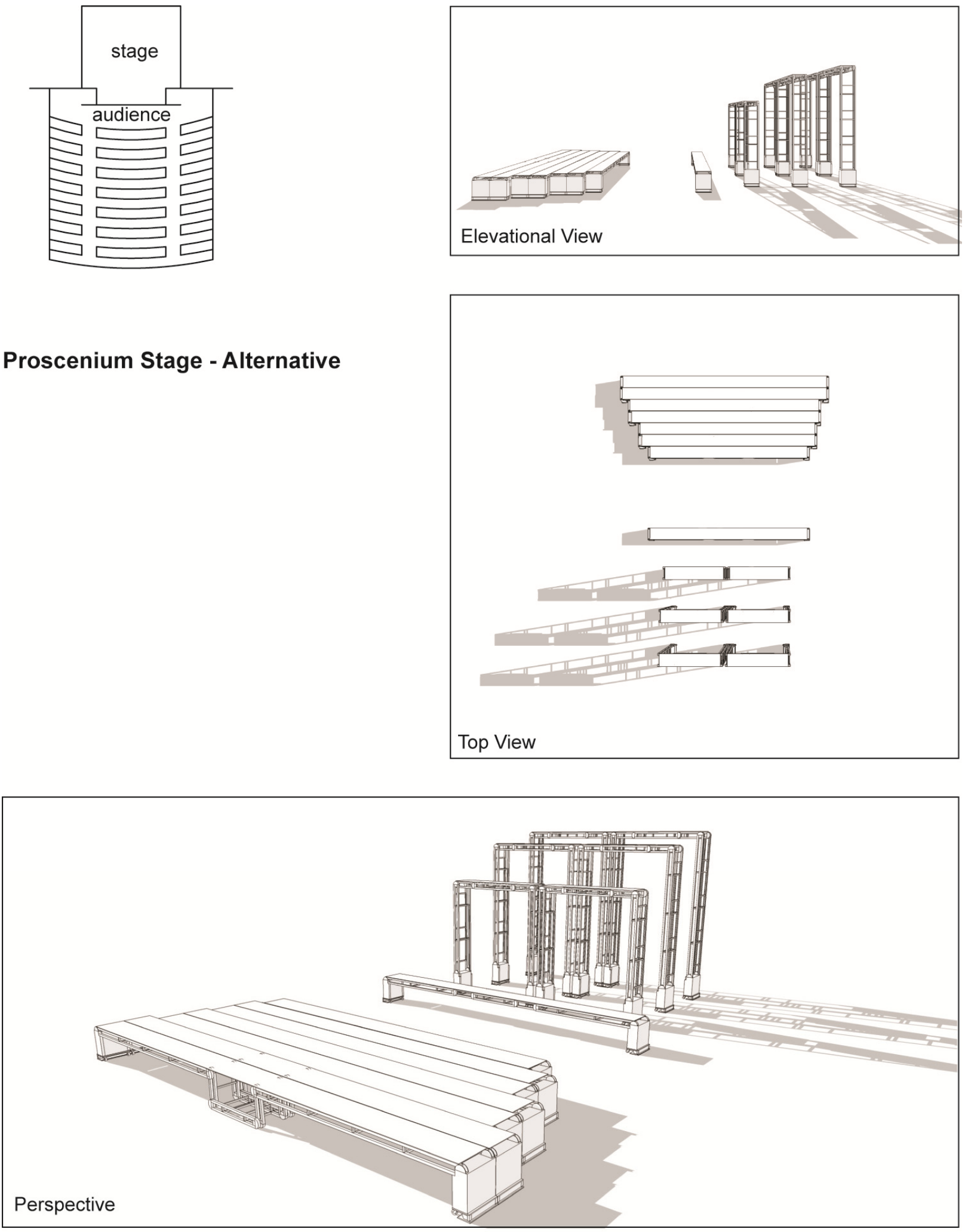

Figure 6.3.5 - Diagrams by author of the Showman in proscenium stage layout alternative. 


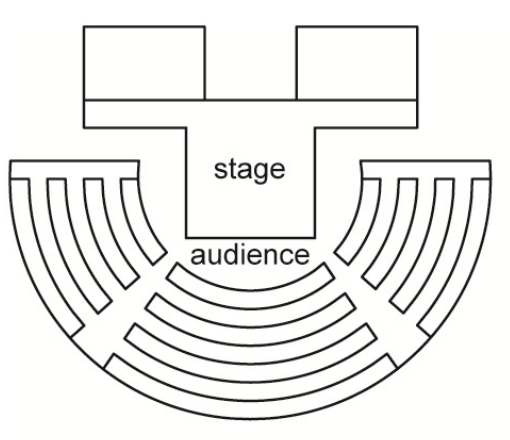

Thrust Stage - Replica

based on the Ancient Greek amphitheatre.

these stages were often along hill sides, which facilitated the creation of tiered seating

referenced once again during the 13th Century; platform stages often converted into wagon stages which were "thrust" into crowded urban social spaces

if seating was provided, it was often layed out in the form of a semi-circle
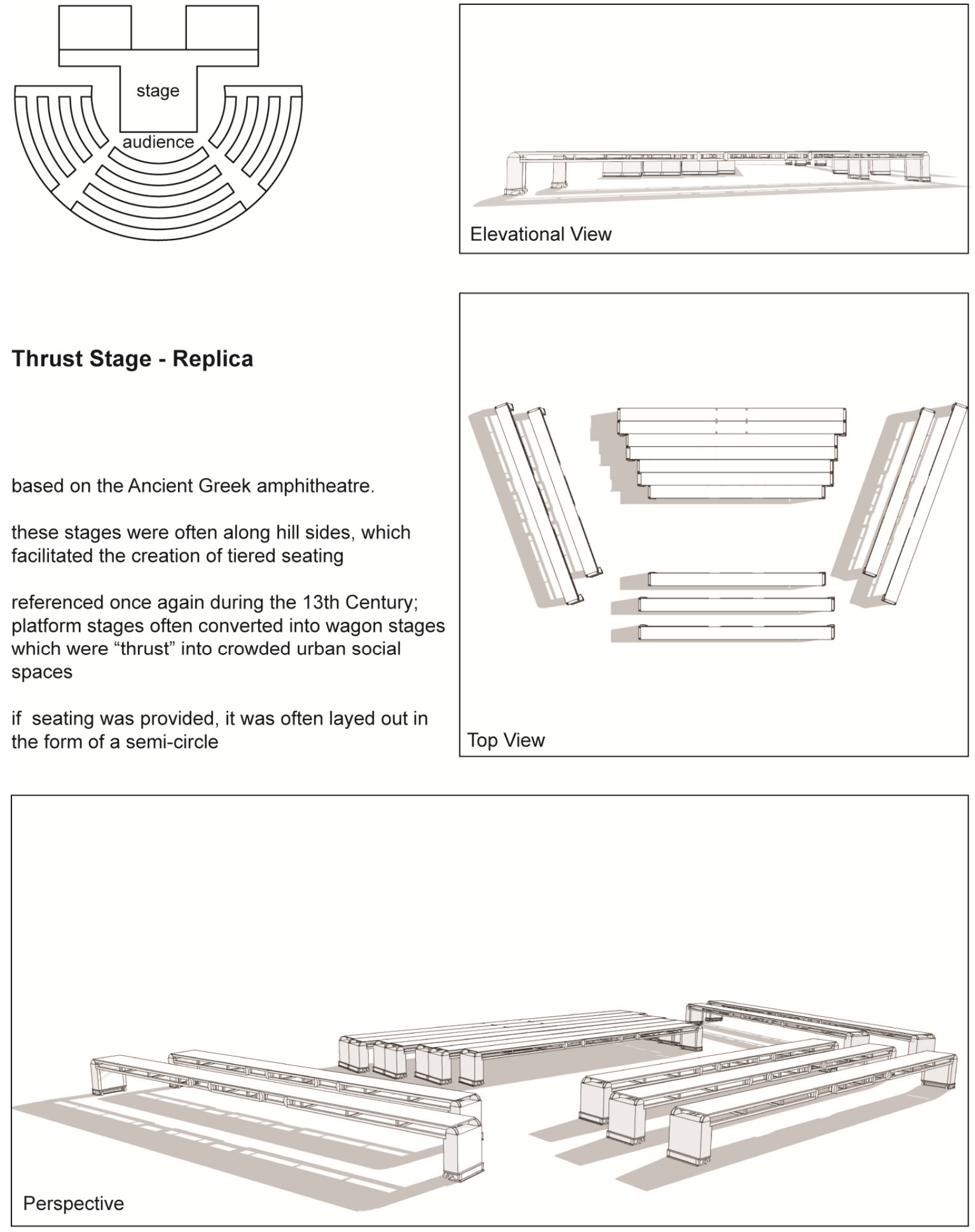

Figure 6.3.6 - Diagrams by author of the Showman in thrust stage layout. 

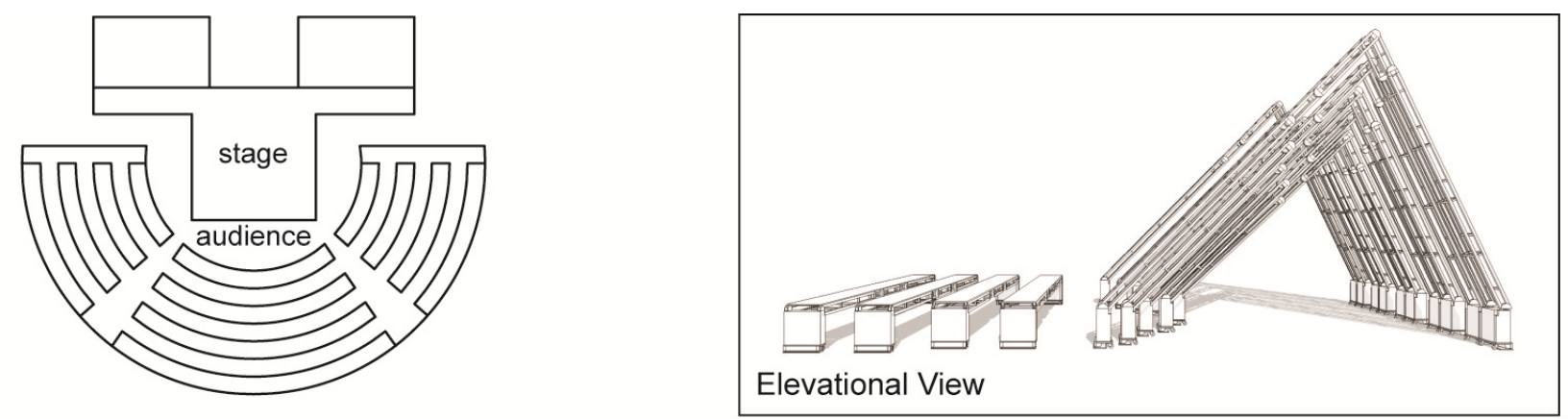

Thrust Stage - Alternative
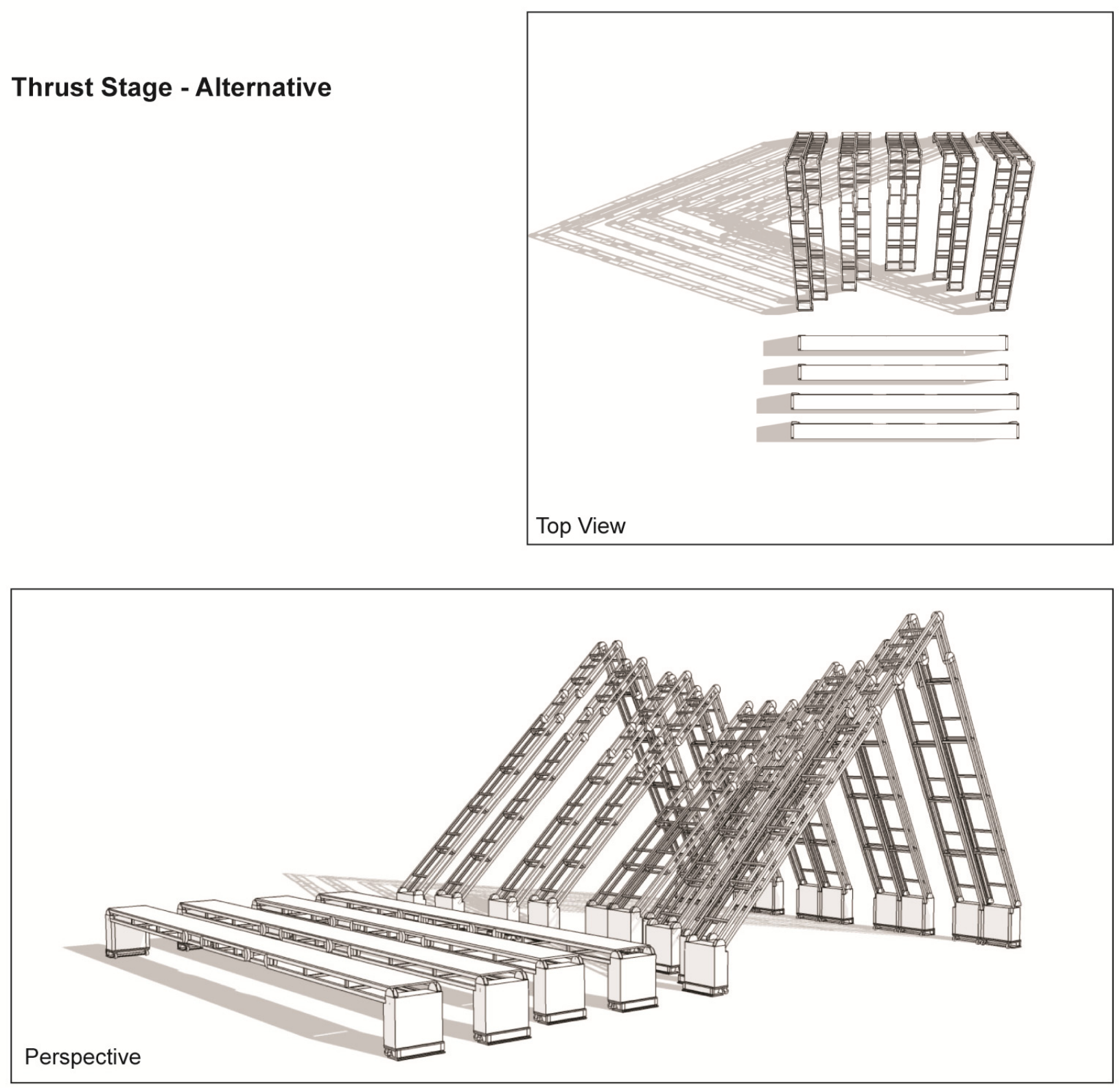

Figure 6.3.7 - Diagrams by author of the Showman in thrust stage layout alternative. 


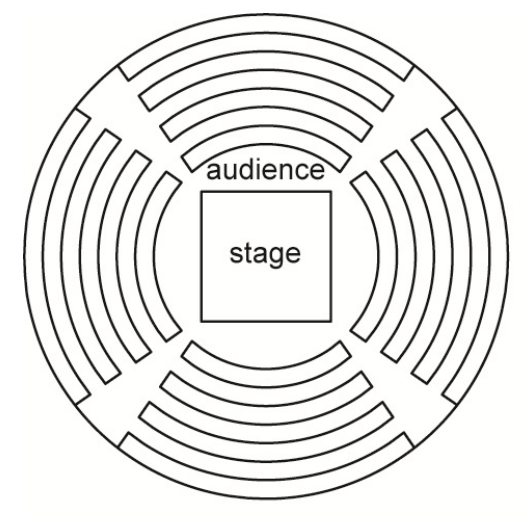

Arena Stage - Replica

an extension of this idea of the thrust stage also known as theatre-in-the-round

geometry resembles greatly that of the Ancient Rome Colliseum

the stage is fully exposed from all sides, completely exploiting the notion of stage-front provides a more intimate setting

a favourite for various sports events such as boxing
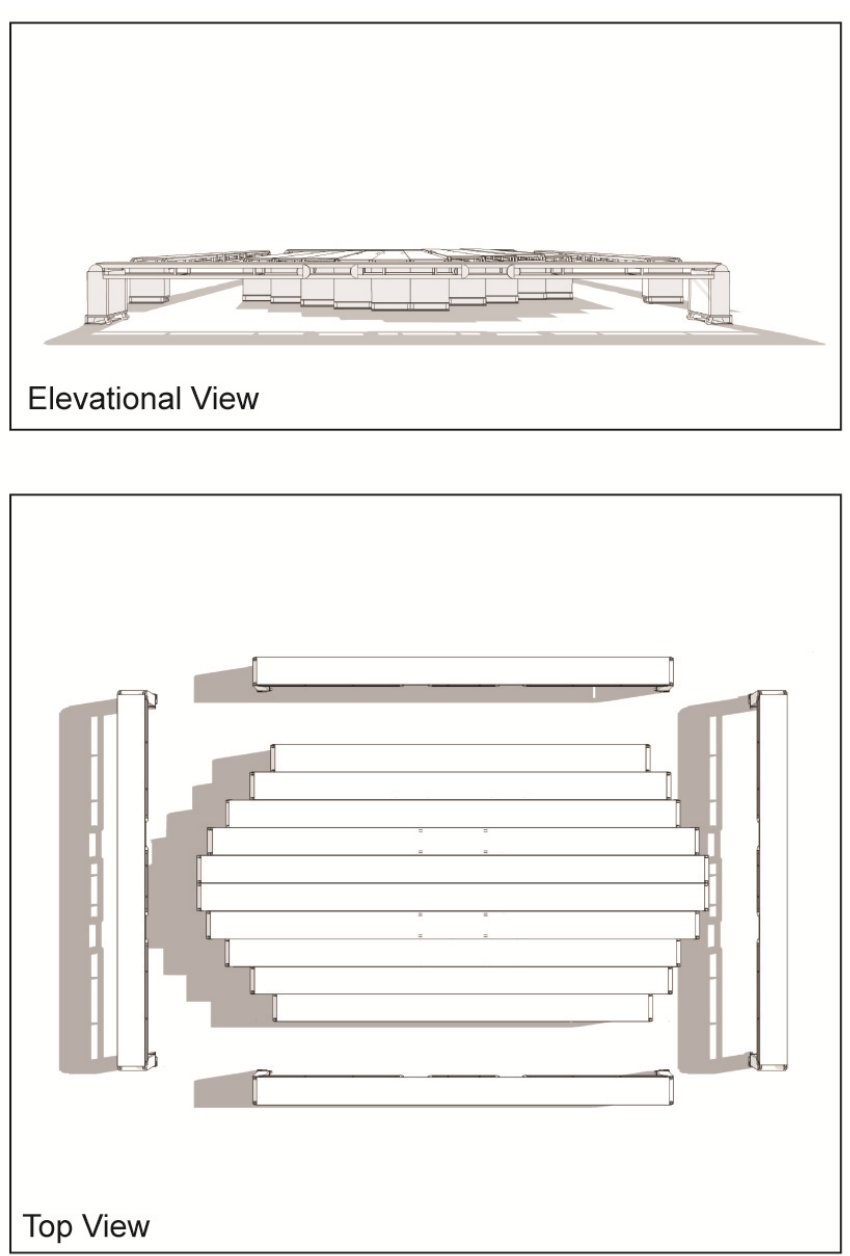

Top View

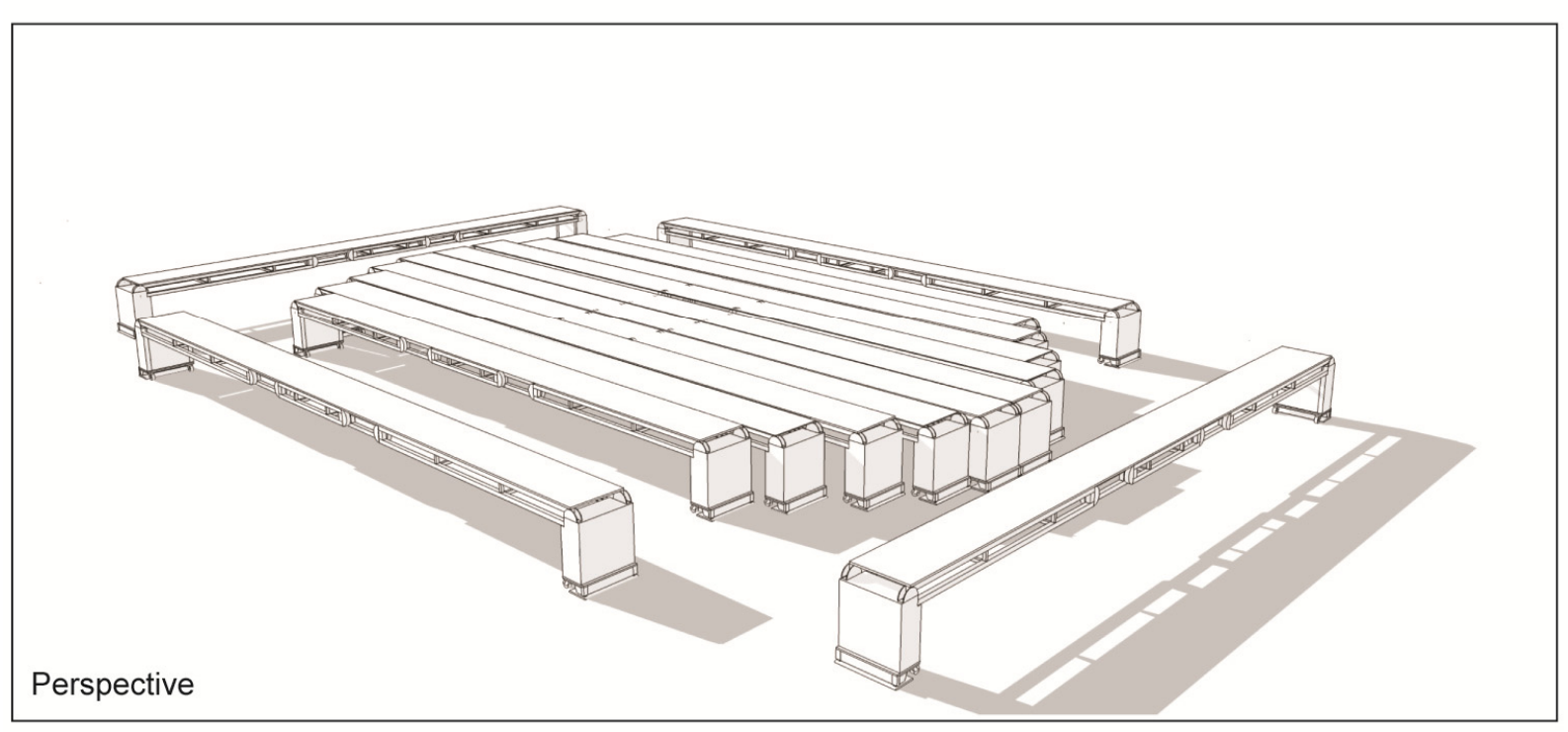

Figure 6.3.8 - Diagrams by author of the Showman in arena stage layout. 

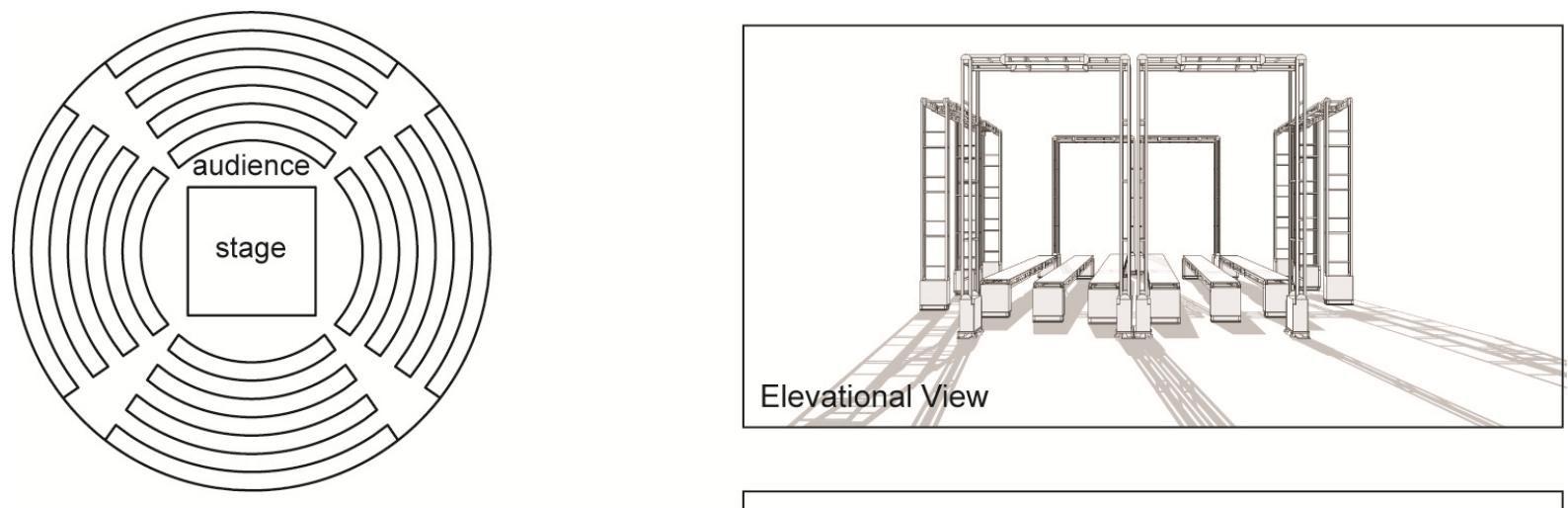

\section{Arena Stage - Alternative}
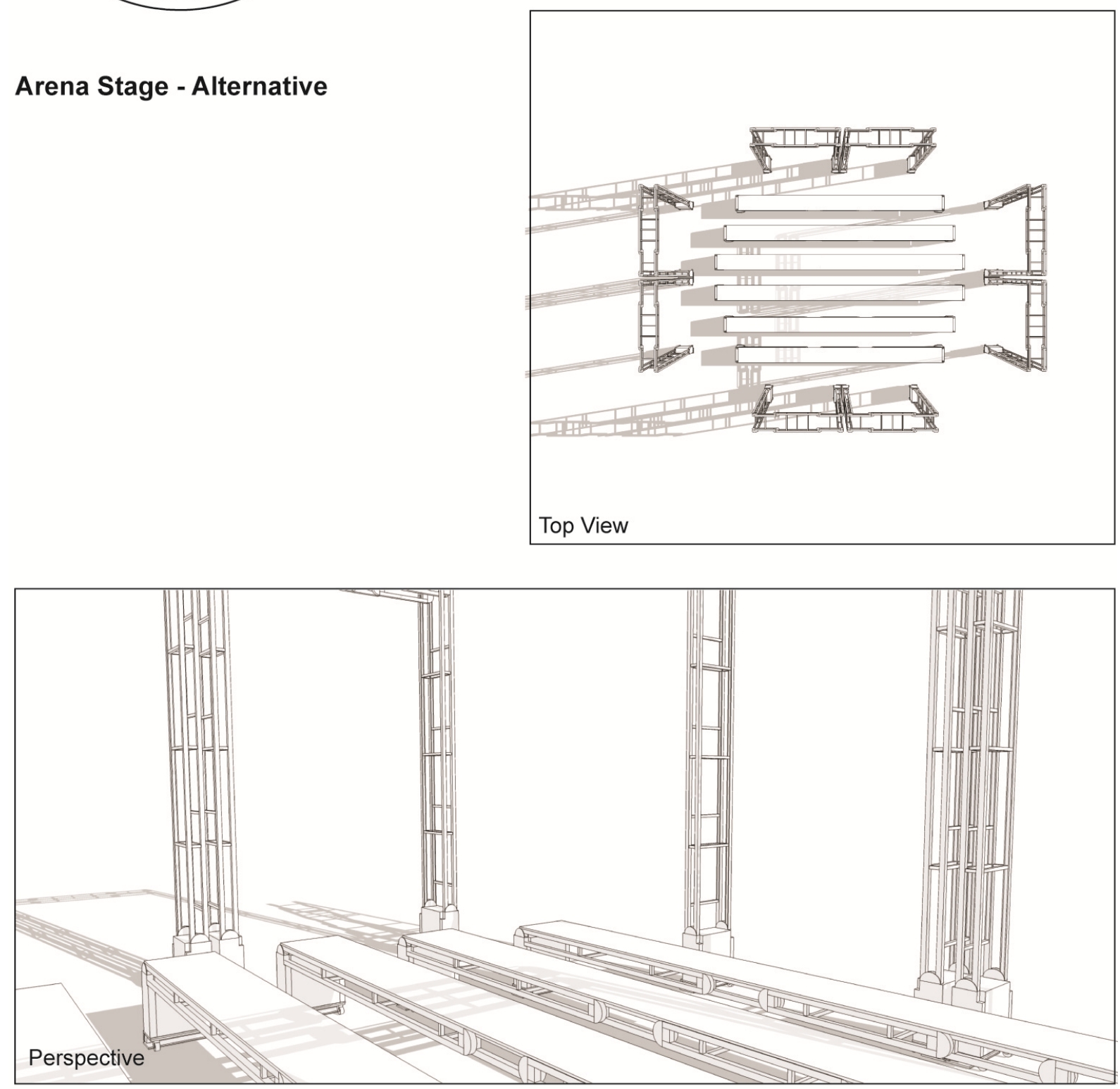

Figure 6.3.9 - Diagrams by author of the Showman in arena stage layout alternative. 


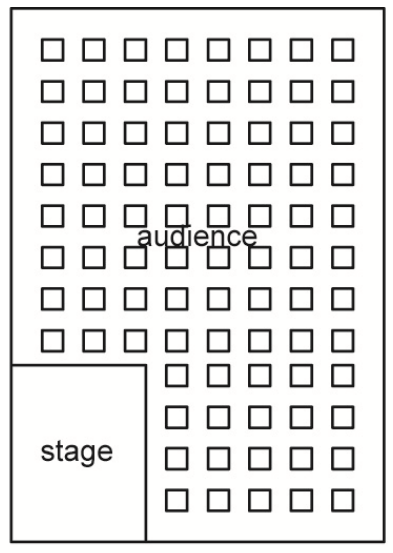

\section{The Black Box Theatre}

the Accommodating Showman functions similarly to the black box theatre concept

just as the black box theatre can match known layouts, so too can the Showman

consequently, one of the reigning features of the black box theatre and the Showman remains their potential to exceed beyond the replication of known typologies and allow for the creation entirely new schemes

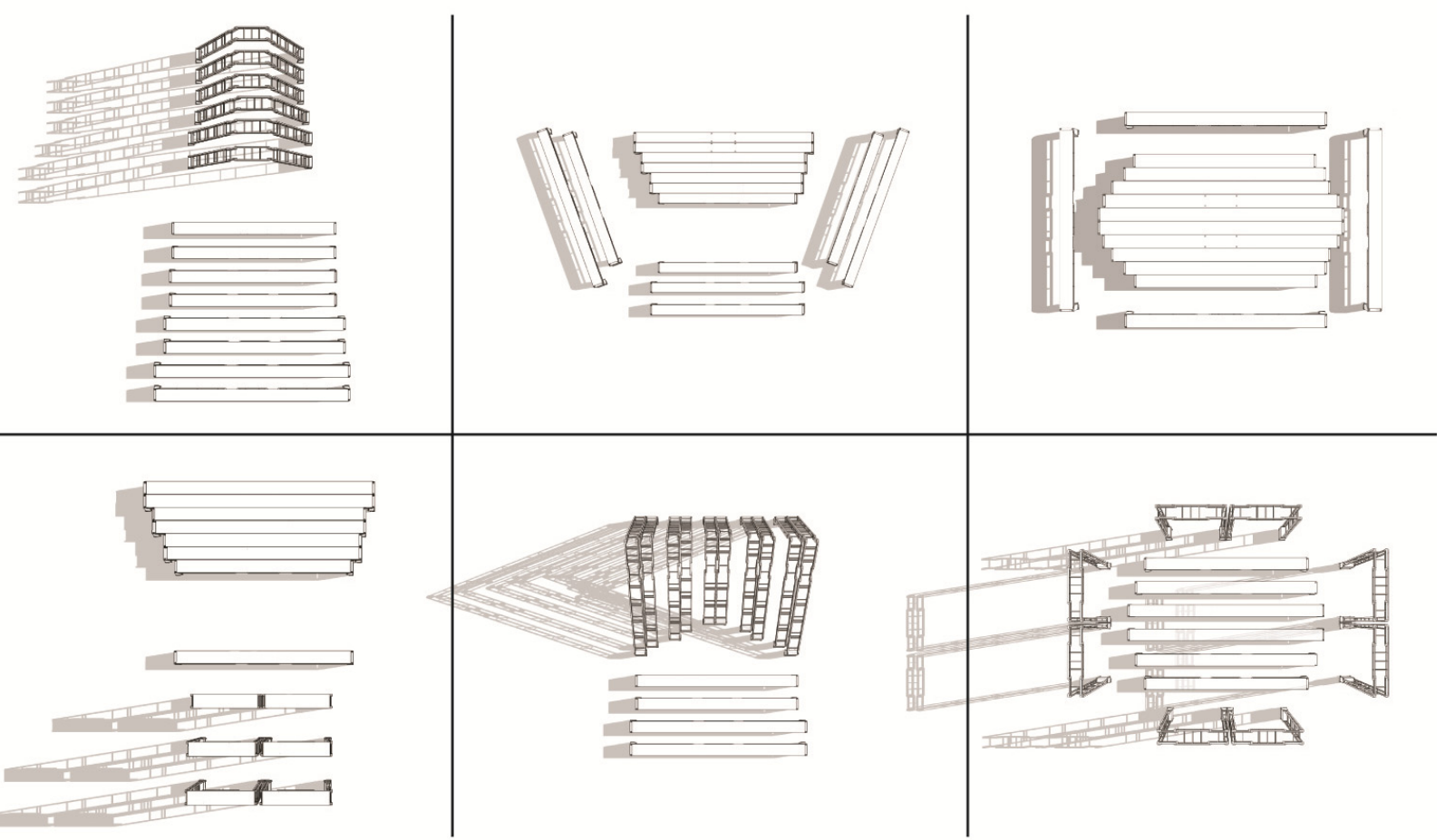

Figure 6.3.10 - Diagrams by author of the Showman in the six previously displayed iterations, to demonstrate its black box-like layout versatility. 


\subsection{Site-Specific Configurations}

The first three settings below demonstrate the three site conditions presented in section 5.2 of the text and act as examples of the primary locations where the Showman would likely be located.
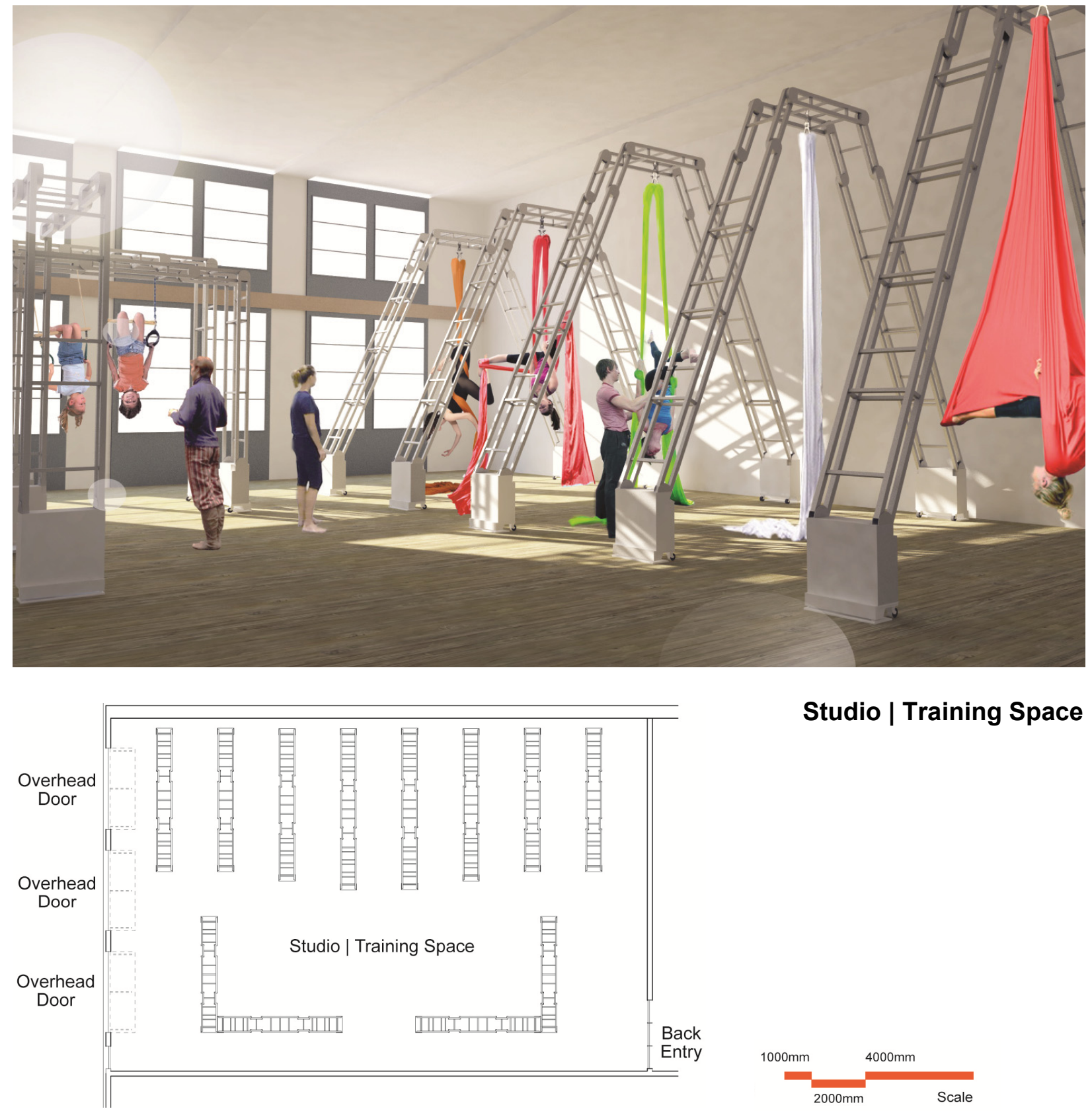

Figure 6.4.1 - Rendering and plan of acrobat troupe's studio and training space activated by Showman installation. 

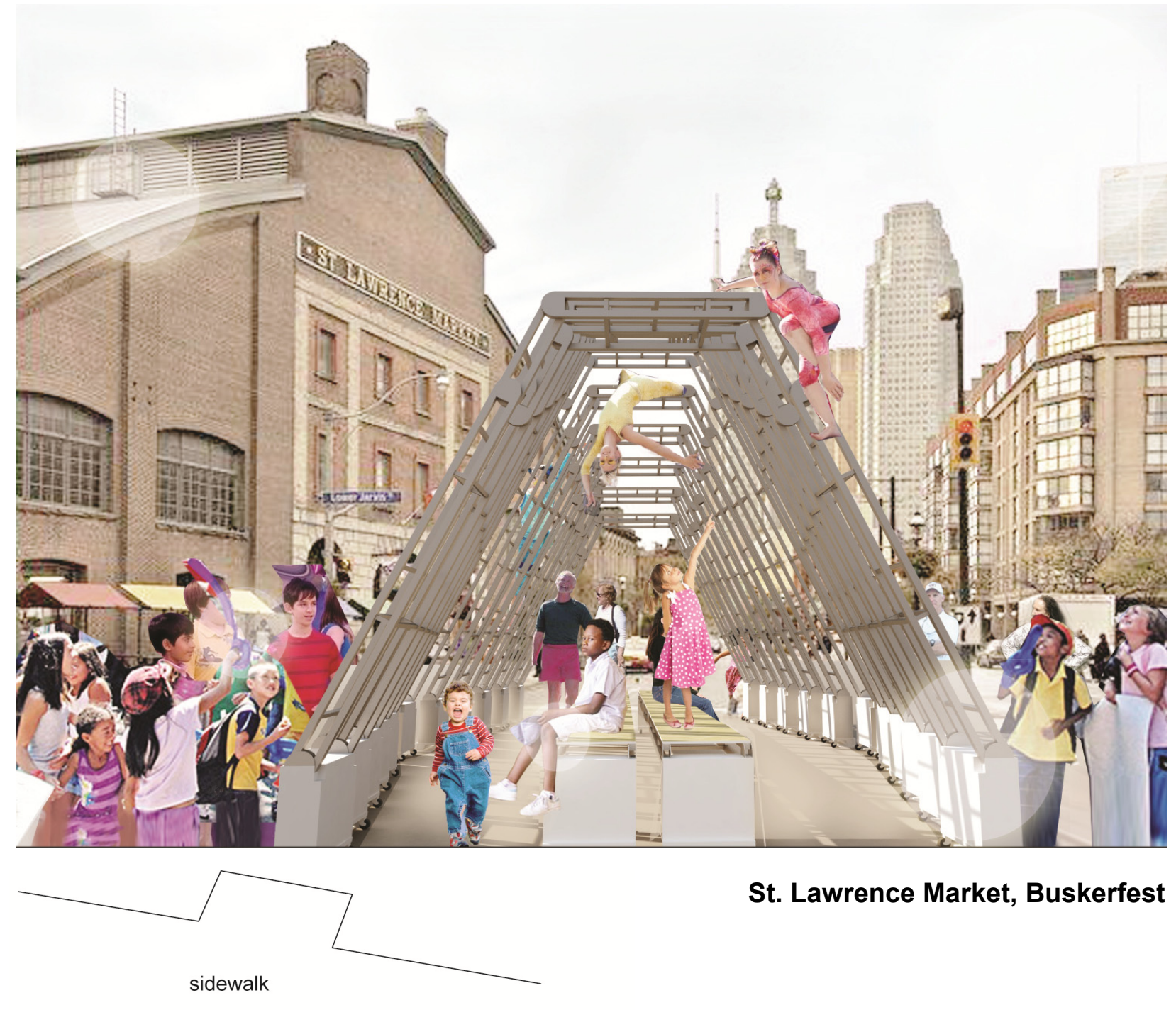

St. Lawrence Market, Buskerfest

Front St.

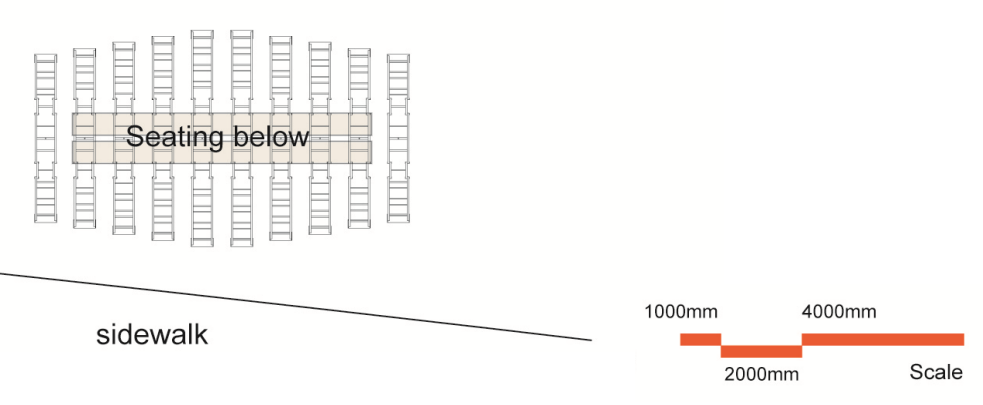

Figure 6.4.2 - Rendering and plan of Showman stationed on Front St. for Buskerfest. 

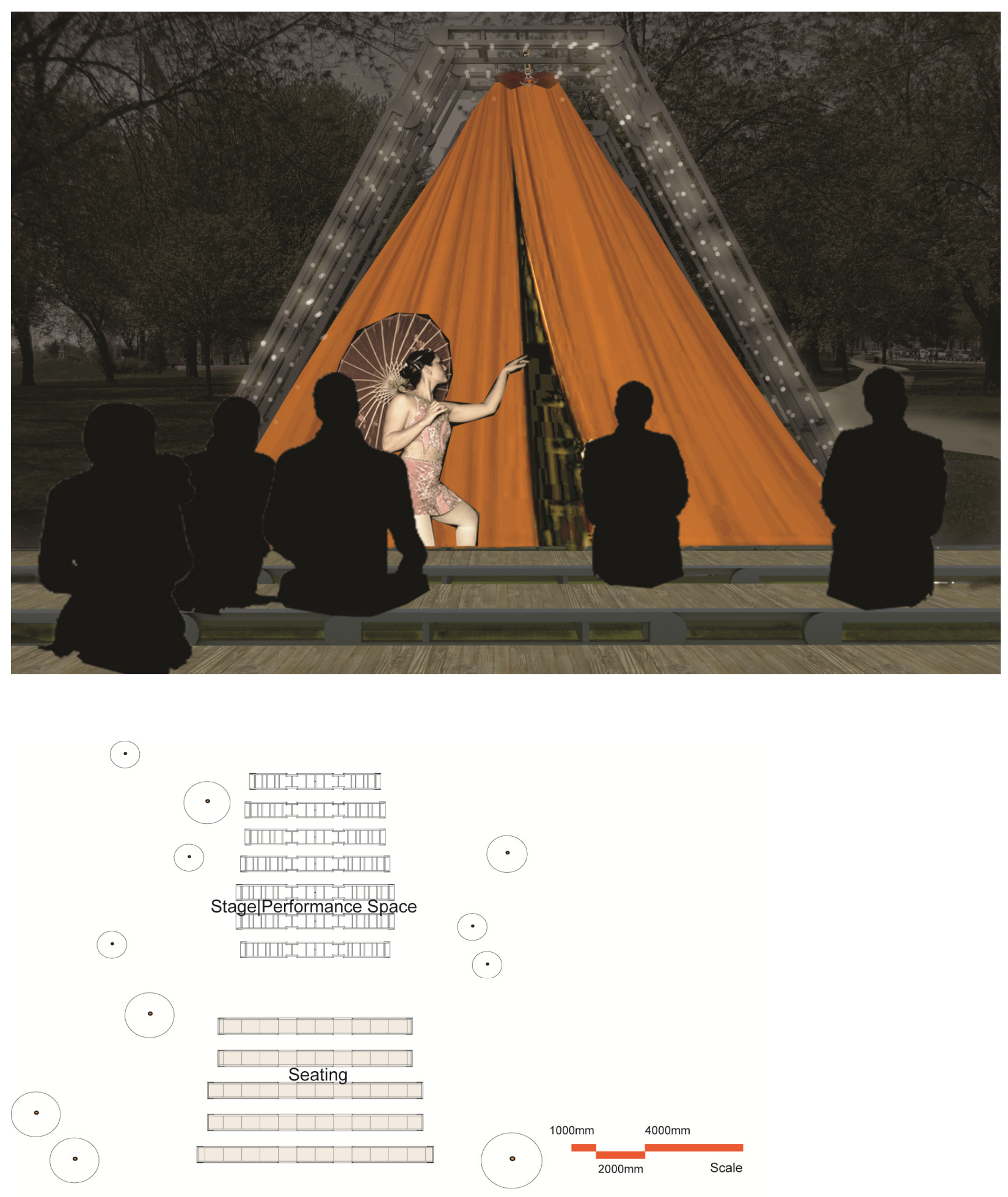

Figure 6.4.3 - Rendering and plan of Showman stationed in Trinity Bellwoods Park. 


\subsection{Show-Specific Configurations}

This final section represents the most case-specific configurations. The HerciniArts Collective performance titled "Gurgle Splash", was selected to demonstrate how the Showman can accommodate changing set requirements within the constraints of one performance ( HerciniArts Collective, 2011). This performance in particular was selected out of their roster of acts due to its longer duration, lending itself as a better candidate for layout shape-shifting following each scene, than for example their more common short gorilla-style performances. It is important to note, that the whimsical nature of this performance is dedicated to children and is often performed for school or youth functions. In general the material presented by the troupe tends to be of a lighter spirit, therefore for the purpose of this study very few offered a more mature outtake. The performance has been summarized and divided within four scene configurations. Each scene will be introduced with a large rendering of the scene in action within, on, or around the Showman and pair with a section listing the required attachments necessary to create the scene.
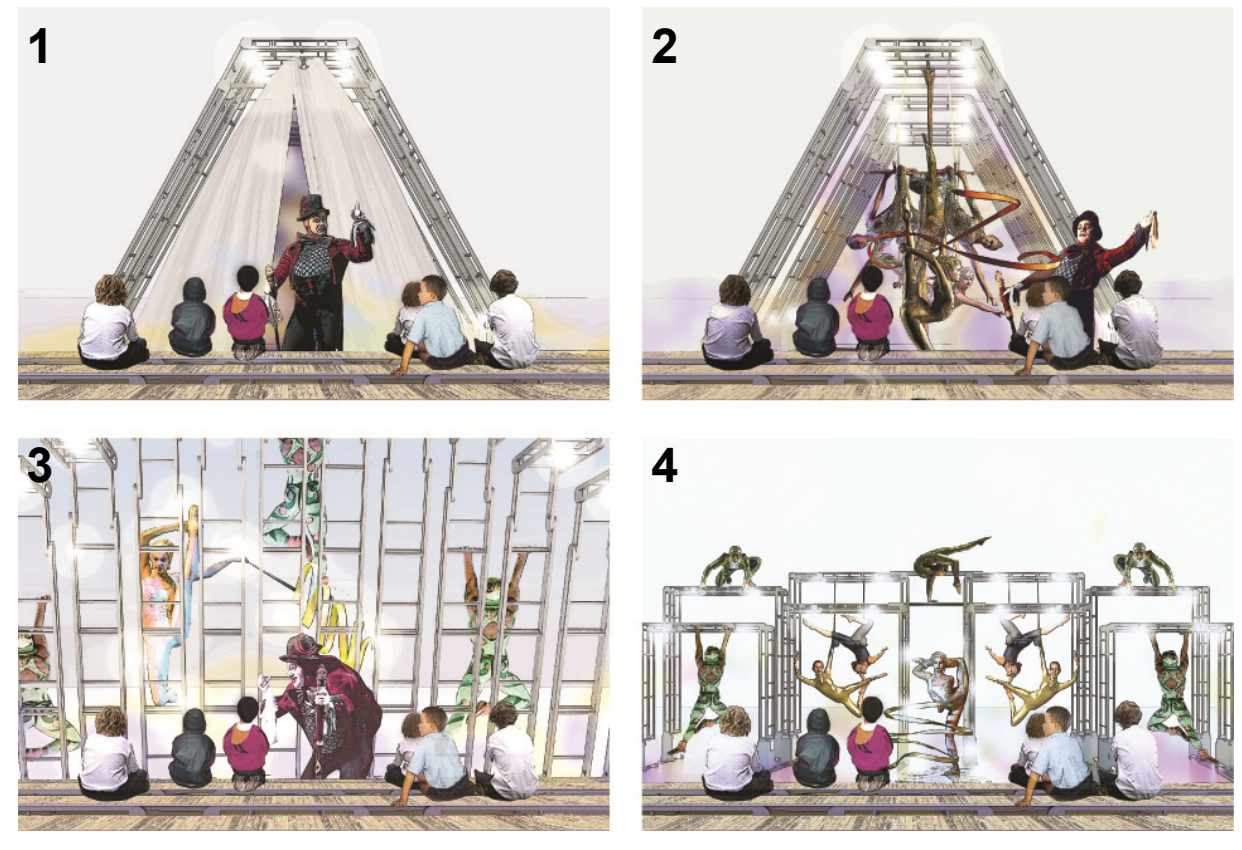

Figure 6.5.1 - All four scene renderings by author. 


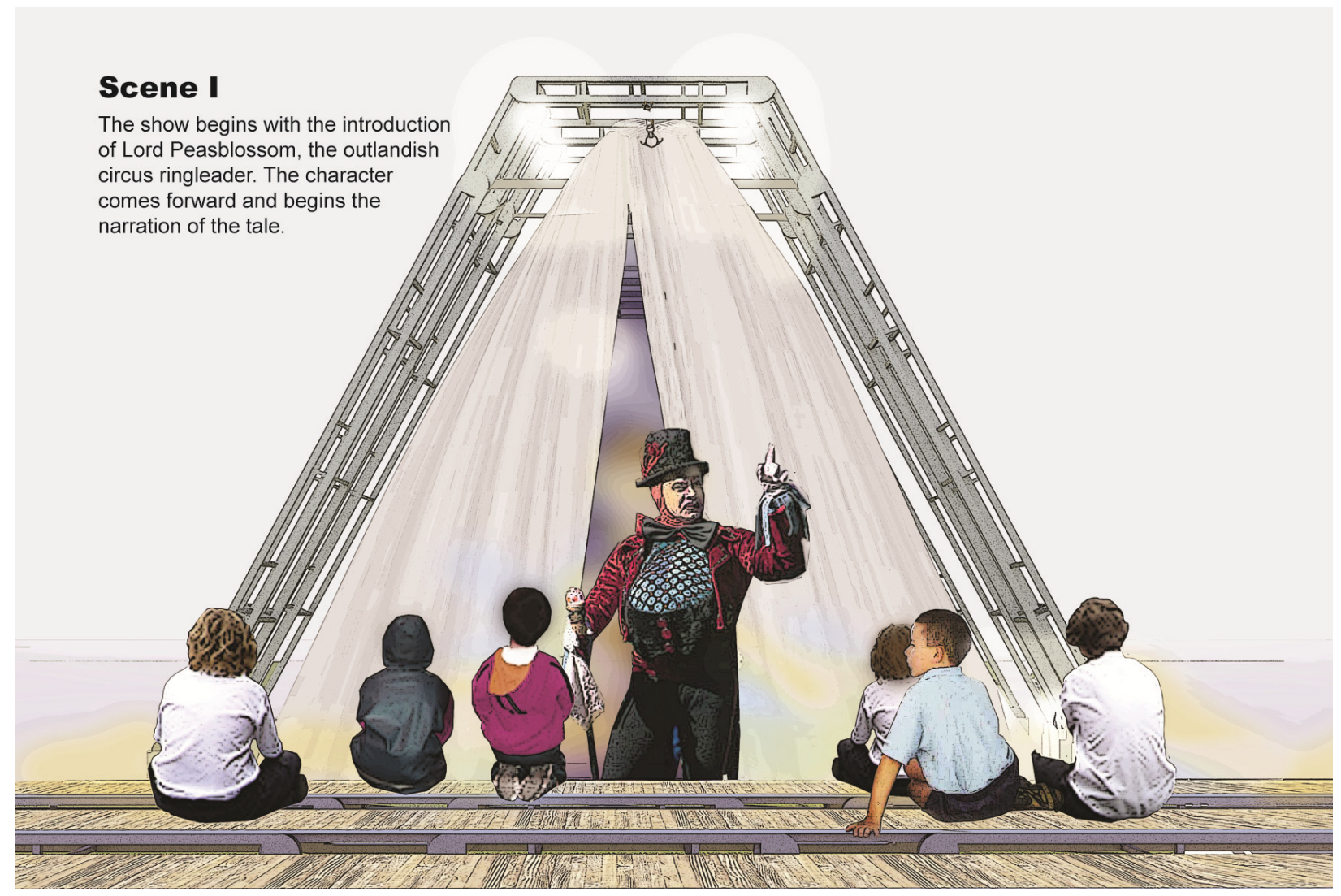

Frame add-ons required to create this scene:

1. Detachable batten theatre light (halogen)

2. Standard aerial right attachments: figure-eight descender, double carabener, and swivel.

3. Ledger scaffolding clamp to structurally secure frame-to-frame

4. Ledger scaffolding clamp at base to structurally secure frame-to-frame

5. Plywood clamp-on platform as bench surface

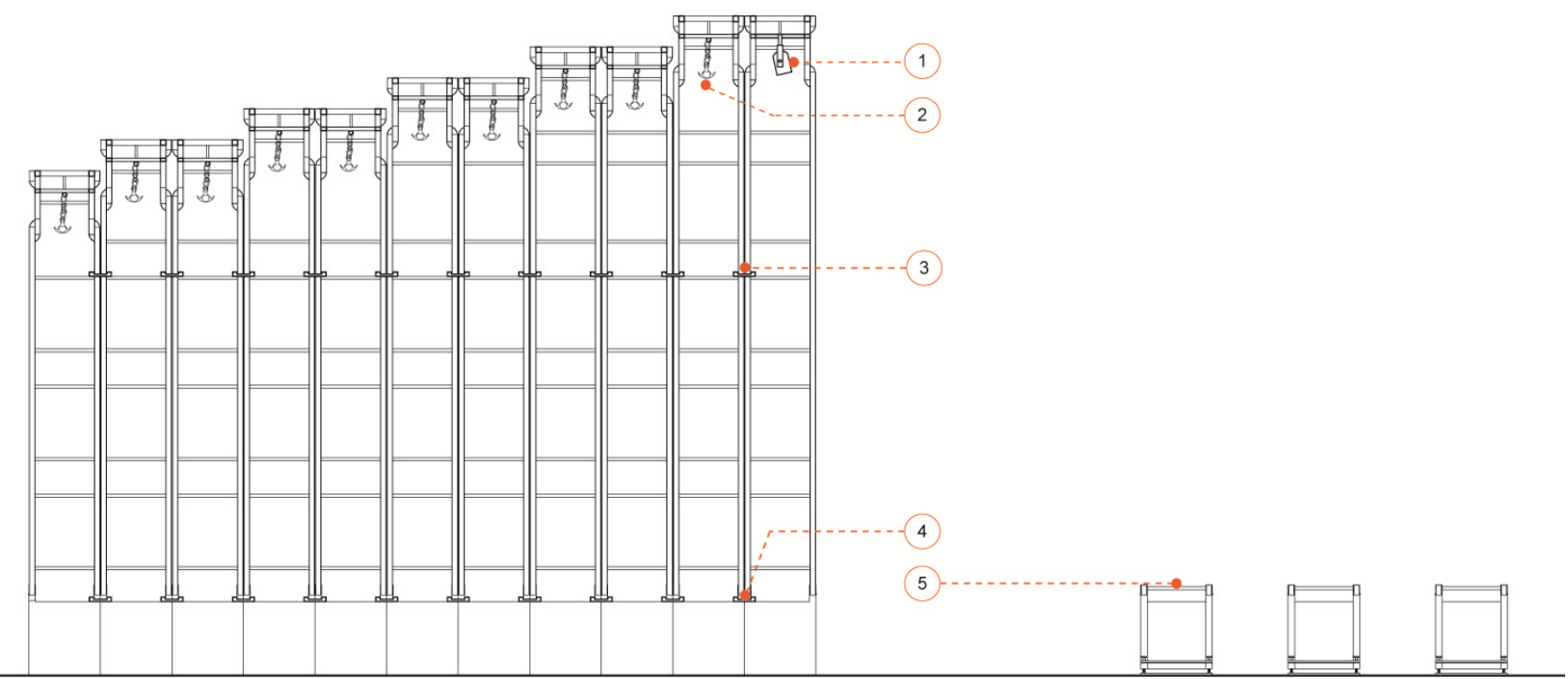

Figure 6.5.2 - Rendering and section by author of Scene 1. 


\section{Scene II}

The curtain (aerial silk) is pulled back and many of the Lord's prized catches appear as the audience witnesses the unfolding of a series of aerial silk and trapeze acts.

A rare underwater creature makes her appearance, stealing the attention of the Lord.

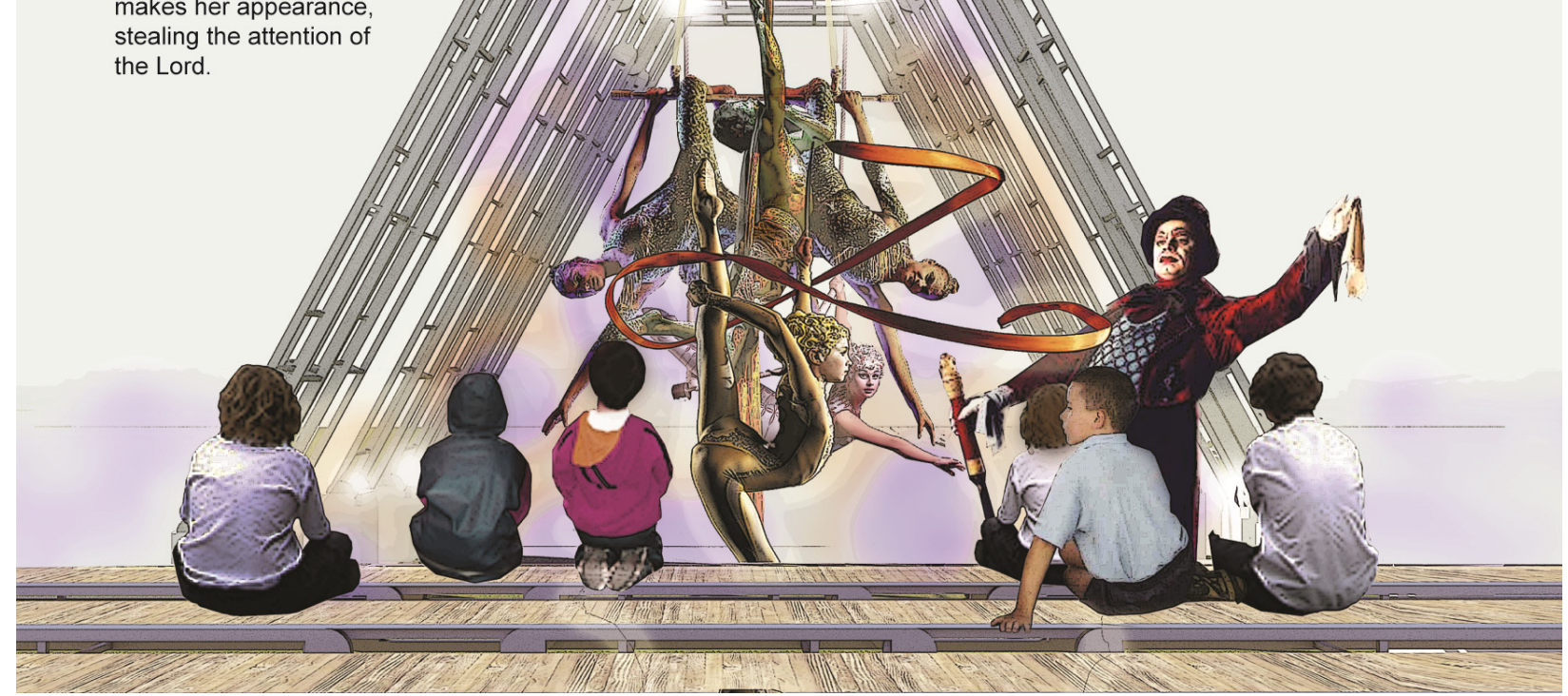

Frame add-ons required to create this scene:

1. Detachable batten theatre light (halogen)

2. Standard aerial right attachments: figure-eight descender, double carabener, swivel, with hanging silk.

3. Ledger scaffolding clamp to structurally secure frame-to-frame

4. Standard trapeze swing

5. Ledger scaffolding clamp at base to structurally secure frame-to-frame

6. Plywood clamp-on platform as bench surface

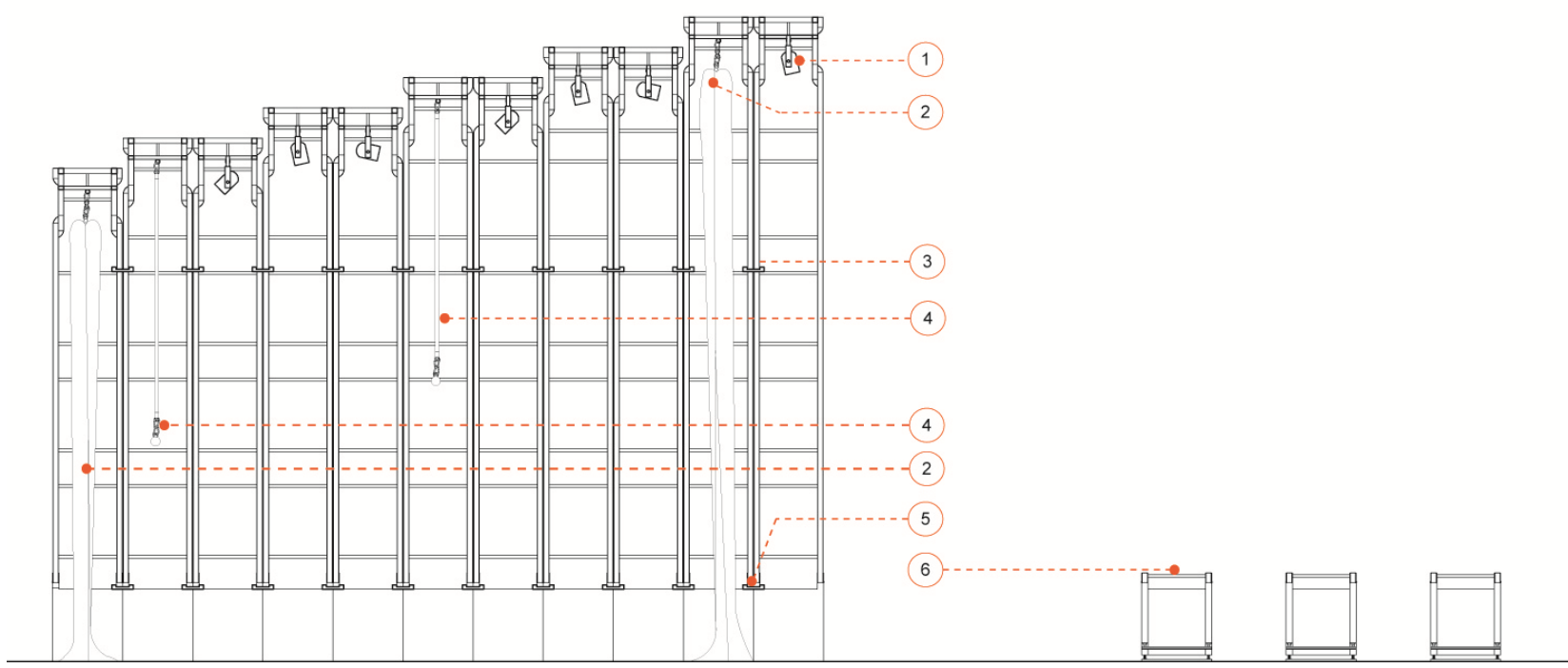

Figure 6.5.3 - Rendering and section by author of Scene 2 . 


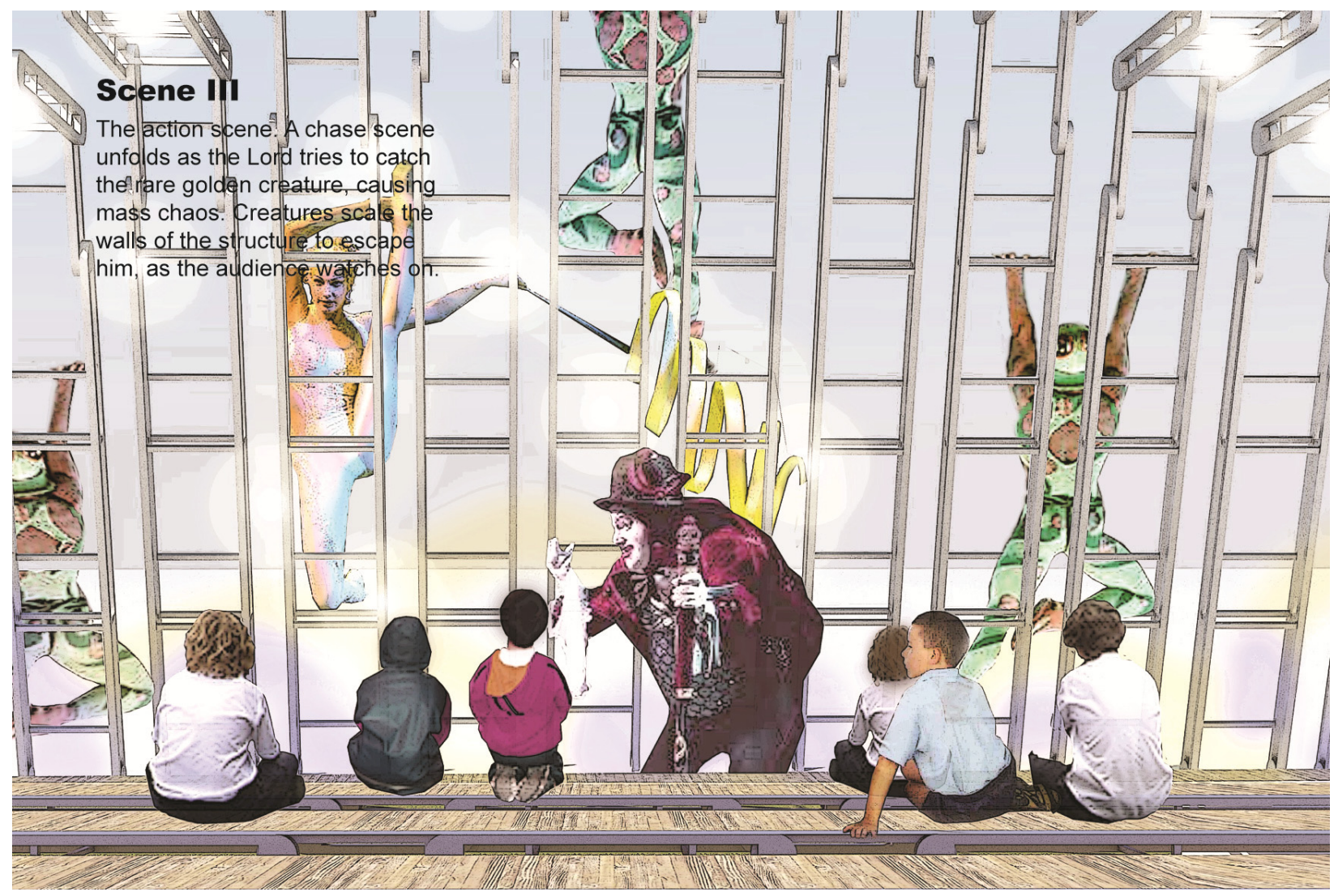

Frame add-ons required to create this scene:

1. Detachable batten theatre light (halogen)

2. Ledger scaffolding clamp to structurally secure frame-to-frame

3. Ledger scaffolding clamp at base to structurally secure frame-to-frame

4. Plywood clamp-on platform as bench surface

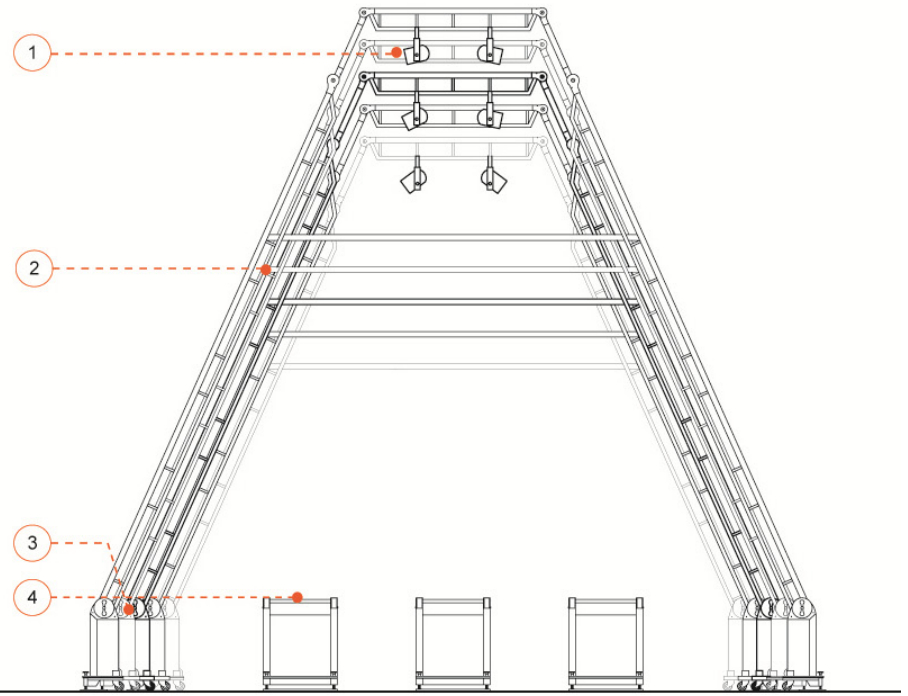

Figure 6.5.4 - Rendering and section by author of Scene 3. 


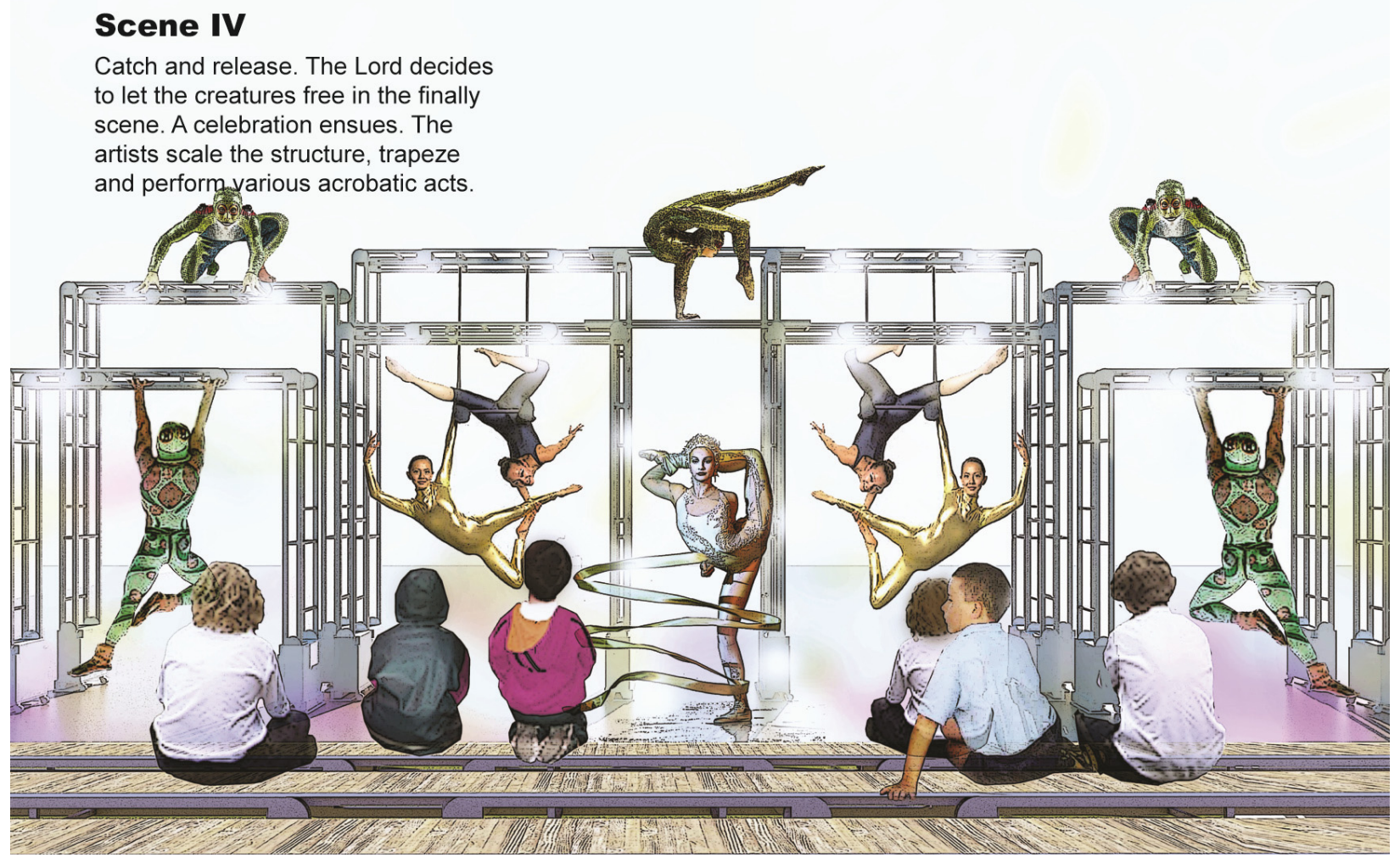

Frame add-ons required to create this scene:

1. Ledger scaffolding clamp to structurally secure frame-to-frame

2. Structural $1100 \mathrm{~mm}$ bracket attachment

3. Standard trapeze swing

4. Ledger scaffolding clamp at base to structurally secure frame-to-frame

5. Plywood clamp-on platform as bench surface

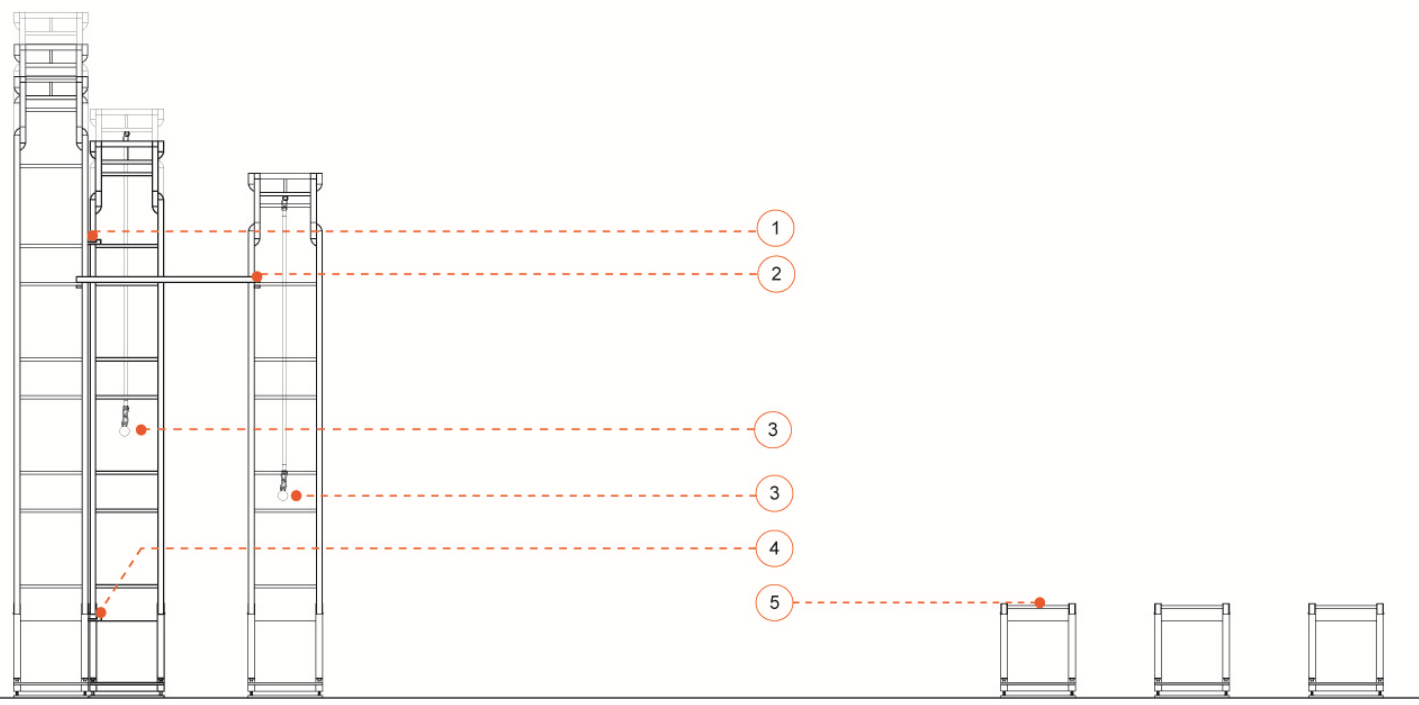

Figure 6.5.5 - Rendering and section by author of Scene 4. 


\section{Conclusion}

The challenge of the scope of this thesis, remained that it shared little likeness to any design project endeavour previously undertaken in my studies. Common training in most architectural pedagogies often focuses on the design and development of larger permanent projects. Perhaps beyond the desire for recognition, these projects are coveted for they reflect a scale and scope for which we have all been are most prepared to undertake. Projects at the small scale, present a layer of complexities rarely encountered in the master project. Every detail is scrutinized in order for the project to uphold its conceptual intentions, one misstep easily overthrowing the entire scheme. One of the many resulting lessons of this investigation therefore being, that for a project of this scale and scope to emerge as effortless and forthright would require unwavering diligence. Consequently as this project evolved, this diligence with respect to the design of the frame modules nearly became a fixation.

The chief challenge of a project which is at once transportable and adaptable is not in it its limitations, but rather in its altogether lack thereof. A set site and specific program act as the preliminary framework of most architectural projects. Remove the first, and blur the second and you are left with a great deal of unknowns. Establishing a client was therefore a monumental step in the development of the proposal. The selection of an acrobatic troupe provided direction for the frame design. Since their performances represented an amalgamation of various acts, each of these needed to be accounted for. The climbing surface provided a spatial boundary despite its open-air nature. Meeting the safety guidelines for aerial silk 
rigging, posed height and width restrictions on the frame's overall dimensions. Facilitating seating demanded that the height of the first hinge point remain below bench height. Lastly the self-prescribed constraint that the units be transported with ease, led to the addition of a secondary interior frame to facilitate manual relocation and the collapsibility of the overall module in order for the grouping of 14 modules to fit within one 24 foot truck.

While shape-shifting and adaptability are characteristics not easily achieved architecturally, they provide the ability to actively react to change unlike their static counterparts. At a large scale this can be reflected in many of the approaches expounded by Adaptable Futures (Chapter 2.3). Transience and adaptability are particularly relevant attributes when negotiating the design of performance spaces (which as identified by Peter Brooks are inherently impermanent). The endeavour to implement temporary architectural methodologies will no doubt remain a point of interest throughout the course this author's career. However the take-home standards extracted (beyond the exploration of transience), were the lessons expounded in the work of Archigram, Aldo Rossi, Raumlabor Berlin, and Peter Brook. While each of these may not appear in detail within the pages of this text, they all share the unapologetic need to question, challenge and expose existing typologies and traditional ideologies; a goal the design project ventured to undertake.

This thesis investigation sought to exploit the notion of temporality at all costs. The Accommodating Showman emerged, personifying the design's intention to shape-shift at the desire of the client. The execution resulted in a design of more simplistic means, "raw" in some dimension 
as Brook's would have it. It is in this interpretation as well as the author's concluding thesis-acquired insight, that better to emerge as rough, than deadly.

| Reference play on Peter Brook's Rough versus Deadly Theatres (Brook, 1969) | 


\section{Image Sources}

Figure 1.1 Allard-Buffet, Veronique (2012). Sketch of Roy Thomson Hall, Toronto.

Figure 1.2 Allard-Buffet, Veronique (2012). Sketch of temporary stage at Yonge and Dundas Square, Toronto.

Figure 1.1.1 unknown. (2009, March 28). Annex Circus 1904 . Retrieved 12 04, 2011, from Ephemera Assembly: http://assemblyman-eph.blogspot.ca/2009/03/vintage-circus-photos.html

Figure 1.1.2 unknown. (2009, March 28). Clowns. Retrieved 12 04, 2011, from Ephemera Assembly: http://assemblyman-eph.blogspot.ca/2009/03/vintage-circus-photos.html

Figure 1.1.3 unknown. (2009, March 28). A group of 20+ circus clowns in "Clown Alley" posing informally while preparing for the ring. Retrieved 12 04, 2011, from Ephemera Assembly: http://assemblyman-eph.blogspot.ca/2009/03/vintage-circus-photos.html

Figure 1.1.4 unknown. (2009, March 28). Emma Ward, a circus trapeze artist, dangles by one hand from a ring high in a circus tent. Retrieved 12 04, 2011, from Ephemera Assembly: http://assemblyman-eph.blogspot.ca/2009/03/vintage-circus-photos.html

Figure 1.1.5 History of Theatre. (2010, April 10). Perspective Scenery . Retrieved 12 04, 2011, from History of Theatre:

http://theatrehistory2010.blogspot.com/2010/04/perspective-scenery.html

Figure 1.1.6 Time \& Life Images. (2009, March). Rolling Stones Voodoo Lounge. Retrieved 12 04, 2011, from Life Magazine:

http://store. life.com/search/?view=grid\&pagesize=15\&q=voodoo+lounge

Figure 1.1.7 Time \& Life Images. (2009, March). Rolling Stones Voodoo Lounge. Retrieved 12 04, 2011, from Life Magazine:

http://store.. life.com/search/?view=grid\&pagesize=15\&q=voodoo+lounge

Figure 2.1.1 Encyclopædia Britannica, Inc. (2011). Conestoga Wagon. Retrieved 12 04, 2011, from Encyclopædia Britannica:

http://www.britannica.com/EBchecked/media/4960/Conestoga-wagon

Figure 2.1.2 Kronenburg, R. (2002). Houses in Motion: The Genesis, History and Development of the Portable Building (2 ed.). West Sussex: Wiley Academy.

Figure 2.1.3 Rud. Rasmussen/Denmark. (2011). The Folding Chair: Mogens Koch. Retrieved 12 04, 2011, from Rud. Rasmussen/Denmark:

http://www.rudrasmussen.com/own-furniture-collection/chairs/the-folding-chair/

Figure 2.2.1 Gorman, Michael John. (2002). Leonardo's Vitruvian Man. Retrieved 18 07, 2012, from The Virtruvian Man:

http://leonardodavinci.stanford.edu/submissions/clabaugh/history/leonardo.html

Figure 2.2.2 Dreyfuss, Henry. (1955). Joe and Josephine. Retrieved 18 07, 2012, from 
The Funambulist:

http://thefunambulist.net/2012/04/29/architectural-theories-a-subversive-approach-to-theideal-normatized-body/

Figure 2.2.3 LeCorbusier. (1949). Le Modulor. Retrieved 12 04, 2011, from Stoa architecture, Mesure: http://www.stoa-architecture.com/theorie/?p=142

Figure 2.3.1 Adaptable Futures. (2012). D11: Framecycle. Retrieved 20 07, 2012, from Adaptable Futures toolkit: http://adaptablefutures.com/our-work/toolkit/

Figure 2.3.2 unknown. (2010). Rietveld Schroder House: Living Room. Retrieved 20 07, 2012, from Contemporary Practice: http://maddme.wordpress.com/2010/01/

Figure 2.3.3 Acme goes Digital. (2008). Interior of Kyusuitei: Shugakuin Imperial Villa Kyoto.

Retrieved 20 07, 2012, from Panoramio: http://www.panoramio.com/user/612318/tags/architecture?photo_page=6

Figure 2.3.4 unnknown. (2007). Hiroshi Nakao: Art in the City, Black Maria 1994.

Retrieved 22 07, 2012, from tejidoecosocialtres:

http://tejidoecosocialtres.blogspot.ca/2007/09/hiroshi-nakao-art-in-cityblack-maria.html

Figure 2.3.5 unnknown. (2007). Hiroshi Nakao: Art in the City, Black Maria 1994.

Retrieved 22 07, 2012, from tejidoecosocialtres:

http://tejidoecosocialtres.blogspot.ca/2007/09/hiroshi-nakao-art-in-cityblack-maria.html

Figure 2.3.6 Dimitri Koubatis (2001). Hiroshi Nakao | Black Maria 1994.

Retrieved 22 07, 2012, from art in the city:

http://www.arch.mcgill.ca/prof/mellin/arch671/winter2001/dkouba/drm/nakao.htm

Figure 2.3.7 Dimitri Koubatis (2001). Hiroshi Nakao | Black Maria 1994.

Retrieved 22 07, 2012, from art in the city:

http://www.arch.mcgill.ca/prof/mellin/arch671/winter2001/dkouba/drm/nakao.htm

Figure 2.3.8 Dimitri Koubatis (2001). Hiroshi Nakao | Black Maria 1994.

Retrieved 22 07, 2012, from art in the city:

http://www.arch.mcgill.ca/prof/mellin/arch671/winter2001/dkouba/drm/nakao.htm

Figure 3.1 Schechner, Richard (2003). Schechner's Fan. Retrieved 13 07, 2012, from Icosilune:

http://www.icosilune.com/2009/01/richard-schechner-performance-theory/

Figure 3.2.1 Boullée, Étienne (1781). Opéra au Carrousel: coupe en face du théâtre. Retrieved 1307 , 2012, from le projet de l'Opéra : http://expositions.bnf.fr/boullee/grand/62.htm

Figure 3.2.2 Allard-Buffet, Veronique (2012). Diagram of the Proscenium Layout.

Figure 3.2.3 Allard-Buffet, Veronique (2011). Epidaurus Theatre. Greece: Author's Personal Travel Photograph.

Figure 3.2.4 Allard-Buffet, Veronique (2012). Diagram of the Thrust Stage.

Figure 3.2.5 Allard-Buffet, Veronique (2012). Diagram of the Arena Stage.

Figure 3.2.6 Allard-Buffet, Veronique (2012). Diagrams of a Black Box Theatre. 
Figure 4.1.1 Rossi, Aldo (1980). Teatro del mondo, Aldo Rossi. Retrieved 08 03, 2012, from design boom: http://www.designboom.com/history/teatromondo.html

Figure 4.1.2 unknown (1980). Teatro del mondo. Retrieved 08 03, 2012, from Universidad Nacional de Rosario: www.biblioteca.fapyd.unr.edu.ar/leaves/archivo/historia-de-laarquitectura/ mas-info/teatro-del-mundo.htm

Figure 4.1.3 unknown (1980). Interior view. Retrieved 08 03, 2012, Retrieved 08 03, 2012 , from design boom: http://www.designboom.com/history/teatromondo.html

Figure 4.1.4 unknown (1980). Teatro del mondo. Retrieved 08 03, 2012, from La Biennale di Venezia: http://www.labiennale.org/en/biennale/photocenter/photogallery_biennale.html?PageN=2

Figure 4.1.5 Rossi, Aldo (1979). Drawing from Aldo Rossi's Studio. Retrieved 08 03, 2012, from design boom: http://www.designboom.com/history/teatromondo.html

Figure 4.2.1 Guerrilla Stoemp. (2009, October 21). Prada Transformer à Seoul (Rem Koolhaus). Retrieved 0412 2011, from Guerrilla Stoemp:

http://guerrilla-stoemp.blogspot.com/2009/10/prada-transformer-seoul-rem-koolhaas.html

Figure 4.2.2 Superfuture Corporation. (2009, September 30). Seoul: Prada Transformer. Retrieved 04 12 2011, from Superfuture:

http://superfuture.com/supernews/seoul-prada-transformer-14308

Figure 4.2.3 Baan, Iwan. (2010). Prada Transformer, Position 2 : Cinema. Retrieved 12112011 , from Archdoc: http://archdoc.mr926.me/tag/art/page/10/

Figure 4.2.4 Superfuture Corporation. (2009, September 30). Seoul: Prada Transformer. Retrieved 04 12 2011, from Superfuture:

http://superfuture.com/supernews/seoul-prada-transformer-14308

Figure 4.2.5 unknown. (2011). prada transformer. Retrieved 1211 2011, from restavec:

http://restavec.tumblr.com/

Figure 4.2.6 Superfuture Corporation. (2009, September 30). Seoul: Prada Transformer. Retrieved 04 12 2011, from Superfuture:

http://superfuture.com/supernews/seoul-prada-transformer-14308

Figure 4.2.7 Stamp, Jimmy. More Than Meets the Runway: The Prada Transformer. Retrieved 0412 2011, from Life Without Buildings :

http://lifewithoutbuildings.net/2009/04/prada-transformer.html

Figure 4.2.8 Stamp, Jimmy. More Than Meets the Runway: The Prada Transformer. Retrieved 0412 2011, from Life Without Buildings :

http://lifewithoutbuildings.net/2009/04/prada-transformer.html

Figure 4.3.1 Raumlabor. (2010, May 11). Mobile culture: Rosy the ballerina. Retrieved 12112011 , from Popwuping:

http://www.popwuping.com/art-design/mobile-culture-rosy-the-ballerina.php 
Figure 4.3.2 Raumlabor. (2011). Rosy (the ballarina). Retrieved 06 11, 2011, from Raumlabor Berlin: http://www.raumlabor.net/?p=4176

Figure 4.3.3 Raumlabor. (2011). Rosy (the ballarina). Retrieved 06 11, 2011, from Raumlabor Berlin: http://www.raumlabor.net/?p=4176

Figure 4.3.4 Raumlabor. (2011). Rosy (the ballarina). Retrieved 06 11, 2011, from Raumlabor Berlin: http://www.raumlabor.net/?p=4176

Figure 4.3.5 Raumlabor. (2011). Rosy (the ballarina). Retrieved 06 11, 2011, from Raumlabor Berlin: http://www.raumlabor.net/?p=4176

Figure 4.3.6 Raumlabor. (2011). Rosy (the ballarina). Retrieved 06 11, 2011, from Raumlabor Berlin: http://www.raumlabor.net/?p=4176

Figure 4.3.7 materialicious.com. (2010) ROSY (the ballerina) bubbletecture. Retrieved 12 11, 2011, from materialicious: http://www.materialicious.com/2010/04/rosy-the-ballerina.html

Figure 4.3.8 Raumlabor. (2011). Rosy (the ballarina). Retrieved 06 11, 2011, from Raumlabor Berlin: http://www.raumlabor.net/?p=4176

Figure 4.4.1 Ritchers, Christian (2011). BMW Gugghenheim Lab Berlin. Retrieved 11 06, 2012, from flickr: http://www.flickr.com/photos/bmwguggenheimlab/7374919404/in/photostream/

Figure 4.4.2 Ruban, Josh (2011). BMW Lab-NYC. Retrieved 11 06, 2012, from coolhunting: http://www.coolhunting.com/culture/bmw-guggenheim-lab-nyc.php

Figure 4.4.3 Hill, John (2011). BMW Gugghenheim Lab Berlin. Retrieved 11 06, 2012, from flickr: http://www.flickr.com/photos/archidose/6005720095/in/photostream/

Figure 4.4.4 Ritchers, Christian (2011). BMW Gugghenheim Lab Berlin. Retrieved 11 06, 2012, from flickr: http://www.flickr.com/photos/bmwguggenheimlab/7344951052/in/photostream/

Figure 4.4.5 Favermann, Mark (2011). The BMW Gugghenheim Lab. Retrieved 11 06, 2012, from Berkshire Fine Arts:

http://berkshirefinearts.com/08-15-2011_the-bmw-guggenheim-lab.htm

Figure 4.4.6 unknown (2011). BMW Gugghenheim NYC. Retrieved 11 06, 2012, from Urban Media Archeology:

http://www.wordsinspace.net/urban-media-archaeology/2011-fall/2011/08/24/63/

Figure 4.4.7 Rudenko, Anna (2010). BMW Gugghenheim Lab Curators Sketch. Retrieved 11 06, 2012, from popsop: http://popsop.com/39222

Figure 5.1.1 HerciniArts Collective. (2011). Birds of a Feather. Retrieved 11 06, 2012, from HerciniArts: http://www.herciniarts.com/galleries.php

Figure 5.1.2 HerciniArts Collective. (2011). Birds of a Feather. Retrieved 11 06, 2012, from HerciniArts: http://www.herciniarts.com/galleries.php 
Figure 5.1.3 HerciniArts Collective. (2011). Godesses and Gargoyles: Nuit Blanche 2010. Retrieved 11 06, 2012, from HerciniArts: http://www.herciniarts.com/galleries.php

Figure 5.1.4 HerciniArts Collective. (2011). Fellini's Dream. Retrieved 11 06, 2012, from HerciniArts: http://www.herciniarts.com/galleries.php

Figure 5.2.1 Allard-Buffet, Veronique (2012). Map of Central Toronto demarcating performance locations. *Edited and labelled by author.

Figure 5.2.2 Napier, Jessica. (2010). St. Lawrence Market. Retrieved 11062012 from the scene in TO: http://thesceneinto.com/2010/06/neighbourhood-profile-st-lawrence-market/

Figure 5.2.3 Allard-Buffet, Veronique (2012). Rendering of unoccupied indoor studio space.

Figure 5.2.4 Sarner, Jamie. (unknown). Trinity Bellwoods Park. Retrieved 11062012 from Jamie Sarner: http://jamiesarner.com/toronto-neighbourhoods/annex-real-estate/

Figure 5.3.1 Allard-Buffet, Veronique (2012). Diagram of Existing Structure.

Figure 6.1 Allard-Buffet, Veronique (2012). Diagram of Existing Structure VS. Early Iterations.

Figure 6.2 Allard-Buffet, Veronique (2012). Diagram of Existing Structure VS. Proposed.

Figure 6.1.1 Allard-Buffet, Veronique (2012). Frame module dimensions.

Figure 6.1.2 Allard-Buffet, Veronique (2012). Frame hinge points and detail.

Figure 6.1.3 Allard-Buffet, Veronique (2012). Frame collapsibility and extension abilities

Figure 6.2.1 Allard-Buffet, Veronique (2012). Four primary frame performance uses.

Figure 6.2.2 Allard-Buffet, Veronique (2012). Detail of aerial silk rigging system.

Figure 6.2.3 Allard-Buffet, Veronique (2012). Diagram of flat bench | stage surface.

Figure 6.2.4 Allard-Buffet, Veronique (2012). Detail of double ledger clamp connection.

Figure 6.2.5 Allard-Buffet, Veronique (2012). Diagram off horizontal structural frame add-on.

Figure 6.2.6 Allard-Buffet, Veronique (2012). Diagram of relocatable frame abilities.

Figure 6.3.1 Allard-Buffet, Veronique (2012). Sketch of circus tent.

Figure 6.3.2 Allard-Buffet, Veronique (2012). Rendering of Accommodating Showman as a circus tent.

Figure 6.3.3 Allard-Buffet, Veronique (2012). Diagram of four primary theatre typologies.

Figure 6.3.4 Allard-Buffet, Veronique (2012). Diagram of Showman in proscenium stage layout.

Figure 6.3.5 Allard-Buffet, Veronique (2012). Diagram of Showman in proscenium stage layout alternative.

Figure 6.3.6 Allard-Buffet, Veronique (2012). Diagram of Showman in thurst stage layout.

Figure 6.3.7 Allard-Buffet, Veronique (2012). Diagram of Showman in thurst stage layout alternative.

Figure 6.3.8 Allard-Buffet, Veronique (2012). Diagram of Showman in arena stage layout.

Figure 6.3.9 Allard-Buffet, Veronique (2012). Diagram of Showman in arena stage layout alternative.

Figure 6.3.10 Allard-Buffet, Veronique (2012). Diagram of Showman as black box theatre interpretation.

Figure 6.4.1 Allard-Buffet, Veronique (2012). Rendering and plan of Showman in studio | training space.. 
Figure 6.4.2 Allard-Buffet, Veronique (2012). Rendering and plan of Showman stationed in St. Lawrence Market, Toronto.

Figure 6.4.3 Allard-Buffet, Veronique (2012). Rendering and plan of Showman stationed in Trinity Bellwoods Park, Toronto.

Figure 6.5.1 Allard-Buffet, Veronique (2012). Rendering of Showman in all four show-specific scenes.

Figure 6.5.2 Allard-Buffet, Veronique (2012). Rendering and section of Showman: Scene 1.

Figure 6.5.3 Allard-Buffet, Veronique (2012). Rendering and section of Showman: Scene 2.

Figure 6.5.4 Allard-Buffet, Veronique (2012). Rendering and section of Showman: Scene 3.

Figure 6.5.5 Allard-Buffet, Veronique (2012). Rendering and section of Showman: Scene 4. 


\section{Bibliography}

Banham, M. (1995). The Cambridge Guide to Theatre. Cambridge: Cambridge University Press.

Bergdoll, B. (2008, June). Home Delivery: Fabricating the Modern Dwelling. Retrieved October 26, 2011, from MoMA Home Delivery: http://www.momahomedelivery.org/

Brook, P. (1969). Empty Space. New York : Avon Books.

Diderot, D. (1771). Oeuvres de théâtre, avec un discours sur la poésie dramatique, v. 2. Paris: La Veuve Duschene.

Dreyfuss, H. (1955). Designing for People. New York: Allworth Press.

Encyclopædia Britannica, Inc. (2011). Conestoga Wagon. Retrieved 12 04, 2011, from Encyclopædia Britannica: http://www.britannica.com/EBchecked/media/4960/Conestoga-wagon

Encyclopædia Britannica, Inc. (2012). Leonardo da Vinci. Retrieved 07 18, 2012, from http://www.britannica.com/EBchecked/topic/336408/Leonardo-da-Vinci/59785/Anatomicalstudies-and-drawings

Encyclopedia Britannica Inc. . (2011). Theatre Design. Retrieved 12 02, 2011, from Encyclopedia Britannica: http://www.britannica.com/EBchecked/topic/1542181/theatre-design

Etymology, T. C. (1996). caravan. Retrieved 11 23, 2011, from encyclopedia.com: http://www.encyclopedia.com/topic/caravan.aspx\#4

Gorman, M. J. (2002). Leonardo Da Vinci. Retrieved 07 18, 2012, from http://leonardodavinci.stanford.edu/submissions/clabaugh/history/leonardo.html

Harrop, J. (1989). Victorian Portable Theatres. London: Alden Press Ltd.

History of Theatre. (2010, April 10). Perspective Scenery . Retrieved 12 04, 2011, from History of Theatre: http://theatrehistory2010.blogspot.com/2010/04/perspective-scenery.html

Kronenburg, R. (1996). Portable Architecture. Oxford: Architectural Press.

Kronenburg, R. (1998). Ephemeral Architecture. New York: John Wiley \& Sons.

Kronenburg, R. (1998). Transportable Environment : Theory, Context, Design and Technology. New York: Routledge.

Kronenburg, R. (2002). Houses in Motion : The Genesis, History and Development of the Portable Building (2 ed.). West Sussex: Wiley Academy.

LeCorbusier. (1954). The Modulor. London: Faber and Faber Limited.

Lepik, A. (2009). Small Scale Big Change. New York: Department of Publications at the Museum of Modern Art.

Oechslin, W., \& Buschow, A. (1995). Architecture de fête: l'architecte comme metteur en scène. Liege: PIERRE MARDAGA ÉDITEUR. 
Plant, M. (2003). Venice: Fragile City 1797-1997. New Haven: Yale University Press.

Raumlabor. (2011). Rosy (the Ballarina). Retrieved 11 06, 2010, from Raumlabor Berlin: http://www.raumlabor.net/?p=4176

Richardson, P. (2001). Big Ideas XS Small Buildings. London: Thames \& Hudson.

Schechner, R. (2003). Performance Theory. New York: Routledge Classics.

Smith, R. E. (2011). Prefab Architecture: A Guide to Modular Design and Construction. New York: John Wiley \& Sons.

The Solomon R. Guggenheim Foundation. (2012). BMW Gugghenheim Lab. Retrieved 03 08, 2012, from http://www.guggenheim.org/guggenheim-foundation/collaborations/bmw-guggenheim

Tschumi, B. (1994). Architecture and Disjunction. Cambridge: The MIT Press.

Wilson, E. (2005). Theatre Experience. New York: McGraw Hill. 